\author{
UNIVERSIDADE DE SÃO PAULO \\ ESCOLA DE ENGENHARIA DE SÃO CARLOS \\ ENGENHARIA DE PRODUÇÃO
}

\title{
MEDIÇÃO DE DESEMPENHO PARA GESTÃO DA PRODUÇÃO EM UM CENÁRIO DE CADEIA DE SUPRIMENTOS
}

\section{Emerson Bond}

Texto apresentado à Escola de Engenharia de São Carlos da Universidade de São Paulo, como parte dos requisitos para obtenção do título de mestre em Engenharia de Produção.

ORIENTADOR: Prof. Dr. Luiz C. R. Carpinetti

São Carlos

2002 


\section{Agradecimentos}

A Luciana, minha esposa, pessoa que sempre me incentivou a pensar em novas possibilidades e a principal responsável pela minha decisão em realizar o mestrado.

Ao Prof. Dr. Luiz Carpinetti, que sempre me apoiou em todas as oportunidades em que tive algum tipo de dificuldade e abriu portas antes inimaginadas por mim.

Aos professores e funcionários da área de Engenharia de Produção.

Ao NUMA, pelo apoio oferecido por eles no projeto IPROS, principalmente ao Prof. Dr. Carlos F. Bremer.

Aos amigos do Reenge: Mateus, Wendell, Manoel, Fábio, Alexandre, Simone e Edwin.

Aos diretores e funcionários da Eaton pela oportunidade de se realizar o estudo de caso.

A FAPESP pelo apoio financeiro.

A todos que de alguma forma contribuíram para a realização deste trabalho ou outras atividades da minha carreira acadêmica. 
A Silas e Zeny

Meus Pais 
Tudo está perdido ...

... mas existem possibilidades.

The Truth is Out There 


\section{SUMÁRIO}

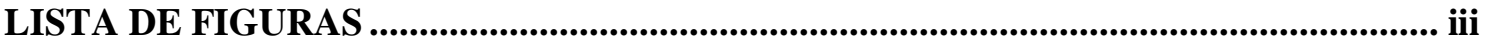

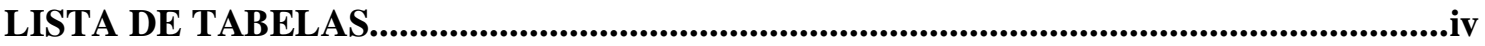

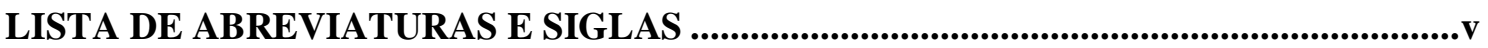

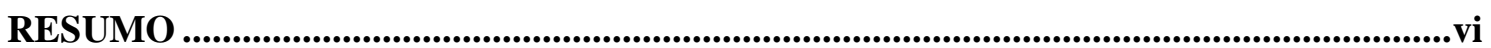

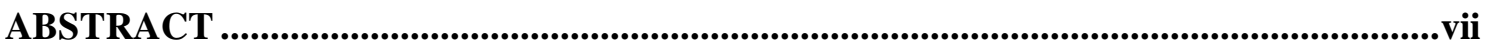

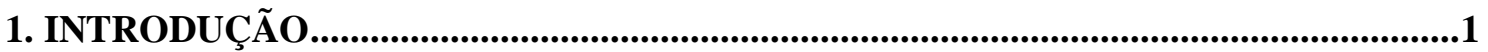

1.1. Contextualização do Problema de Pesquisa.......................................................... 1

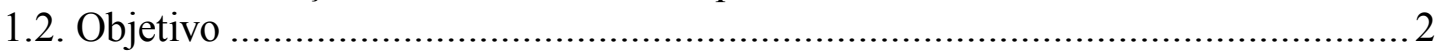

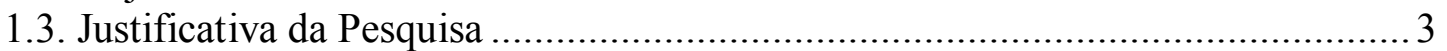

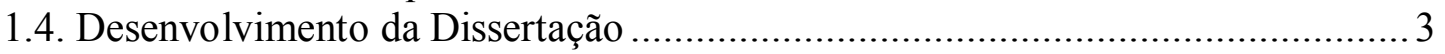

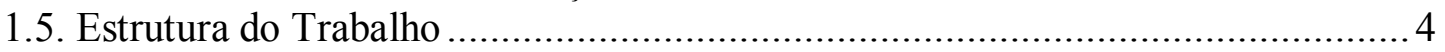

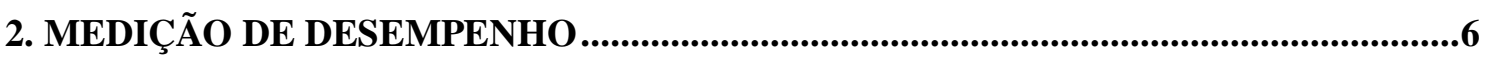

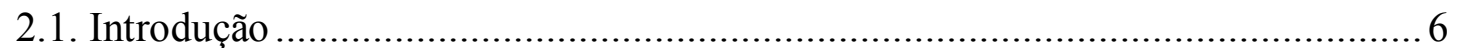

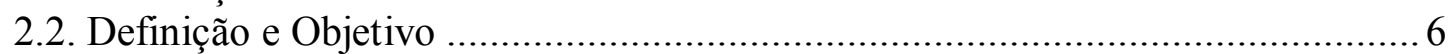

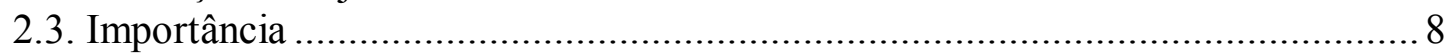

2.4. Medição de Desempenho Tradicional ............................................................ 9

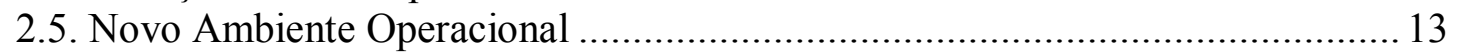

2.6. Novos Sistemas de Medição de Desempenho .................................................... 15

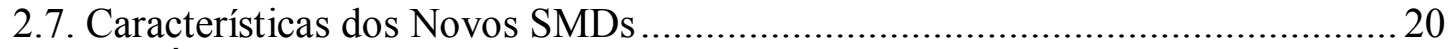

2.7.1. Áreas Chave ou Dimensões Competitivas ................................................ 21

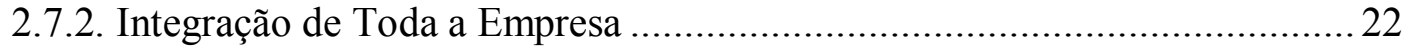

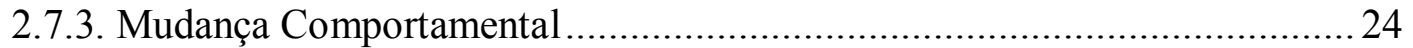

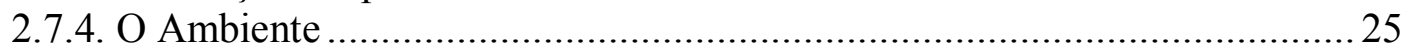

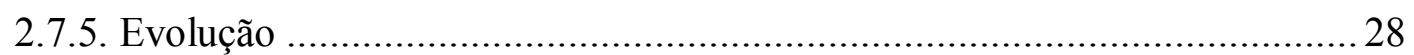

2.8. Sistemas de Medição de Desempenho como Entidade ................................... 29

2.8.1. Balanced Scorecard ............................................................................... 30

2.8.2. Desempenho Quantum.................................................................... 33

2.9. Métodos de Desenvolvimento de Sistemas de Medição de Desempenho ............ 36

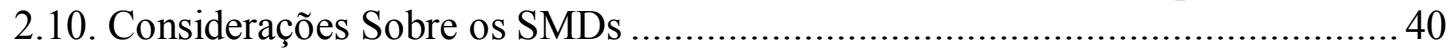

2.11. Sistemas de Informação como Suporte a Medição de Desempenho .................. 43

2.11.1. Agilidade aos Sistemas de Medição de Desempenho.............................. 45

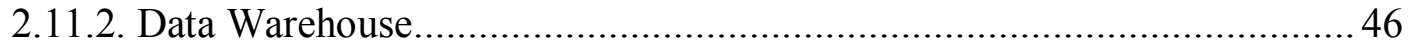

3. MEDIÇÃO DE DESEMPENHO NA CADEIA DE SUPRIMENTOS ..............................48

3.1. Conceituação e Práticas da Gestão da Cadeia de Suprimentos........................... 48

3.2. Medição de Desempenho na Cadeia de Suprimentos ...................................... 50

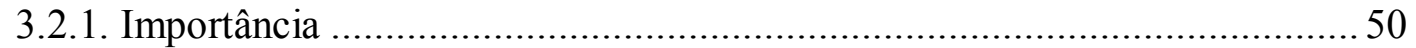

3.2.2. Os Indicadores na Cadeia de Suprimentos................................................52

3.3. Modelos de Medição de Desempenho em Cadeias de Suprimentos................... 57

3.3.1. Processo Integrado da Cadeia de Suprimentos ........................................5 57

3.3.2. Modelo de Benita Beamon....................................................................... 59

3.3.3. Modelo SCOR (Supply Chain Operations Reference Model) .................... 62 
4. MEDIÇÃO DE DESEMPENHO PARA O PROJETO IPROS .....................................66

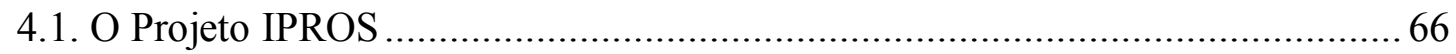

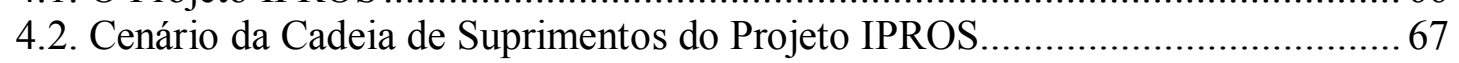

4.3. Proposição de um conjunto de Indicadores de Desempenho................................69

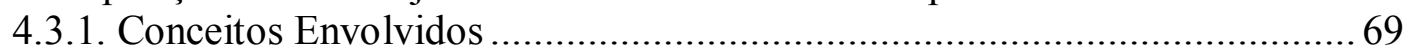

4.3.2. Método de Desdobramento dos Indicadores do Projeto IPROS ................. 72

4.3.3. Indicadores de Desempenho do Cenário IPROS ..................................... 74

4.4. Infra-estrutura de Coleta de Dados e Tratamento da Informação ....................... 85

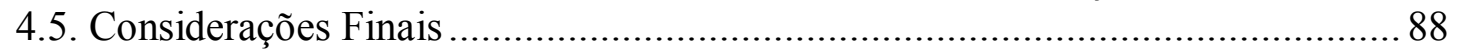

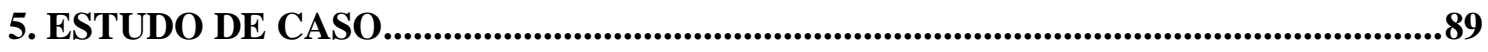

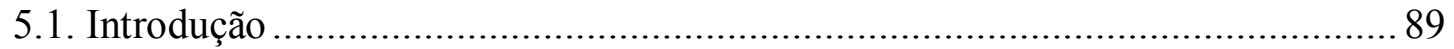

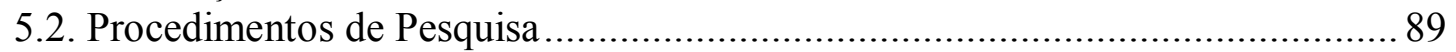

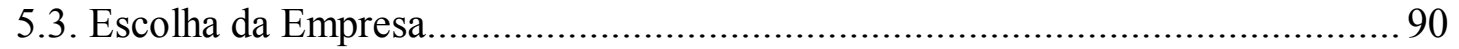

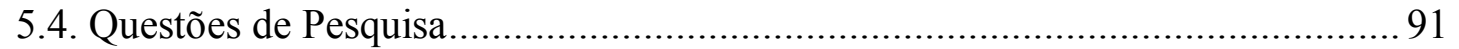

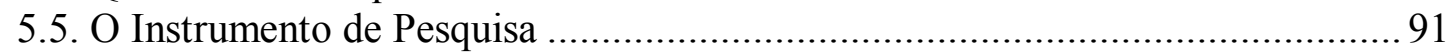

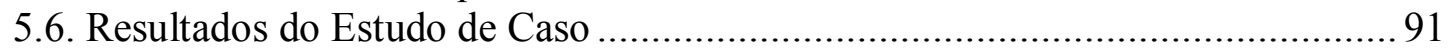

5.7. Discussão Sobre as Questões de Pesquisa .................................................... 102

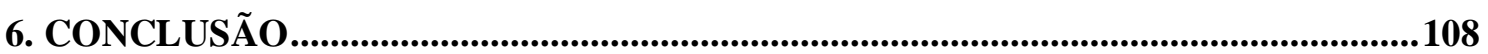

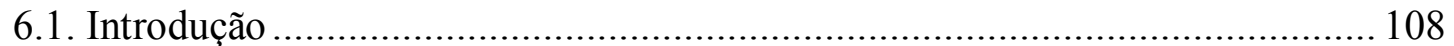

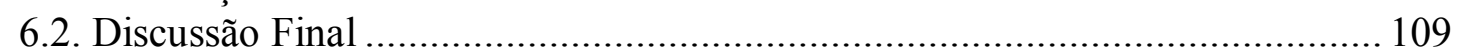

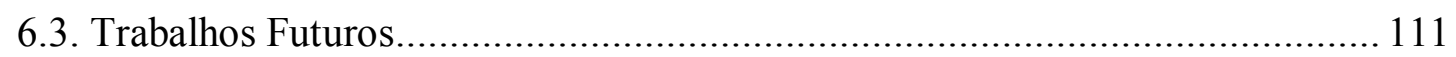

ANEXO A - Questões de Pesquisa e o Questionário ............................................................112

ANEXO B - Questionário para Levantamento de Informações......................................113

REFERÊNCIAS BIBLIOGRÁFICAS .......................................................................118 


\section{LISTA DE FIGURAS}

Figura 1.1. Esquema de condução e elaboração da dissertação. ................................... 4

Figura 2.1. Abordagem estratégica da medição de desempenho.................................. 18

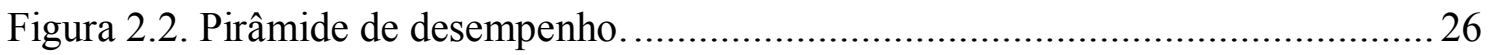

Figura 2.3. Modelo de um sistema de medição de desempenho. ................................. 27

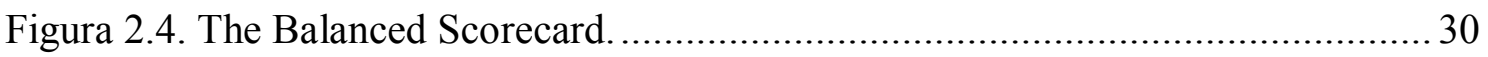

Figura 2.5. Exemplo de relacionamento entre medidas de desempenho de um BSC..... 31

Figura 2.6. Modelo Quantum de medição de desempenho........................................... 35

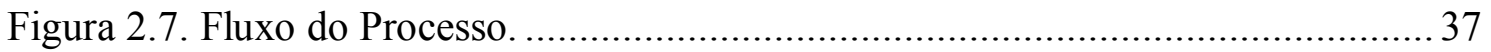

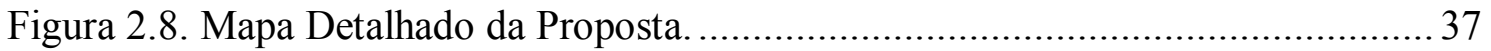

Figura 2.9. Modelo Conceitual de Carpinetti ................................................................... 38

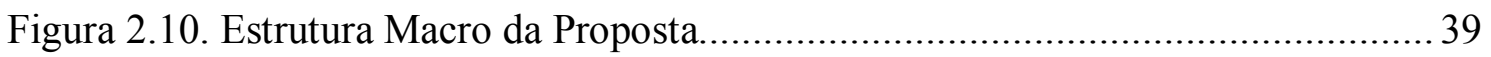

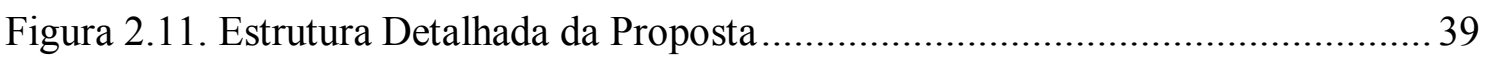

Figura 2.12. Passos para o desenvolvimento de um SMD ........................................ 40

Figura 3.1. Concorrência entre unidades virtuais de negócios..................................... 49

Figura 3.2. Estrutura de um SMD para cadeias de suprimentos..................................52

Figura 3.3. Indicadores funcionais versus indicadores de processos........................... 53

Figura 3.4. Referência das operações da cadeia de suprimentos.................................. 62

Figura 3.5. Exemplo de decomposição de métricas para cadeia. ................................. 63

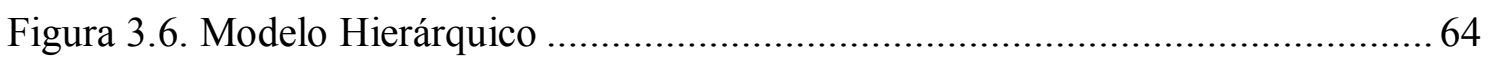

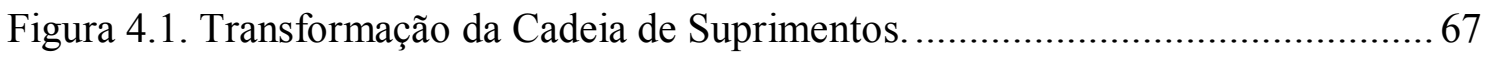

Figura 4.2. Relações entre clientes e fornecedores das fábricas de eixos e redutores.... 68

Figura 4.3. Perspectivas do conjunto de indicadores do projeto IPROS. ...................... 70

Figura 4.4. O modelo SCOR de processos de negócio na cadeia de suprimentos ..........71

Figura 4.5. Integração entre o modelo SCOR e as perspectivas de desempenho ilustradas

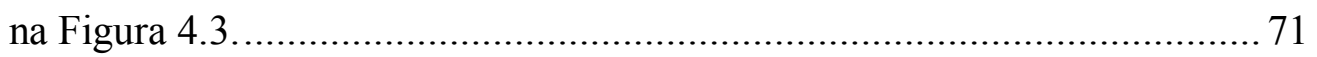

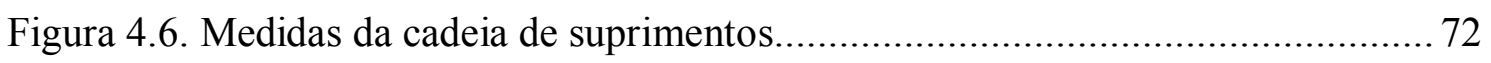

Figura 4.7. Modelo de relacionamento das métricas do projeto IPROS....................... 85

Figura 4.8. Processo de coleta de informações do chão de fábrica. .............................. 86

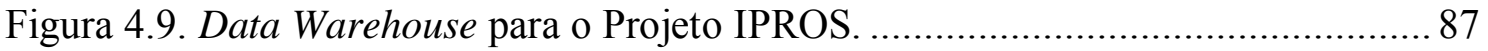

Figura 4.10. Exemplo de Consulta OLAP no Excel 2000 ........................................ 88 


\section{LISTA DE TABELAS}

Tabela 2.1. Recomendações para a construção de um SMD. Compilada pelo autor ..... 17

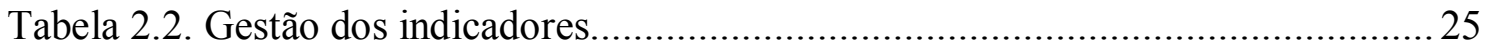

Tabela 2.3. Matriz de medição de desempenho............................................................ 26

Tabela 2.4. Matriz Quantum de Medição de Desempenho......................................... 34

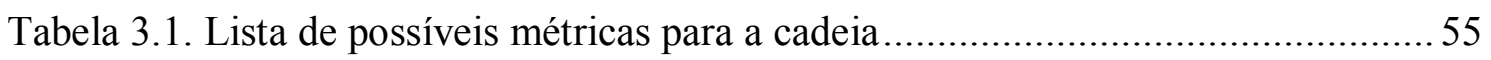

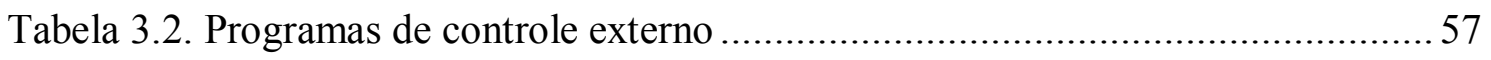

Tabela 4.1. Áreas chave e medidas de desempenho da perspectiva financeira.............. 75

Tabela 4.2. Áreas chave e medidas de desempenho da perspectiva dos clientes........... 76

Tabela 4.3. Áreas chave e medidas de desempenho da perspectiva das operações........ 79

Tabela 4.4. Áreas chave e medidas de desempenho da perspectiva dos fornecedores... 80

Tabela 4.5. Áreas chave e medidas de desempenho da perspectiva dos recursos

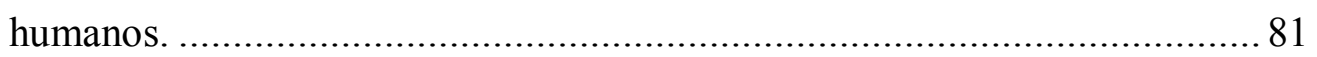

Tabela 4.6. Indicadores de desempenho e suas perspectivas. .................................. 83

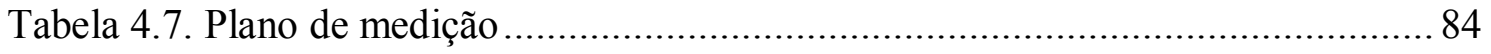

Tabela 5.1. Projeto e Montagem no Brasil .................................................................. 91

Tabela 5.2. Matriz de medição de Desempenho.......................................................... 93

Tabela 5.3. Classificação dos Fornecedores............................................................... 102

Tabela A.1. Relação entre questões de pesquisa e o questionário.............................. 112 


\section{LISTA DE ABREVIATURAS E SIGLAS}

AMR - Advanced Manufacturing Research

BPR - Business Process Reengineering

BSC - Balanced Scorecard

CRP - Continuous Replenishment Program

DW - Data Warehouse

IPROS - Integrated Production And Supply Chain Management

JIT - Just In Time

MRP - Material Requirement Planning

MTO - Make to Order

NUMA - Núcleo de Manufatura Avançada

OEM - Original Equipment Manufacturing

OLAP - On Line Analytical Processing

P\&D - Pesquisa e Desenvolvimento

ROI - Return on Investment

SCOR - Supply Chain Operations Reference Model

SCM - Supply Chain Management

$\operatorname{SMD}(\mathrm{s})$ - Sistema(s) de Medição de Desempenho

SQL - Structured Query Language

TQM - Total Quality Management

VMI - Vendor Management Inventory 


\section{RESUMO}

BOND, E. (2001). Medição de desempenho para um cenário de empresas de uma cadeia de suprimentos. São Carlos, 2002. 125 p. Dissertação (Mestrado). Escola de Engenharia de São Carlos. São Carlos, Universidade de São Paulo.

A freqüência nas mudanças no ambiente empresarial exige que as empresas tenham uma elevada capacidade de adaptação. Neste sentido, é fundamental que mecanismos para avaliar suas ações e operações tenham totais condições de análise objetiva da situação atual e futura da empresa. É dentro deste enfoque, que os indicadores de desempenho se tornam instrumentos eficazes para estas análises e avaliações. A partir dessa constatação, este trabalho trata do desenvolvimento de indicadores de desempenho para as operações de produção de uma empresa de manufatura inserida no contexto de uma cadeia de suprimentos. O conjunto de indicadores de desempenho foi desenvolvido para o cenário da cadeia de suprimentos de moto redutores criado para o projeto IPROS. Como características fundamentais destacam-se o ambiente de sistemas de gestão, onde o Data Warehouse é utilizado como ferramenta principal e o ambiente de cadeia de suprimentos onde os indicadores foram focados tanto no desempenho dos processos internos de uma empresa elo da cadeia, quanto no relacionamento desse elo com a cadeia de suprimentos. É também proposto um estudo de caso que analisa uma empresa representativa da cadeia de suprimentos que está sendo estudada.

Palavras-chave: Medição de Desempenho, Gerenciamento da Cadeia de Suprimentos, Sistemas de Gestão, Data Warehouse. 


\begin{abstract}
BOND, E. (2001). Performance measurement to production management in a supply chain scenario. São Carlos, 2002. 125 p. Dissertação (Mestrado). Escola de Engenharia de São Carlos. São Carlos, Universidade de São Paulo.
\end{abstract}

The frequent changes in the management environment demand that the companies must have a high capacity of adaptation. In this way, it is fundamental that mechanisms to measure the actions and operations have conditions to analyze the current and future situation of the company. In these analyses, the performance measures became good tools to analyze these evaluations. Following this argument, this work discusses the development of performance measures to the operations of one manufacturing company in a supply chain environment. The performance measures were developed in a scenario of a company that produces gearbox, and this scenario was called IPROS project. As fundamental characteristics of this scenario, the use of a system called Data Warehouse, as the main tool for process the informations, and the supply chain environment, where performance measures was focused in the internal processes of one company and the relationship between this company with all the supply chain. This work also presents a case study that discusses the performance measures of a representative company.

Keywords: Performance Measurement, Supply Chain Management, Management Systems, Data Warehouse. 


\section{INTRODUÇÃO}

\subsection{Contextualização do Problema de Pesquisa}

Face aos avanços do mundo contemporâneo, as empresas se vêem frente a novas oportunidades e desafios ao longo de todo o mundo. Para atingir e manter uma posição competitiva neste mercado, as corporações devem manter procedimentos de alta qualidade de produtos a custos e tempos de produção baixos além de orientação ao cliente (Noble, 1997; Rolstadås, 1998).

Para Atkinson et al. (1997) e Daniels \& Burns (1997), o alinhamento da função manufatura com prioridades estratégicas se torna essencial para competitividade neste mercado mundial e o melhoramento contínuo da manufatura tem um importante papel na busca de competitividade a longo prazo.

Consoante a esta visão, Carpinetti (2000a) afirma que para atingir a melhoria do desempenho organizacional, as empresas devem acompanhar os movimentos e avanços tecnológicos da produção. Desta maneira, operações estratégicas como Administração da Qualidade Total (TQM), Reengenharia dos Processos de Negócios (BPR), Just-in-time (JIT), Benchmarking, Medição de Desempenho, entre outras, são comumente utilizadas.

Por outro lado, para Martins (1999) estas operações estratégicas ao serem implantadas pelas corporações na busca de sua própria sobrevivência, levaram as empresas, em muitos casos, a privilegiarem as mudanças do padrão tecnológico da organização da produção em detrimento a mudança dos sistemas de gestão. Nem sempre as mudanças no sistema de gestão acompanham a taxa de mudança da tecnologia de produção. Essa defasagem leva a uma incoerência que, no melhor dos casos, resulta em uma sub otimização do investimento feito. 
Kaydos (1991) considera ainda que a medição de desempenho é um dos elementos centrais de gestão, com a percepção de que o desempenho é em parte resultado das decisões tomadas e, nesse sentido, a qualidade da decisão, em boa parte, é limitada pela informação disponível em termos de qualidade e quantidade. $\mathrm{O}$ benefício mais importante dos indicadores de desempenho é o entendimento de como a empresa funciona, as forças que a dirigem, além de mostrar como as ações e operações estratégicas se alinham com o sistema de gestão. Isso enriquece o processo de tomada de decisão.

Desta maneira, levar também em consideração o gerenciamento da cadeia de suprimentos é essencial na formulação de um sistema de medição de desempenho. Destaca-se aqui, que indicadores individuais de cada empresa são importantes, mas, além destes, para Beamon (1999), existem alguns indicadores que são comuns para toda a cadeia. Desta forma, o desempenho da cadeia em questão será indicado por meio desses indicadores comuns às unidades de negócios que dela fazem parte.

Para isto, o uso de sistemas informatizados que auxiliam as empresas em processar informações são de fundamental importância, já que conseguem conectar várias áreas da empresa e da cadeia, dentro de uma base única e concisa, proporcionando uma melhor atuação dos sistemas de medição de desempenho.

\subsection{Objetivo}

Esta dissertação tem por objetivo principal a proposição de um conjunto de indicadores de desempenho das operações de produção de uma empresa de manufatura inserida no contexto de uma cadeia de suprimentos.

Este objetivo principal pode ser desdobrado nos seguintes objetivos intermediários:

a) Revisão bibliográfica: é o suporte como referencial teórico deste trabalho, onde se buscou identificar na literatura as características fundamentais e as boas práticas dos modelos de medição de desempenho organizacional. A revisão objetiva procura também identificar como as práticas de medição de desempenho se adaptam aos contextos de cadeia de suprimentos e sistemas integrados de produção, ou sistemas de gestão; 
b) Proposição de um conjunto de indicadores de desempenho para o cenário da cadeia de suprimentos de moto redutores desenvolvido para o projeto IPROS (Integrated Production And Supply Chain Management, e descrito no capítulo 5) focados tanto no desempenho dos processos internos de uma empresa elo da cadeia, principalmente no gerenciamento do chão de fábrica, quanto no relacionamento desse elo com o desempenho da cadeia de suprimentos auxiliados por sistemas de gestão;

c) Estudo de Caso: estudo dos indicadores de desempenho de uma empresa que se encontre em uma cadeia de suprimentos similar ao projeto IPROS e que utilize indicadores de desempenho como instrumento gerencial.

\subsection{Justificativa da Pesquisa}

Muitas empresas estão reformulando seus sistemas de medição de desempenho para acompanhar critérios não financeiros e reforçar novas estratégias competitivas. As novas tecnologias e os bancos de dados mais sofisticados tornaram possível e economicamente viável a mudança para sistemas não financeiros de mensuração do desempenho. Nesta situação, existe a clara tendência de que cada empresa terá seus próprios indicadores e processos diferenciados para implementação da mudança (Eccles, 2000).

Neste contexto, este trabalho tem a intenção de ajudar na melhor compreensão de modelos de medição de desempenho, que observem de forma detalhado o chão de fábrica das empresas, e dentro desta proposta, tentar conciliar estas informações com as da cadeia de suprimentos, auxiliado por ferramentas computacionais que promovem agilidade a este modelo.

\subsection{Desenvolvimento da Dissertação}

Como suporte para a realização da pesquisa descrita nesta dissertação, o primeiro passo foi à realização de uma vasta pesquisa bibliográfica, que serviu de base para o desenvolvimento do objetivo aqui proposto. 
Em seguida, foi descrito como a proposta de um conjunto de indicadores de desempenho para o cenário do projeto IPROS foi realizada e a condução de um estudo de caso, que permitirá a finalização com a conclusão do trabalho. Este esquema é descrito na Figura 1.1.

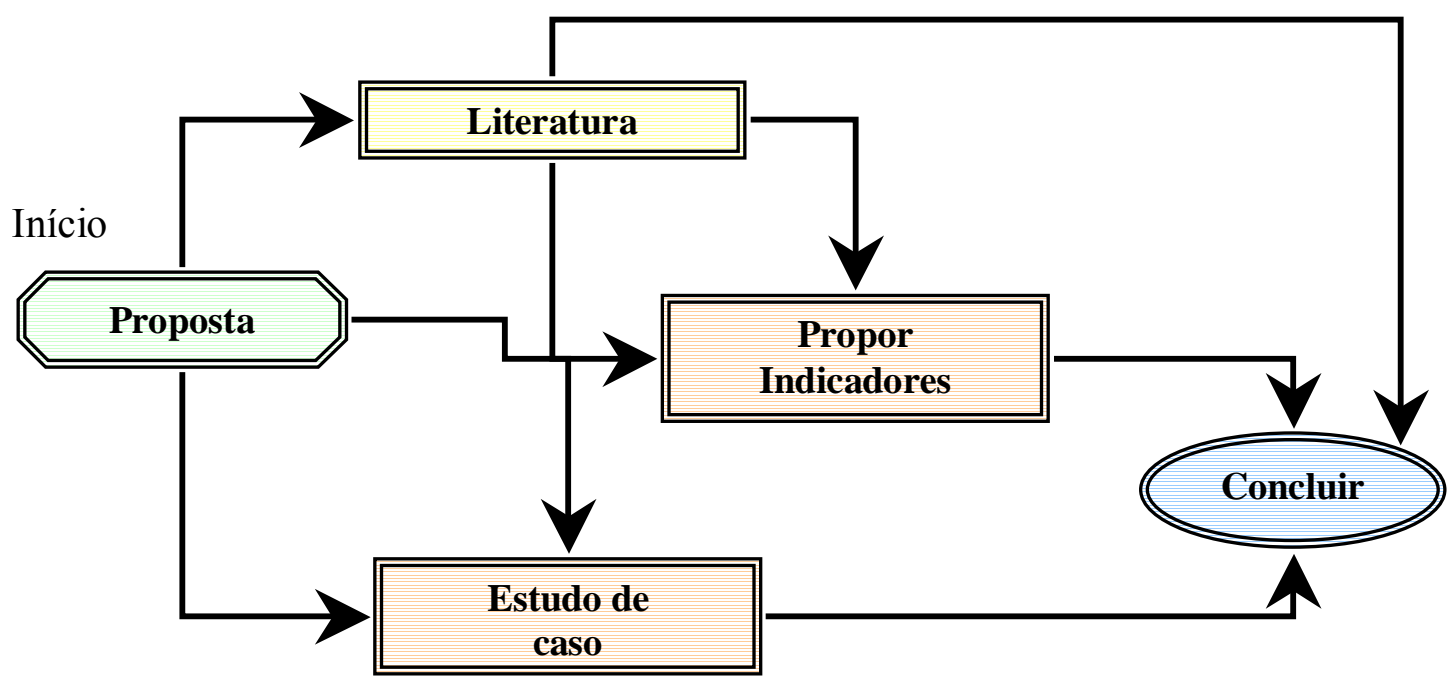

Figura 1.1. Esquema de condução e elaboração da dissertação.

\subsection{Estrutura do Trabalho}

Este trabalho está estruturado em 6 capítulos.

O capítulo 1 foi construído de forma breve com uma discussão introdutória para contextualizar o tema de pesquisa a ser desenvolvido. Logo após, são apresentados a formulação do problema, o objetivo principal do trabalho, a justificativa da pesquisa, limitações e o desenvolvimento da dissertação.

O capítulo 2 apresenta uma revisão bibliográfica sobre medição de desempenho.

O capítulo 3 continua a revisão bibliográfica, apresentando e discutindo conceitos relacionados com a medição de desempenho nas cadeias de suprimentos, abordando de forma geral a sua efetiva aplicação.

O capítulo 4 apresenta a formulação de indicadores de desempenho para o cenário IPROS. Aqui é descrito o cenário como entidade bem como as ferramentas utilizadas. 
O capítulo 5 relata o estudo de caso com uma descrição da empresa estuda, seu sistema de medição de desempenho, além das conclusões a respeito das questões de pesquisa.

Finalmente, o capítulo 6 descreve a conclusão do trabalho. 


\section{MEDIÇÃO DE DESEMPENHO}

\subsection{Introdução}

Este capítulo apresenta uma revisão bibliográfica do conceito, evolução histórica e desdobramentos dos Sistemas de Medição de Desempenho (SMDs).

O que se pretende com esta revisão é mostrar que o conceito de medição de desempenho é relevante para o ambiente empresarial atual, já que a formulação de estratégias, o desenvolvimento de ações, programas e processos de melhoria e mudança das operações passam pela criação de métricas ${ }^{1}$ que monitoram seus estágios passados e atuais, permitindo previsões para o futuro.

\subsection{Definição e Objetivo}

A medição de desempenho pode ser definida, genericamente, como a atividade de se determinar as medidas de desempenho, sua extensão, grandeza e avaliação, no sentido de adequar, ajustar, proporcionar ou regular alguma atividade. Quando sistematizada, é vista como uma entidade que agrega um conjunto integrado de indicadores individuais, que visam prover informações sobre o desempenho de determinadas atividades para determinados fins.

No entanto, para outros autores, a medição de desempenho pode ser entendida como:

- “...uma relação matemática que mede, numericamente, atributos de um processo ou de seus resultados, com o objetivo de comparar esta medida com metas numéricas, pré-estabelecidas..." (FPNQ, 1995).

\footnotetext{
${ }^{1}$ Neste texto serão utilizadas as palavras métricas, indicadores e medidas. Porém todos estes termos podem ser lidos e entendidos com o mesmo significado.
} 
- "Gerenciar é controlar e agir corretamente. Sem controle não há gerenciamento. Sem medição não há controle." (Juran \& Gryna, 1988).

- "...sinais vitais da organização, no sentido da quantificação de como andam as atividades dentro de um processo ou se o output atinge a meta específica." (Hronec, 1994).

- “...a técnica usada para quantificar a eficiência e a eficácia das atividades do negócio. A eficiência vai tratar da relação entre utilização econômica dos recursos, levando em consideração um determinado nível de satisfação. Por sua vez, a eficácia avalia o resultado de um processo onde as expectativas dos diversos clientes são ou não atendidas." (Neely et al. 1995).

Porém, definir o que é medição de desempenho não é uma tarefa simples, devido ao fato deste conceito envolver uma estrutura física/lógica, através dos equipamentos, pessoas e o fluxo e o armazenamento de informações. O mau gerenciamento desta configuração pode deixar o processo de medição incompleto e atos e decisões podem não acontecer por conta de falhas nesta estrutura.

Da mesma forma, os objetivos atribuídos à medição de desempenho vão depender da visão do corpo gerencial da empresa, da composição estrutural/hierárquica, bem como da infra-estrutura de suporte ao sistema de medição.

Pode-se então entender que o objetivo principal da medição de desempenho, é apontar se as empresas estão no caminho correto para atingir as metas estrategicamente estabelecidas. Neste direcionamento, Kaydos (1991), apresenta sub objetivos da medição de desempenho:

- Comunicar estratégia e clarear valores;

- Identificar problemas e oportunidades;

- Diagnosticar problemas;

- Entender processos;

- Definir responsabilidades;

- Melhorar o controle e planejamento;

- Identificar momentos e locais de ações necessárias;

- Mudar comportamentos;

- Tornar possível a visualização de trabalhos; 
- Envolver pessoas;

- Fazer parte ativa da remuneração funcional;

- Facilitar a delegação de responsabilidades.

\subsection{Importância}

Historicamente, os SMDs desenvolveram-se como meio de monitorar e manter o controle organizacional. Daí a importância atribuída aos indicadores no controle das operações, no sentido de se conhecer e identificar pontos críticos que comprometam o desempenho, e auxiliar no processo de implementação e gerenciamento das melhorias e mudanças.

Em uma empresa, o objetivo de se conhecer melhor os processos, produtos, eficiência operacional $\mathrm{e}$ atendimentos às exigências dos clientes, reside no fato de que por traz destes itens, existe a clara necessidade de melhor compreensão organizacional da realidade, o que vai permitir que melhores decisões sejam tomadas no futuro.

Neste sentido, os SMDs ajudam os gestores em acompanhar a implementação das estratégias pela comparação dos resultados, através da reunião de métodos para alinhar e agrupar objetivos, com relatórios periódicos que indicam o andamento da implementação das estratégias. Desta maneira, a medição de desempenho assume um papel crítico em ajudar os gestores em se adaptar ou aprender sobre sua real posição frente ao mercado.

O'mara et al. (1998), acrescentam ainda que um SMD não apenas fornece dados necessários para a gerencia controlar as várias atividades da empresa, mas também influenciam as decisões e o comportamento organizacional. Já Stainer \& Nixon (1997), afirmam que um sistema de medição focado em metas, pode ser um instrumento valioso para propor mudanças na administração de processos.

Devido então a importância da medição de desempenho, as métricas podem ser consideradas como o centro do entendimento de uma organização. Entender então o questionamento das razões de uma organização precisar medir seu desempenho é um pré-requisito importante. Os gestores, que possuem o entendimento dos objetivos de uma coleta de dados, serão capazes de decidirem 
adequadamente o que medir e como a informação será utilizada (Dickinson et al. 1997).

Porém, o uso de medidas de desempenho, como elemento estratégico, é relativamente recente. Se, por um lado, as empresas têm estado medindo há muito tempo qualidade, eficiência, produtividade, tempo de ciclo, etc., de seus processos, produtos e serviços, por outro, as novas abordagens para os SMDs procuram determinar o que deve ser realmente medido, a fim de entender e melhorar o trabalho no dia-a-dia.

É também bem divulgado junto a esta literatura que, assim como o mundo capitalista passa por um intenso processo de mudança, o uso de indicadores de desempenho também acompanha essas mudanças, passando por uma espécie de ajuste ou reformulação, o que lhe confere novas características, deixando, portanto, seu caráter apenas tradicional ou financeiro, típico até os anos 80, apenas para os relatórios contábil/financeiro. Esse processo é discutido logo abaixo.

\subsection{Medição de Desempenho Tradicional}

Ao longo do tempo, pode-se observar que os SMDs possuíam um caráter notoriamente de natureza financeira. O registro contábil das transações financeiras data de centenas de anos (egípcios, fenícios etc.) para facilitar as transações comerciais. Nos séculos das grandes explorações, as atividades das empresas globais de comércio eram medidas e monitoradas pelos livros-caixa de partidas dobradas ${ }^{2}$ dos contadores.

Da mesma forma, Kaplan \& Norton (1996a), identificaram que na Revolução Industrial, as grandes corporações dos setores têxtil, ferroviário, siderúrgico, industrial e varejista, desenvolveram algumas inovações na medição do desempenho financeiro, que exerceram um papel vital em seu crescimento.

Ainda relacionado às inovações financeiras, Dearden (1969) conclui que indicadores como a medida do Retorno Sobre o Investimento (ROI), o orçamento

\footnotetext{
${ }^{2}$ Sistema contábil utilizado em balanços patrimoniais no qual para cada crédito, existe um débito de igual valor e vice-versa, com o intuito de se obter o equilíbrio entre ativo, passivo e patrimônio líquido.
} 
operacional e o orçamento de caixa, foram fundamentais para o grande sucesso de empresas fundadas no início do século XX, como DuPont e a General Motors.

Neste contexto, para Bititci et al. (1997), existe ainda um grande número de empresas que possuem SMDs baseados em indicadores tradicionais. No entanto, tais indicadores possuem muitas limitações, por falharem em apoiar os objetivos estratégicos das empresas e não promovem melhoramento contínuo.

Ainda segundo Bititci (1994), os indicadores financeiros não reconhecem a necessidade de integração do negócio, por serem focados em processos de controles isolados. Isto promove projetos de melhoria que não levam em consideração a empresa como um todo. Desta forma, os sistemas de custeio produzem informações baseadas em dados históricos, o que é incompatível com a necessidade dos gestores que necessitam de dados atualizados e relevantes em um ambiente dinâmico.

Complementando, Neely (1998) afirma que indicadores tradicionais são criticados porque:

- focam em resultados de curto prazo;

- faltam informações relacionadas à qualidade, entrega e flexibilidade, além de não apresentarem um foco estratégico;

- encorajam otimizações locais, por exemplo produzir estoques para manter máquinas e operadores produtivos;

- incentiva pouco as inovações, ao invés de buscar melhorar continuamente;

- não conseguem traduzir métricas sobre o foco no cliente e desempenho da concorrência.

Já para Noble (1997), os indicadores tradicionais são também limitados porque:

- deixam passar algumas medidas, já que os relatórios financeiros são usualmente fechados mensalmente, ao passo que existem decisões que são tomadas em um ou dois meses prioritários. Os resultados financeiros são, em algumas vezes, muito velhos para serem úteis;

- tentam quantificar o desempenho e outros esforços de melhoria somente em termos financeiros. Muitos destes esforços são de difícil mensuração possuindo significantes impactos no sucesso global, como redução de tempos e fidelidade ao esquema de produção; 
- possuem um formato predeterminado. Todo registro é inflexível e ignora o fato de que cada departamento ou agente tem suas únicas e próprias características, prioridades e contribuições.

$\mathrm{Na}$ visão de Maskell (1991), os indicadores tradicionais apresentam os seguintes problemas:

- Pouco úteis para a manufatura: Os relatórios da contabilidade não têm relação direta com a estratégia da manufatura, além de não serem significativos para o controle de operações da produção e de distribuição;

- Distorção do custo: O padrão dos elementos de custo mudou ao longo dos anos, resultando em uma distinção entre custos diretos e indiretos (e custos variáveis e fixos). Em conseqüência, estas abordagens podem significar uma distorção no custo dos produtos;

- Inflexibilidade: Os relatórios tradicionais não variam de unidade para unidade dentro de uma organização e não acompanham a mudança das necessidades do negócio. Conseqüentemente, estes relatórios são recebidos tardiamente, sendo vistos geralmente com descaso pelos gerentes das operações;

- Obstáculo ao progresso: Os métodos tradicionais de avaliar o retorno de um projeto podem impedir a introdução de conceitos de Manufatura Classe Mundial, fazendo que os gerentes realizem tarefas desnecessárias para mostrar dados relevantes.

Em um trabalho semelhante, Manoochehri (1999) faz uma análise dos sistemas financeiros/contábeis, onde se parte de um pressuposto básico de que estes sistemas não apresentaram, ao longo do século XX, nenhuma mudança significativa para acompanhar as mudanças ocorridas no final do século. Seu trabalho descreve três pontos principais:

- Falta de relevância: Os relatórios financeiros não são relevantes para controle operacional ou estratégico, além de, em muitos casos, não serem diretamente relacionados com a estratégia da empresa. Atualmente, as empresas têm de possuir excelente desempenho na satisfação dos clientes, qualidade, velocidade, flexibilidade e inovação. Os relatórios financeiros não medem e relatam tais dimensões de desempenho; 
- Falta de flexibilidade: Sistemas contábeis são desenvolvidos para enfatizar objetividade e consistência. Enquanto estas características são por um lado muito úteis para auditorias e avaliações, por outro, estes relatórios são inapropriados e inflexíveis para níveis operacionais. Os objetivos e necessidades, e conseqüentemente os indicadores de desempenho, variam constantemente nas unidades de negócio, departamentos, produtos e grupos de trabalho. Os administradores devem ser capazes de criar e modificar as métricas para atender às suas necessidades específicas, assim que novos eventos, mudanças ou melhorias são implementadas;

- Falta de visão progressiva: Os relatórios tradicionais focam em indicadores inapropriados e informações enganosas. Esses relatórios tipicamente enfatizam muito o custo da mão-de-obra, e quaisquer melhorias promovidas aos processos ou produtos têm de possuir justificativas baseadas em redução deste custo.

Entretanto, em uma leitura feita por Kaplan \& Norton (1992), apesar dos indicadores tradicionais serem criticados pelo seu foco retrospectivo e da incapacidade de refletir uma trajetória para criação de valor, alguns autores vão mais longe na crítica a estes indicadores, afirmando que eles não melhoraram a satisfação dos clientes, a qualidade e a motivação dos empregados. Entendem que estas métricas são resultados de ações operacionais e que o sucesso financeiro é a conseqüência lógica do bom desempenho.

Porém, ao contrário de que se possa parecer, as empresas não devem simplesmente abandonar suas medidas financeiras, visto que elas são valiosas para sintetizar as conseqüências econômicas imediatas de ações consumadas, além de guiarem o lucro, satisfazer acionistas e o próprio mercado acionário, que se alimenta deste tipo de métrica para prever oscilações dos valores de ações.

Hornec (1993) acrescenta que o custo afeta as decisões sobre terceirizações, rentabilidade de produto, linhas de produto e segmentos de clientes. Já para Kaplan \& Norton (1996a), objetivos financeiros servem de foco para os objetivos e medidas de outras dimensões competitivas. 


\subsection{Novo Ambiente Operacional}

As empresas estão em meio a um caminho de transformação que começaram a trilhar no século passado. Durante a era industrial (aproximadamente de 1850 até 1970), o sucesso das empresas era determinado pela maneira como se aproveitava dos benefícios das economias de escala e de escopo. A tecnologia era importante, porém as empresas bem sucedidas eram sempre aquelas que incorporavam as novas tecnologias aos ativos, que permitiam a produção eficiente de produtos padronizados.

Entretanto, Kaplan \& Norton (1996a) identificaram que os avanços das últimas duas décadas tornaram obsoletos muitos conceitos da concorrência industrial. As empresas não conseguem mais obter vantagens competitivas sustentáveis apenas com a rápida alocação de novas tecnologias a ativos físicos, e com a gestão eficaz dos ativos e passivos financeiros.

Para Takashina \& Flores (1999), em função desta evolução das condições de competição do mercado mundial, novos modelos de gestão empresarial estão surgindo, aumentando a necessidade de informações que possibilitem processos decisórios mais descentralizados. O fluxo de informações está se horizontalizando, além de crescerem de volume. Os produtos possuem um maior esforço de desenvolvimento para atender a especificações ditadas por clientes, e os processos produtivos buscam cada vez mais a melhoria contínua, crescendo em flexibilidade e decrescendo em custos e estoques.

Kaplan \& Norton (1996a), também identificaram esforços e diversas iniciativas de melhoria (Gestão da Qualidade Total, Produção e sistemas de distribuição just-in-time, competição baseada em tempo, Produção Enxuta/Empresa Enxuta, organização focada no cliente, Gestão de Custos Baseada em Atividades, Empowerment dos funcionários e Reengenharia), justamente pela razão das atuais empresas estarem baseadas em um novo conjunto de premissas operacionais como:

- Processos interfuncionais: processos de negócios interligados que abrangem todas as funções tradicionais, combinando os benefícios da especialização funcional com a agilidade, eficiência e qualidade da integração dos processos; 
- Ligação com clientes e fornecedores: a tecnologia da informação permite que as empresas de hoje integrem os processos de suprimentos, produção e entrega, de modo que as operações sejam "puxadas" pelos pedidos dos clientes;

- Segmentação de clientes: existe uma tendência à diminuição de produtos e serviços padronizados, dando lugar a customização de diversos segmentos de clientes, sem a penalização de preços, devido às operações envolverem alta variedade;

- Escala global: as fronteiras nacionais deixaram de ser um obstáculo à concorrência entre empresas. Hoje se deve combinar a eficiência e agressividade competitiva do mercado global com a sensibilidade às expectativas dos clientes locais;

- Inovação: os ciclos de vida dos produtos continuam diminuindo. As empresas que competem em setores de rápida inovação tecnológica, devem prever as necessidades futuras dos clientes, idealizando produtos e serviços inovadores e incorporando rapidamente novas tecnologias de produto;

- Trabalhadores do conhecimento (Knowledge Workers): deixa de existir a elite intelectual (gerentes e engenheiros), e os trabalhadores diretos que só utilizavam a força física. Agora, os funcionários devem agregar valor pelo que sabem e pelas informações que podem fornecer.

Colaborando com esta visão, Neely (1998), também apresenta fatores de mudança no ambiente organizacional:

- A mudança da natureza do trabalho: o valor relativo do custo da mão de obra direta diminuiu muito em relação aos custos finais dos produtos ao longo do tempo. Isto traz uma dificuldade ao se apropriar os custos indiretos;

- O aumento da competição: existe agora a necessidade de uma maior eficiência e eficácia por parte das empresas, resultando na necessidade de se medir novas dimensões de desempenho, que torna os SMDs mais robustos e em congruência com o alinhamento estratégico;

- Iniciativas de melhorias específicas: novas métricas são necessárias como suporte para filosofias de gestão como programas de qualidade, adoção de novas tecnologias etc; 
- Prêmios internacionais e nacionais de qualidade: estes prêmios exigem um controle mais refinado das ações das empresas;

- Mudança das demandas externas: forças impulsionadas prioritariamente pela demanda, exercem pressão nos sistemas de medição de desempenho das empresas;

- O poder da tecnologia da informação: como ferramenta impulsionadora dos indicadores, os novos sistemas informatizados facilitaram a coleta, armazenagem e distribuição das informações nas empresas.

\subsection{Novos Sistemas de Medição de Desempenho}

Conforme as pesquisas em medição de desempenho avançavam, o surgimento de trabalhos em áreas funcionais, principalmente dentro da manufatura, começaram a surgir. Porém, a literatura apresentada, até o final da década de 80, mostrava pouco sobre o alinhamento do desempenho funcional com o objetivo do negócio. Para Lockamy (1998), as publicações deste período focavam na otimização local das áreas funcionais, levando pouco em consideração como outras funções ou unidades de negócios eram impactadas.

Por outro lado, para vários autores, a década de 90 marcou um intenso desenvolvimento do assunto medição de desempenho, que Andy Neely, da Cambridge University, chamou de "A Revolução da Medição" (Neely, 1998), e Robert G. Eccles, da Harvard Business Scholl, chamou de "Manifesto do Desempenho" (Eccles, 2000).

Assim, nesta linha, Carpinetti (2000b), constatou que a prática de medição de desempenho não financeiro passou a ser valorizada como um instrumento importante para:

- gerenciar o desempenho da organização;

- identificar pontos críticos que comprometam o desempenho e que devam ser alvos de melhorias;

- obter parâmetros confiáveis para a comparação entre empresas e entre os setores das empresas; 
- auxiliar o processo de implementação e gerenciamento das melhorias e mudanças.

Em uma compilação realizada por Neely et al. (1997), vários autores convergem suas visões nas seguintes características que as novas medidas de desempenho devam possuir:

- ser derivadas da estratégia;

- $\quad$ ser simples de se entender e claramente definidas;

- garantir feedback rápido e acurado;

- baseadas em quantidades que possam ser influenciadas ou controladas pelo usuário dos dados, ou em cooperação com outros;

- refletir os processos de negócio;

- se relacionar a metas específicas;

- $\quad$ ser parte de um processo gerencial cíclico;

- ter um impacto visual;

- focar na melhoria;

- explicitamente baseada em uma fórmula e fonte de dados;

- empregar taxas ao invés de números absolutos;

- baseadas em tendências ao invés de momentos isolados;

- usar dados coletados automaticamente sempre que possível.

De acordo com Maskell (1991), as características que os novos SMDs possuem em comum nas empresas classe mundial são:

- Direta relação com a estratégia do negócio;

- Uso primordial de medidas não tradicionais;

- Variação entre diferentes localizações;

- Mudam ao longo do tempo;

- São simples e fácies de serem utilizadas;

- Fornecem rápido retorno das informações;

- Favorece a melhoria ao invés de meramente monitorar.

A Tabela 2.1 apresenta uma compilação de recomendações feitas por diferentes autores para o desenvolvimento de sistemas de medição de desempenho. 
Tabela 2.1. Recomendações para a construção de um SMD. Compilada pelo autor

\begin{tabular}{|c|c|c|c|c|c|c|c|c|c|}
\hline & $\begin{array}{c}\text { Alinhamento } \\
\text { com a } \\
\text { estratégia }\end{array}$ & \begin{tabular}{|c|} 
Suporte a \\
melhoria \\
contínua
\end{tabular} & $\begin{array}{l}\text { Abrangência } \\
\text { da cadeia de } \\
\text { suprimentos }\end{array}$ & $\begin{array}{c}\text { Relações } \\
\text { causa- } \\
\text { efeito }\end{array}$ & $\begin{array}{c}\text { Uso de } \\
\text { indicadores } \\
\text { financeiros e } \\
\text { não financeiros }\end{array}$ & \begin{tabular}{|c|} 
Reflexo de \\
progresso e \\
tendências
\end{tabular} & \begin{tabular}{|c|} 
Mudança do \\
ambiente \\
institucional
\end{tabular} & $\begin{array}{c}\text { Identificação de } \\
\text { área chave de } \\
\text { desempenho }\end{array}$ & $\begin{array}{c}\text { Equalização } \\
\text { entre visões or } \\
\text { perspectivas di } \\
\text { empresa } \\
\end{array}$ \\
\hline Maskell (1991) & $\mathrm{X}$ & & & $\mathrm{X}$ & $\mathrm{X}$ & $\mathrm{X}$ & & $\mathrm{X}$ & $\mathrm{X}$ \\
\hline Kaplan \& Norton (1992) & $\mathrm{X}$ & $\mathrm{X}$ & & $\mathrm{X}$ & $\mathrm{X}$ & $\mathrm{X}$ & & $\mathrm{X}$ & $\mathrm{X}$ \\
\hline Eccles e Pybum (1992) & & & & $\mathrm{X}$ & $\mathrm{X}$ & $\mathrm{X}$ & & & $\mathrm{X}$ \\
\hline McGee \& Prusak (1994) & & & $X$ & $X$ & $X$ & & & & $X$ \\
\hline Hronec (1994) & $X$ & $X$ & & & $X$ & & $X$ & $X$ & \\
\hline Nelly et al (1994) & $\mathrm{X}$ & $\mathrm{X}$ & $\mathrm{X}$ & & $\mathrm{X}$ & & & $\mathrm{X}$ & \\
\hline Bititci (1995) & & $X$ & $X$ & $X$ & $\mathrm{X}$ & & $X$ & $X$ & $X$ \\
\hline Drucker (1995) & $X$ & $X$ & & & $X$ & $X$ & & $X$ & $X$ \\
\hline Lebas (1995) & & $X$ & & $X$ & $\mathrm{X}$ & $X$ & $X$ & & $X$ \\
\hline Rose (1995) & $\mathrm{X}$ & & & & & $\mathrm{X}$ & $X$ & $X$ & \\
\hline Ghalayini \& Noble (1996) & & $\mathrm{X}$ & & & & $\mathrm{X}$ & & & \\
\hline White (1996) & & $X$ & & & $X$ & & & $X$ & \\
\hline Lockamy (1998) & & & & & $X$ & & & $X$ & \\
\hline Beamon (1999) & $X$ & & $X$ & & $X$ & & & & \\
\hline Brown (2000) & $X$ & & & $X$ & $\mathrm{X}$ & $X$ & $X$ & $\mathrm{X}$ & $X$ \\
\hline Simons (2000) & $\mathrm{X}$ & & $\mathrm{X}$ & & $\mathrm{X}$ & $X$ & & $\mathrm{X}$ & $X$ \\
\hline
\end{tabular}


Martin (1997) enfoca suas afirmações na necessidade de indicadores não financeiros por eles conseguirem focar os objetivos estratégicos da empresa desde o nível mais alto até o mais baixo, além de ressaltar as diferentes necessidades de indicadores de cada nível (Figura 2.1).

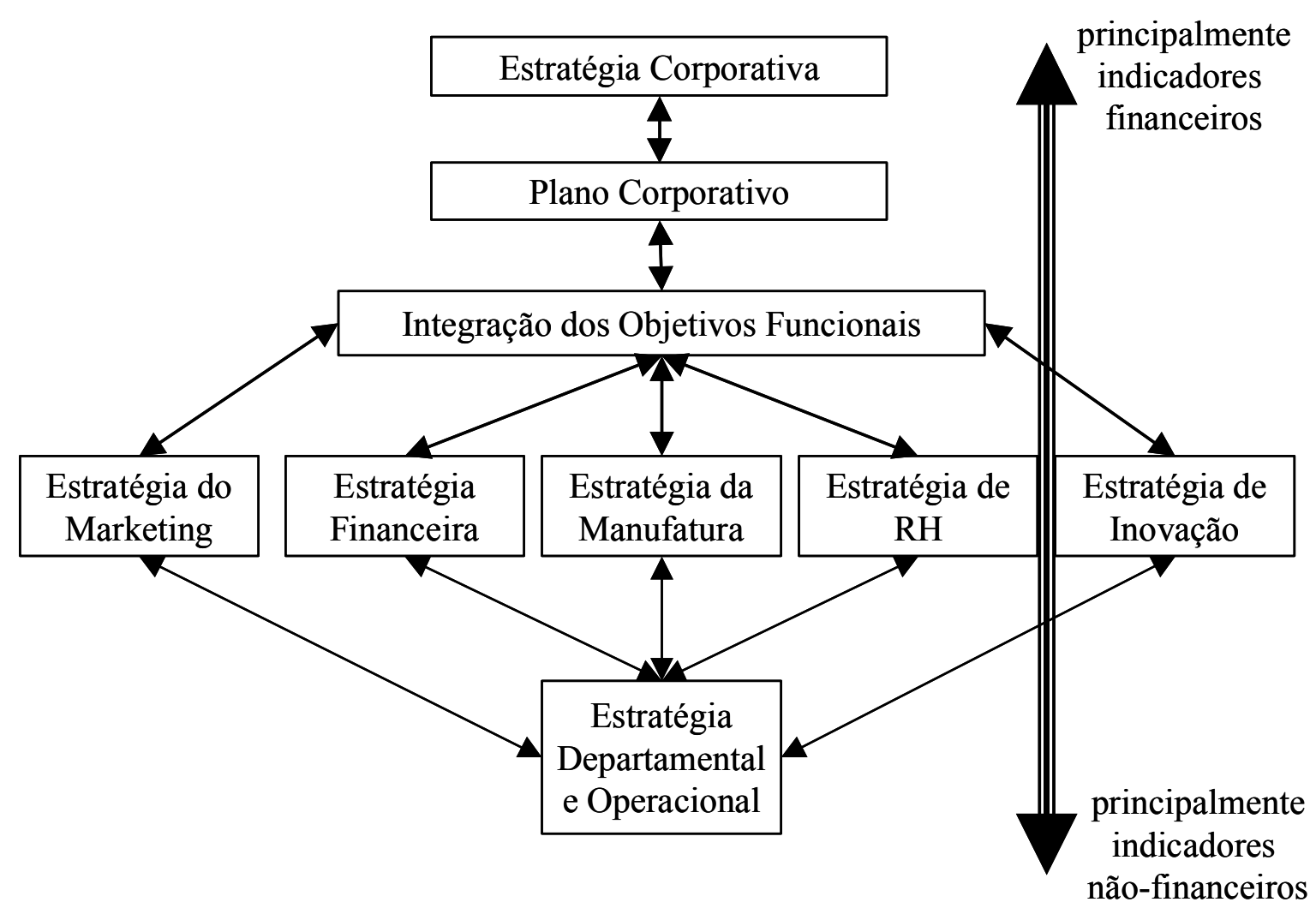

Figura 2.1. Abordagem estratégica da medição de desempenho.

Fonte: Martin (1997).

Bititci et al. (1997) concluem que a crítica às medidas financeiras, trouxe para a grande maioria dos pesquisadores a certeza da necessidade de formulação de sistemas de medição de desempenho que contemplem não apenas os indicadores financeiros. White (1996) e Kaplan \& Norton (1993) afirmam que parte destas pesquisas surgiram a partir da clara necessidade de cada empresa utilizar medidas sejam relevantes para sua própria situação e que o desenvolvimento de um equilibrado conjunto de indicadores otimiza o uso das métricas existentes e guia a empresa a um melhor desempenho dos negócios. 
Para Dixon ${ }^{3}$ apud Waggoner et al. (1999), um SMD precisa ser desenvolvido, administrado e avaliado periodicamente para se ter à certeza do rendimento dos resultados aferidos. O sistema por si só, é composto de vários elementos chaves incluindo: (a) um conjunto de procedimentos de coletagem e processamento de informações; (b) horários e protocolos para a distribuição das informações dentro ou fora da empresa; (c) um mecanismo de aprendizagem organizacional para identificar quais ações podem ser tomadas para uma melhora futura do desempenho e (d) uma revisão do processo o qual avalia se o SMD está sendo regularmente atualizado.

Da mesma maneira, Erban ${ }^{4}$, Flowler ${ }^{5}$ apud Neely et al. (1994), reconhecem que um SMD pode ser usado para influenciar o comportamento e ter influência na implementação de estratégias. De fato, na área de estratégia dos negócios, os SMDs ajudam os gestores a identificar bons desempenhos, torna explicito a introdução de metas estratégicas e dá a certeza do momento certo de intervir quando o desempenho está deteriorando.

Bititci (1995a) acrescenta que pesquisadores como Neely et al. (1995), Kaplan \& Norton (1992), Eccles \& Pyburn (1992), Meyer (1994) e O'mara et al. (1998) conduziram seus estudos na percepção da ligação entre indicadores de desempenho e planos estratégicos ou fatores de sucessos críticos dos negócios. Em suma, a necessidade de um conjunto de indicadores integrados que suportem a estratégia global da empresa está efetivamente estabelecida.

Portanto, os trabalhos destacados anteriormente apresentam a visão clara de que o não uso de um SMD, deixa as empresas aquém dos ajustes ou mudanças necessárias no ambiente competitivo atual. Conseqüentemente, estes autores estão engajados em pesquisas para determinar quais fatores influenciam a evolução dos SMDs usados pelas organizações, identificando os fatores que tendem a encorajar ou inibir gerentes a introduzirem novas métricas ou eliminar aquelas obsoletas. $\mathrm{O}$

\footnotetext{
${ }^{3}$ DIXON, J.R. et al. (1990). The new performance challenge: measuring operations for world-class competition. Homewood, IL. Dow Jones-Irwin.

${ }^{4}$ ERBAN, P. (1989). How they manage performance in windsor. Personnel Management, Feb. p. 4245.

${ }^{5}$ FOWLER, A. (1990). Performance management - the MBO of the 90s. Personnel Management, Jul. p. 47-51.
} 
principal objetivo destas pesquisas é identificar mecanismos no qual se possa gerenciar a evolução e subseqüentemente mudar seus SMDs.

Para Meyer (1994), Neely et al. (1996), Eccles \& Pyburn (1992), Bititci, (1995a) e Brown (1996), um SMD deve conter dados para monitorar o passado e planejar o futuro. Os indicadores de desempenho tradicionais e os não financeiros, devem ser integrados dentro de um sistema único, onde se deve considerar informações disponíveis, para fornecer o nível necessário de dados em termos de acurácia e confiabilidade.

Os gestores, ao conceber e implementar um SMD, devem resolver questões como o desenvolvimento de metodologias para a coleta das medidas, assim como a sua periodicidade e destino. Devem prover a solução para indicadores conflitantes, a inclusão do reflexo da cultura organizacional e o apropriado equilíbrio do sistema com o ambiente que o circunda, levando em consideração as medidas internas (da própria organização) e externas (fornecedores, consumidores e concorrentes).

Ao longo do tempo, o desenho de qualquer sistema de indicadores de desempenho deve refletir as operações básicas do suporte organizacional, sempre lembrando da importante relação intrínseca entre indicadores de desempenho e estratégia.

Portanto, o objetivo geral de um SMD, é conduzir a empresa à melhoria de suas atividades, pelo fornecimento de medidas alinhadas com o ambiente e os objetivos estratégicos, de forma a permitir o monitoramento do progresso no sentido de atingir esses objetivos. Essas medidas podem ser vistas como a essência da melhoria do desempenho.

\subsection{Características dos Novos SMDs}

A constatação de novas funcionalidades para os SMDs, lhes confere novas características. Dentre elas, a incorporação de novas dimensões competitivas é algo de suma importância, pois proporciona uma melhor integração de toda a empresa. Porém, deve existir também a preocupação com a mudança comportamental que os SMDs podem causar. Outra preocupação é com o ambiente e como ele vai influenciar na escolha dos indicadores de desempenho. 
Esses desdobramentos bem equacionados, disponibilizam um sistema constantemente atualizado e com características propicias para acompanhar o estado evolutivo das empresas. Esta situação é detalhada na seqüência deste texto.

\subsection{1. Áreas Chave ou Dimensões Competitivas}

Os SMDs consistem em uma quantidade de indicadores de desempenho individuais, que podem ser categorizados. A verdade é que a necessidade de mensuração destas categorias, que também podem ser chamadas de dimensões ou áreas chave de desempenho, vem de encontro com a utilização de indicadores nãofinanceiros. Porém, as áreas chave que cada organização vai medir, dependem diretamente de suas características e estratégias, por isso, a existência de diversas dimensões que podem ser encontradas na literatura.

Com referência ao trabalho de Carpinetti (2000b) e Kiyan (2001), pode-se observar que a definição de dimensões ou áreas chave leva à identificação de algumas áreas prioritárias para a melhoria de desempenho, e que qualquer ação neste sentido não deve ser a melhoria específicas, mas sim a melhoria de desempenho em dimensões correlatas a essas áreas.

Este trabalho discute algumas dessas áreas chave como: qualidade, tempo, flexibilidade, capacitação e satisfação de funcionários.

A área chave de desempenho qualidade traz respostas a inúmeros problemas, desde a falta de controles e padrões até a não observância das conformidades com as especificações técnicas (Perera et al., 1997; Toni et al., 1995). Neste sentido, Garvin (1992), identificou oito dimensões da qualidade, conforme segue:

- Desempenho: que se refere às características básicas de um produto;

- Características: que são os adereços do produto, aquelas características secundárias que suplementam o funcionamento básico do produto;

- Confiabilidade: que reflete a probabilidade de falha ou de mau funcionamento de um produto em um determinado período;

- Conformidade: atendimento das especificações ou o grau de variabilidade em torno de um valor de um parâmetro estabelecido como meta;

- Durabilidade: refere-se à vida útil do produto; 
- Atendimento: rapidez e eficiência do serviço;

- Estética: a aparência de um produto;

- Qualidade percebida: percepção sobre a qualidade do produto.

De acordo com Neely et al. (1995), o tempo se caracteriza como uma vantagem chave. As formas como as empresas gerenciam os prazos e a pontualidade na produção, em vendas e em distribuição, representam novas fontes de vantagem competitiva.

Stalk (1998) acrescenta que o sistema de produção pode ser inviabilizado pelo tempo de demora na percepção de mudanças ou ocorrência de novos eventos mercadológicos. Quanto maior esse tempo, mais distorcida será a visão de mercado. Essas distorções proliferam por todo o sistema, produzindo paralisações, desperdícios e ineficiências.

A flexibilidade, segundo Neely et al. (1995) e Slack et al. (1995), é entendida como a medida da capacidade de mudar para atender variações da demanda, ou seja, como e com quanto tempo o sistema de manufatura responde às várias mudanças. Os indicadores desta área chave visualizam o mix de produtos (número de componentes processados pelos equipamentos), e a capacidade em termos de volume de uma unidade de produção.

A capacitação e satisfação de funcionários é uma área chave que fornece condições para se obter um desempenho melhor em outras dimensões. Para tal, Brown (1996) e Kaplan \& Norton (1996a), discorrem sobre a importância de se investir em áreas, como infra-estrutura, pessoal, sistemas e procedimentos. Para esta dimensão, os indicadores podem derivar de três categorias: 1) capacidade dos funcionários, 2) capacidade dos sistemas de informação e 3) motivação, empowerment e alinhamento.

\subsubsection{Integração de Toda a Empresa}

Os SMDs podem ser vistos como ferramentas de integração de uma empresa. Por isso, é importante que problemas na implementação como a falta de informação compartilhada pelos departamentos devam ser evitados (Dumond, 1994). 
Meyer (1994), afirma que o projeto de qualquer SMD deve refletir os pressupostos operacionais básicos da respectiva organização. Se a empresa muda e o SMD permanece inalterado, implica em dizer que o SMD será desatualizado refletindo problemas na forma em que ele integra os indicadores.

Já para Bititci (1995b), a integração de uma empresa otimiza o uso de seus recursos, pois identifica conflitos de gestão. Posteriormente, este autor apresenta um modelo de medição de desempenho para medir o nível de integração da empresa, onde os indicadores de desempenho integrados exercem o papel de facilitadores.

Artley \& Stroh (2000) acrescentam que os componentes de um SMD integrado são:

- O plano estratégico;

- Processos chave do negócio;

- Necessidades de todos os membros da empresa;

- Envolvimento dos funcionários;

- Contabilização das medidas;

- Uma estrutura conceitual;

- Comunicação;

- Senso de urgência .

$\mathrm{Na}$ visão do U.S. DOE (2000) e de Brown (2000), um SMD deve ser conduzido por gestores que esclareçam a missão, visão, valores e direcionamento estratégico para os stakeholders. A integração torna possível que a medição de desempenho seja um efetivo agente de mudança.

Assim, quando é implementado um SMD, deve-se necessariamente refletir os processos que nela estão em andamento como: integração interfuncional, parcerias cliente-fornecedor, escala global, melhoria contínua e responsabilidade das equipes. A combinação destas métricas ajuda os gerentes a compreender muitas interconexões dentro das empresas. Essa compreensão contribui para a transposição das barreiras funcionais tradicionais e proporciona condições para a melhoria do processo decisório (Kaplan \& Norton, 1992). 


\subsubsection{Mudança Comportamental}

É reconhecido pela literatura, que as estratégias organizacionais devem atingir todos os agentes da empresa. Desta maneira, as estratégias são traçadas para obtenção de resultados, e com essa conotação, deverão encaminhar as ações das pessoas, sejam elas participantes da alta administração ou membros do chão de fábrica. Para que isso aconteça, há a necessidade de uma espécie de feedback de informações sobre os resultados das atividades, comparadas com os planos e metas da organização, resultando em modificações e ajustamentos se forem necessários.

Por outro lado, Spinola \& Pessôa (1997), argumentam que no desenvolvimento de um SMD, as características da empresa determinam os caminhos a serem adotados, ou seja, a informação e a organização possuem uma interdependência.

Rose (1995) afirma que neste sentido, um SMD se torna uma ferramenta comportamental, na medida em que as metas das empresas passam a guiar as ações dos funcionários. O problema que este autor identifica é que os funcionários podem encarar esta situação como uma ameaça.

Outro ponto a se destacar, é que no processo de implementação de um SMD, pode ocorrer mudanças das funções das pessoas, que também pode seguir um caminho de mudança nos comportamentos. Este esquema pode ser observado no modelo de Takashina \& Flores (1999). Observa-se que nas fases da Tabela 2.2, os itens em destaque são aqueles em que os funcionários têm importância decisiva no processo de gestão dos indicadores.

Por outro lado, Blenkinsop \& Burns (1992), identificaram que existem empresas que não dispõe de boa situação para a implementação de um SMD, por apresentarem limitações em sua configuração organizacional, cultural, estrutural, estratégica e tipo de liderança. Certos fundamentos devem ser modificados antes de uma eventual aplicação.

Desta forma, Parker (2000) argumenta que é essencial que a alta administração da empresa apóie a implantação de novas métricas. Da mesma forma, os funcionários de níveis mais baixos também devem entender seu compromisso com 
os indicadores, já que um dos propósitos de um SMD é melhorar os desempenhos de todos os níveis da organização.

Tabela 2.2. Gestão dos indicadores.

\begin{tabular}{|c|c|}
\hline Fases & Descrição \\
\hline 1 - Preparação & $\begin{array}{l}\text { - Criar cultura e clima adequados para medições e melhorias. } \\
\text { - } \frac{\text { Formar equipes de desenvolvimento: conhecedores de indicadores }}{\text { e sistemas de informação, gerentes e pessoal envolvido nos processos. }} \\
\text { - Estabelecer os propósitos da organização com relação ao sistema } \\
\text { de indicadores. } \\
\text { - Planejar o contato com os clientes, com base em diagnósticos e } \\
\text { ações passadas. }\end{array}$ \\
\hline $\begin{array}{l}2 \text { - Definição das } \\
\text { características, } \\
\text { indicadores e metas }\end{array}$ & $\begin{array}{l}\text { - Realizar pesquisa orientada para conhecer o mercado e os clientes. } \\
\text { - Traduzir as necessidades e expectativas dos clientes, desdobrar as } \\
\text { características do produto e do processo, desenvolver os indicadores } \\
\text { e estabelecer as metas de nível superior, observando os objetivos e } \\
\text { - } \frac{\text { estratégias da organização e os referenciais da corporação. }}{\text { - Desdobrar os indicadores e as metas na estrutura organizacional. }} \\
\text { - Selecionar aqueles mais importantes para uso no dia-a-dia. }\end{array}$ \\
\hline $\begin{array}{l}3 \text { - Desenvolvimento } \\
\text { do sistema de } \\
\text { informação }\end{array}$ & $\begin{array}{l}\text { - Escolher a técnica de medição. } \\
\text { - Identificar as fontes de dados. } \\
\text { - Eliminar os indicadores inviáveis ou dificeis de operacionalizar. } \\
\text { Desenvolver ou aprimorar as metodologias para coleta e } \\
\text { - Vrocessamento, análise e uso de dados e resultados. }\end{array}$ \\
\hline $\begin{array}{r}4 \text { - Medição } \\
\text { dos dac }\end{array}$ & $\begin{array}{l}\text { - Coletar e processar os dados. } \\
\text { - } \frac{\text { Analisar os dados e os resultados, envolvendo a gerência e sua }}{\text { Procurar reduzir o ciclo de acesso e análise dos indicadores. }}\end{array}$ \\
\hline $\begin{array}{l}5 \text { - Uso dos dados e } \\
\text { resultados }\end{array}$ & $\begin{array}{l}\text { - } \quad \text { Disponibilizar Tabelas, gráficos, relatórios, mapas etc. } \\
\text { - } \quad \text { Analisar criticamente os dados e resultados. } \\
\text { - } \quad \text { Vincular os resultados a decisóes e açóes. } \\
\text { - Medir o uso dos dados e resultados. } \\
\end{array}$ \\
\hline $\begin{array}{c}6 \text { - Ciclo de avaliação } \\
\text { e melhoria }\end{array}$ & $\begin{array}{l}\text { - Avaliar a abrangência dos indicadores com relação aos propósitos } \\
\text { da organização, e sua aplicação na tomadas de decisão e no } \\
\text { planejamento. } \\
\text { - Aprimorar o sistema de indicadores: o enfoque deve ser primeiro } \\
\text { na melhoria e depois na medição, de forma que a medição esteja } \\
\text { vinculada ao processo. } \\
\text { - Reconhecer os esforços das pessoas que contribuíram na melhoria. }\end{array}$ \\
\hline
\end{tabular}

Fonte: Takashina \& Flores (1999).

\subsubsection{O Ambiente}

A interação com o ambiente é elemento importante na implementação de um SMD. Dentro desta discussão, devem ser considerados dois fundamentos principais: o ambiente interno e o externo. Internamente, assim que as estratégias são criadas, o 
SMD assume parte das ações através do controle o qual devem incluir objetivos e feedback. Externamente, deve-se levar em consideração três elementos: fornecedores, clientes e competidores.

Alguns dos primeiros modelos de medição de desempenho que levaram em consideração o ambiente foram, primeiro o desenvolvido por Keegan et al. (1989), no qual existe a tentativa de integração de indicadores financeiros com não financeiros, internos e externos (Tabela 2.3), e segundo o de Lynch \& Cross (1991), onde os autores estabelecem uma pirâmide que tenta hierarquizar categorias de medição de desempenho, conforme apresentado na Figura 2.2.

Tabela 2.3. Matriz de medição de desempenho.

\begin{tabular}{|c|ll|l|}
\hline Indicador & \multicolumn{1}{|c|}{ Não Financeiro } & \multicolumn{1}{c|}{ Financeiros } \\
\hline \multirow{2}{*}{ Externo } & $\bullet$ Participação no mercado & $\bullet$ Gastos com P\&D \\
& $\bullet \quad$ Clientes que retornam & $\bullet \quad$ Posição competitiva de preços \\
\hline \multirow{2}{*}{ Interno } & $\bullet \quad$ Time-to-Market & $\bullet$ Custo dos novos produtos \\
& $\bullet \quad$ Número de novos produtos & $\bullet \quad$ Custo de material \\
& $\bullet$ Custo da manufatura \\
\hline
\end{tabular}

Fonte: Keegan et al. (1989).

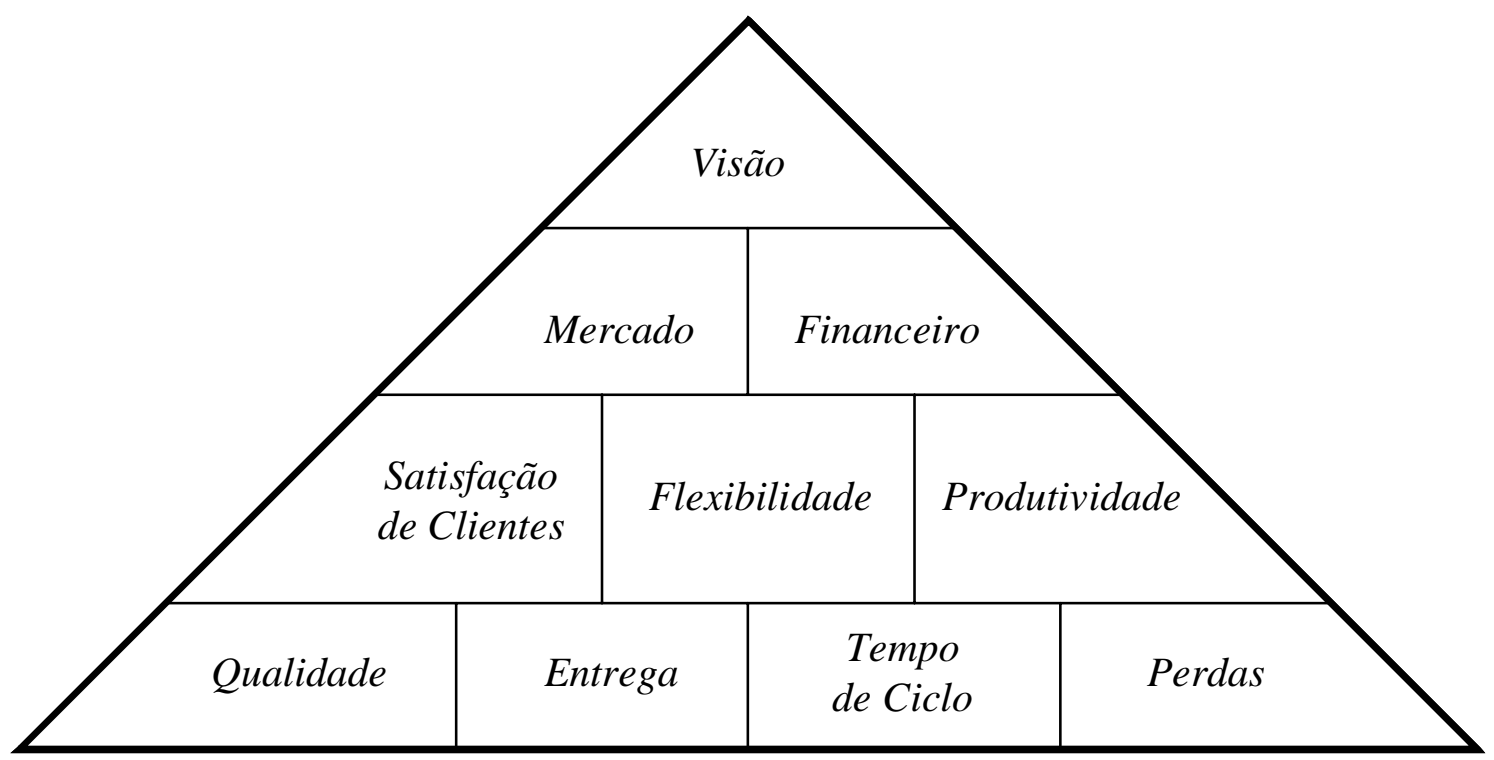

Figura 2.2. Pirâmide de desempenho.

Fonte: Lynch \& Cross (1991). 
Autores como Neely et al. (1995) e Tonchia (2000) propõem uma análise de medição de desempenho justamente observando como este sistema se relaciona com o ambiente. Posteriormente a análise destes autores observa como os indicadores individuais são agrupados dentro de um SMD como entidade, conforme apresentado na Figura 2.3.

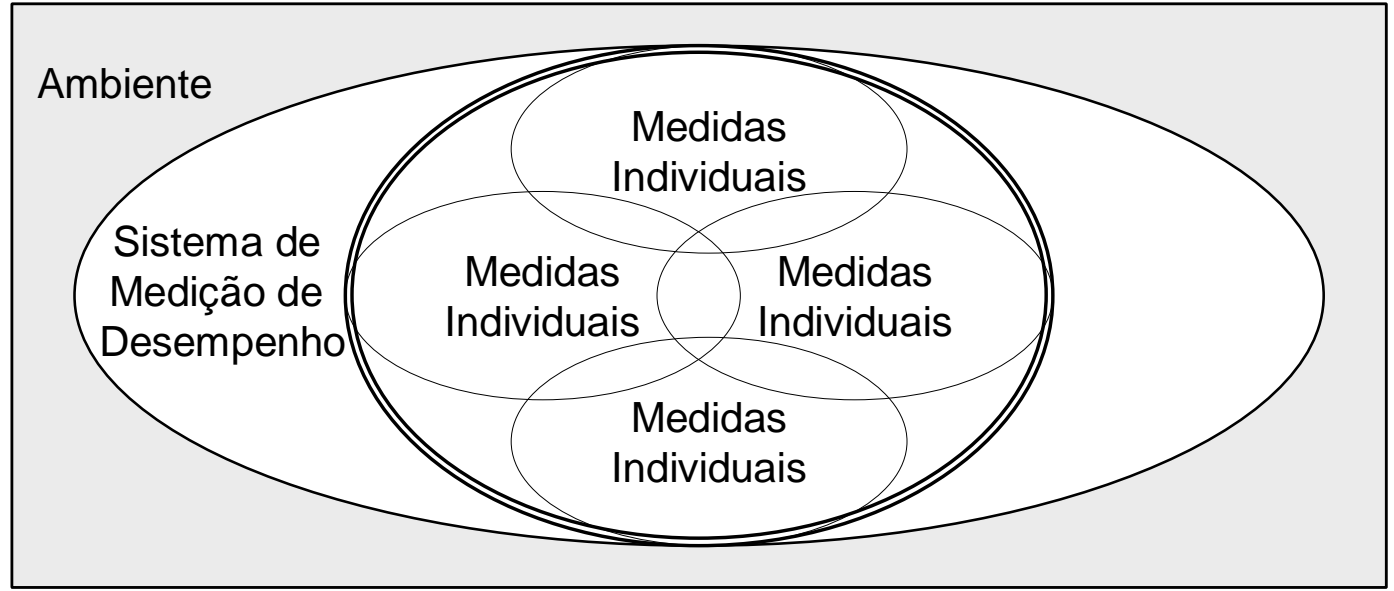

Figura 2.3. Modelo de um sistema de medição de desempenho.

Fonte: Neely et al. (1995).

Segundo Bititci et al. (2000), um SMD orientado para a análise do ambiente de negócios, deve possuir estas características:

- Um sistema de monitoramento externo o qual constantemente relata as mudanças neste ambiente;

- Um sistema de monitoramento interno, que monitora os procedimentos e que fornece avisos ou alarmes de maus desempenhos;

- Um sistema de revisão que utiliza informações internas e externas, cruzando-as com os objetivos e prioridades pré-determinadas. Desta maneira, o sistema pode ajudar no desenvolvimento e revisão de objetivos e prioridades críticas da empresa.

Já Neely analisa o ambiente a partir das seguintes questões (Neely et al., 1995):

- Os indicadores de desempenho reforçam a estratégia da empresa?

- Os indicadores de desempenho são condizentes com a cultura da empresa?

- Os indicadores de desempenho são condizentes com a estrutura de reconhecimento e recompensa? 
- Alguns dos indicadores focam a satisfação do consumidor?

- Alguns dos indicadores focam no que os competidores estão fazendo?

Portanto, a escolha de métricas tanto internas quanto externas torna um SMD mais completo e abrangente. Desta maneira, os gerentes podem monitorar as atividades internas, e não peder o foco dos clientes, fornecedores e concorrentes, e o quanto determinadas ações destes agentes, podem causar impactos nas ações e metas de uma empresa.

\subsubsection{Evolução}

As medidas de desempenho não devem ser estabelecidas como meros julgamentos, tais como: rápido, ótimo, perfeito, etc., mas sim como indicadores que esclareçam a verdadeira dimensão das saídas e dos processos.

Sob a visão da melhoria contínua, deve-se entender que essas medidas, e seus parâmetros são passíveis de mudança, por isso devem ser constantemente avaliadas.

De qualquer forma, é comumente reconhecido que os ambientes interno e externo não são estáticos. Um SMD necessita, portanto, de ser dinâmico e sensível às mudanças ambientais, revisando e re-priorizando objetivos internos quando as mudanças externas são suficientemente significantes.

Para Takashina \& Flores (1999), a evolução de um SMD parte do princípio de que, a eficácia do processo de gestão dos indicadores depende da introdução e desenvolvimento, sempre que necessário, de ações corretivas no sentido de avaliar os indicadores e sua aplicação.

Bourne et al. (2000) também discutem a evolução dos SMDs em função da constante atualização que a empresa deve realizar. Este processo segue os seguintes passos:

- Revisão e atualização periódica das métricas;

- Desenvolvimento de novos indicadores quando necessário;

- Atualização das metas;

- Mudança do SMD assim que estratégias ou objetivos mudam.

Outro ponto importante na análise evolutiva dos SMD é a identificação de metas, que são os sinais que dizem se um indicador deve ser revisto ou não. $\mathrm{O}$ 
estabelecimento de metas e/ou padrões não se limita a quantidades numéricas, mas se estendem às práticas de negócios, rotinas, métodos e procedimentos.

Metas de desempenho segundo Ñauri (1998), caracterizam-se por ser:

- Atingíveis: devem ser alcançáveis com um esforço razoável sob condições que as levem a prevalecer;

- Econômicas: o custo de implementação e administração deve ser baixo em relação à atividade coberta;

- Aplicáveis: devem adaptar-se às condições sob as quais serão usadas. Se as condições mudarem, devem ter flexibilidade suficiente para encontrar essas variações;

- Consistentes: devem ajudar a unificar as operações e comunicações através de todos os setores e funções da empresa;

- Abrangentes: devem cobrir todas as atividades inter-relacionadas;

- Compreensíveis: devem ser expressas em termos simples e claros, a fim de evitar incerteza ou interpretação errônea. As informações, para seu uso, devem ser específicas e completas;

- Mensuráveis: devem ser capazes de comunicá-las com precisão;

- Adaptáveis: devem ser desenhadas de modo que elementos possam ser mudados ou adicionados, sem necessidade de refazer toda sua estrutura;

- Legítimas: devem ser oficialmente reconhecidas e aprovadas;

- Eqüitativas: devem ser aceitas, pelas pessoas que têm de lidar ou trabalhar com elas, como uma base justa, para comparação.

Portanto, o dinamismo atual do ambiente de negócios requer que as empresas verifiquem constantemente seus SMDs e promovam mudanças, pois a curto/médio prazo, seus sistemas poderão ser ineficientes ou contra-produtivos. A evolução portanto apresenta-se como elemento decisivo.

\subsection{Sistemas de Medição de Desempenho como Entidade}

Esta seção tem por objetivo a descrição, de forma geral alguns SMDs, para mostrar suas características próprias, enfatizando a discussão teórica que este trabalho vem abordando até aqui. 


\subsubsection{Balanced Scorecard}

Robert S. Kaplan e David P. Norton desenvolveram, a partir de estudos realizados junto a grandes empresas norte-americanas, o Balanced Scorecard (BSC) no início da década de 90. O BSC é uma abordagem da medição de desempenho que combina métricas financeiras com não financeiras com o intuito de fornecer informações mais relevantes sobre as atividades (Kaplan \& Norton, 1992, 1996a e 1996b). Uma das mais importantes características do BSC é focar uma quantidade limitada de métricas, que melhoram o foco e a gerência e o agrupamento de métricas similares em grupos (também chamados de perspectivas), apresentadas na Figura 2.4 .

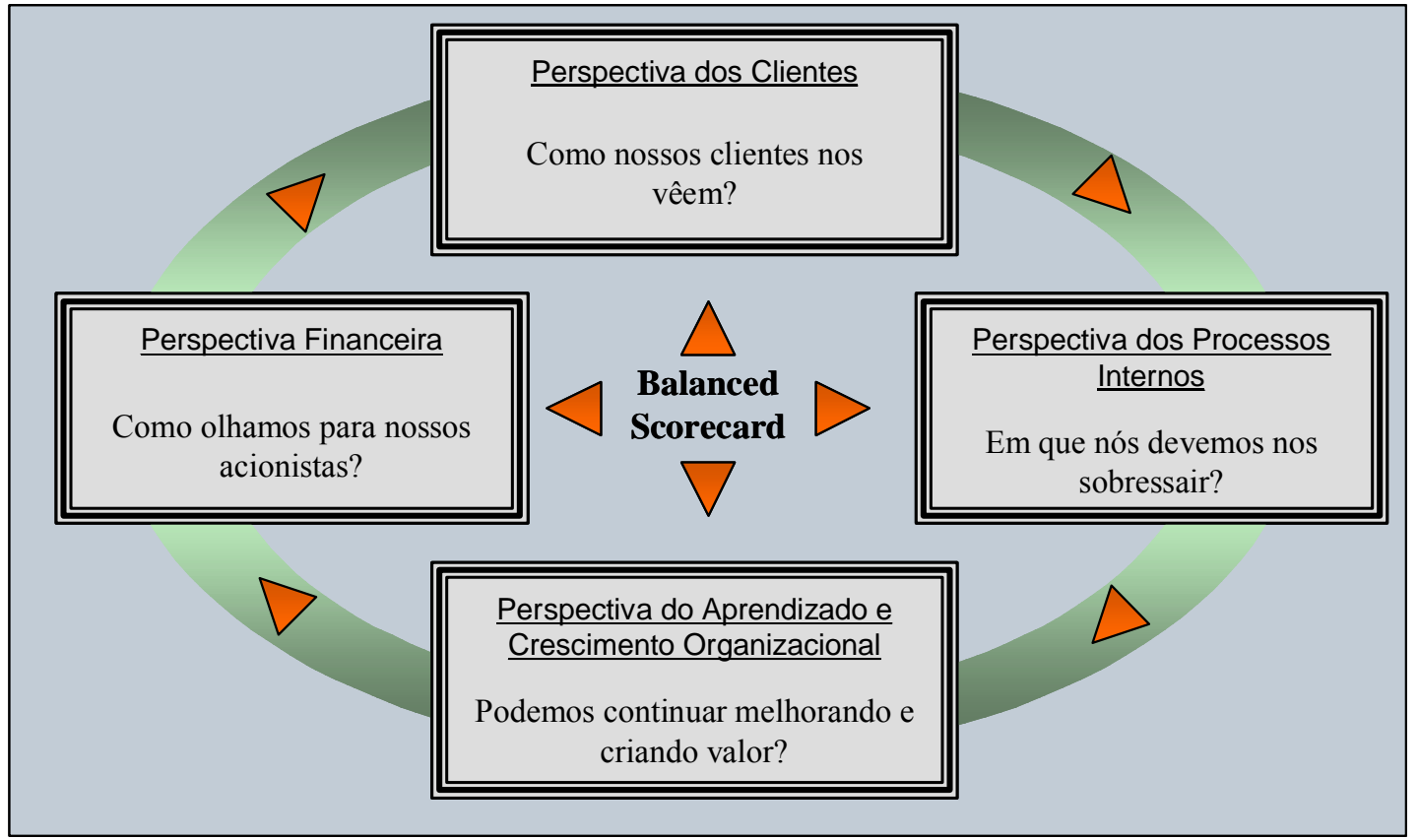

Figura 2.4. The Balanced Scorecard.

Fonte: Adaptado de Kaplan \& Norton (1992).

- Perspectiva Financeira: O BSC conserva os indicadores financeiros porque no modelo, eles indicam se a estratégia de uma empresa, sua implementação e execução estão contribuindo para a melhoria dos resultados financeiros;

- Perspectiva dos Clientes: Permite a identificação dos segmentos de clientes e mercados nos quais a unidade de negócios competirá e as medidas de desempenho da unidade nesses segmentos-alvo; 
- Perspectiva dos Processos Internos: É a identificação dos processos internos críticos nos quais a empresa deve alcançar a excelência. Estas medidas estão voltadas para os processos que terão maior impacto na satisfação dos clientes, e na consecução dos objetivos financeiros da empresa;

- Perspectiva do Aprendizado e Crescimento: Identifica-se a infra-estrutura que a empresa deve construir para gerar crescimento e melhoria a longo prazo.

A elaboração do BSC compreende a eleição, a partir das definições de visão, missão e estratégia da empresa, de uma relação de objetivos estratégicos, seus indicadores de monitoramento, suas metas de superação e as iniciativas correspondentes para o seu alcance.

A partir dos objetivos financeiros, tem-se uma derivação de objetivos e medidas para as outras perspectivas do scorecard que deverão possuir relacionamentos para facilitar a execução de um ou mais objetivos desta perspectiva. Assim, toda medida selecionada deve fazer parte de uma cadeia de relações de causa e efeito, entre os resultados financeiros e as outras perspectivas, e além disso, representa um tema estratégico para a unidade de negócios como apresentado na Figura 2.5 (Kaplan \& Norton, 1996a).

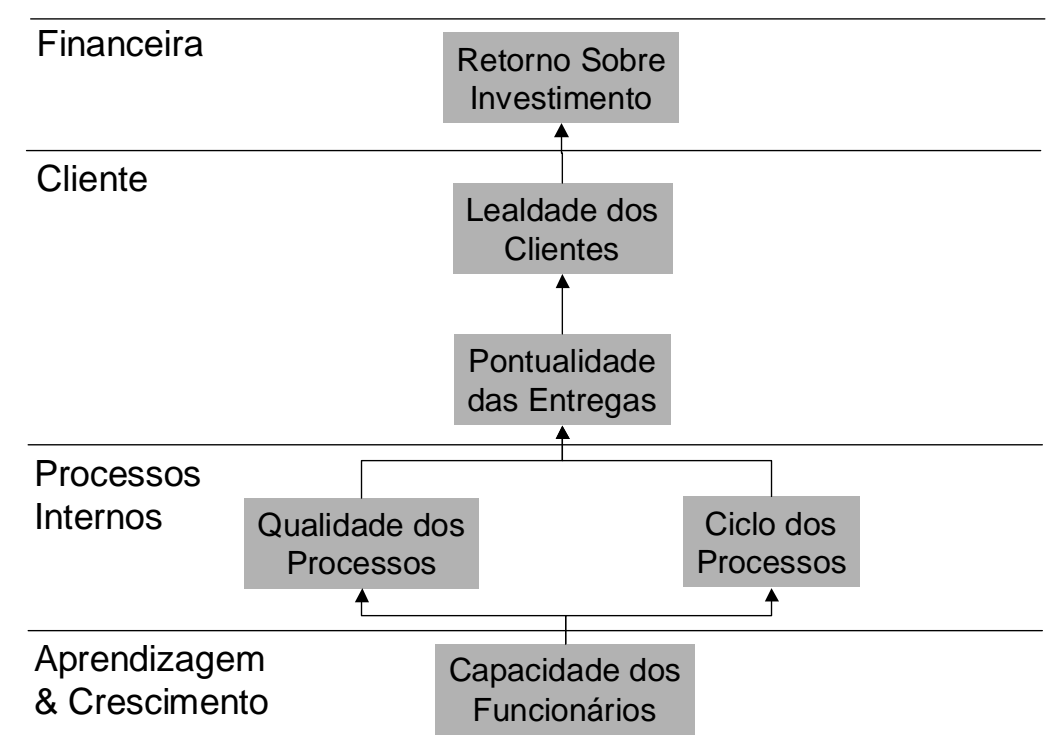

Figura 2.5. Exemplo de relacionamento entre medidas de desempenho de um BSC. Fonte: Kaplan \& Norton (1996a). 
A partir então de sua implantação, o programa passa por reavaliações periódicas que culminam com os processos de revisão estratégica, o alinhamento de programas em andamento e a adequação das atividades de comunicação, recompensas e orçamento da empresa. Todo este processo é implementado em oito etapas que segue (Kaplan \& Norton, 1993):

1. Preparação: Identificar as unidades de negócio para o qual a aplicação do BSC é apropriada.

2. Entrevistas (primeira etapa): Entrevistas com a alta administração e posterior identificação dos objetivos da empresa.

3. Workshop Executivo: (primeira etapa): Alta administração debate sobre a missão e a estratégia da empresa Um rascunho do BSC é desenhado nesta etapa.

4. Entrevistas: (segunda etapa): Um facilitador do processo sumariza as informações do primeiro workshop executivo e discute estas informações com cada executivo. O facilitador também colhe informações a respeito sobre a implementação.

5. Workshop Executivo: (segunda etapa): Grandes seções onde os participantes comentam sobre possíveis indicadores e seus propósitos e iniciam o plano de implementação. Também são sugeridas metas para cada métrica.

6. Workshop Executivo: (terceira etapa): Os executivos se encontram, são divididos em grupos, para chegar a um consenso final sobre visão, objetivos, e indicadores desenvolvidos nos primeiros encontros. Aqui também é desenvolvido um programa preliminar para se atingir as metas. Cada grupo deve concordar com o programa de implementação, em comunicar as ações para os funcionários, integrar o BSC a filosofia gerencial e desenvolver um sistema de informação como suporte às métricas.

7. Implementação: Times de implementação formulam planos de ações. Aqui devem ser definidas ligações entre métricas e sistema de informações, como será comunicado para toda a empresa, e desenvolvimento de um segundo nível de métricas.

8. Revisões Periódicas: A cada quatro meses, um livro de informações do BSC é preparado para a revisão da alta administração e discussão com os níveis 
intermediários. As métricas são revisadas anualmente como parte do planejamento estratégico.

O BSC é construído em torno da idéia de que deve existir um balanço entre medidas de resultados e medidas de determinantes de resultados, que são chamados de vetores de desempenho (ou performance drivers).

Esse é um ponto importante para o BSC já que Neely et al. (1995), observam que as medidas de desempenho em uma organização podem ser classificadas em dois tipos básicos: aquelas relacionadas a resultados, como resultados financeiros; e aquelas relacionadas aos determinantes desses resultados, como qualidade, entrega, flexibilidade, inovação, entre outras. Enquanto as medidas de resultados informam sobre o passado, as medidas de tendências são indicativas do desempenho futuro. Assim, para que a medição de desempenho possa ser usada como um instrumento gerencial, é preciso fazer uso de uma combinação adequada de medidas de resultado e medidas de tendência.

Outro ponto importante destacado por Kaplan \& Norton (1996a), é o uso do BSC como instrumento para o processo de implementação e revisão da estratégia da empresa. Para os autores o BSC é usado como instrumento para traduzir e comunicar a estratégia, planejar e estabelecer metas e rever o progresso.

\subsubsection{Desempenho Quantum}

O livro Sinais Vitais, que traz o conceito de desempenho Quantum, foi escrito por Steven M. Hornec em conjunto com a consultoria de Arthur Andersen em 1993.

Segundo o autor, o desempenho quantum pode ser definido como o nível de realização que otimiza o valor e o serviço da organização para seus interessados: clientes, empregados, acionistas, fornecedores, etc.

Este SMD é composto basicamente por uma matriz de desempenho, chamada de quantum, que permite a administração entender e desenvolver medidas de desempenho que venham a equilibrar três dimensões de desempenho:

- qualidade: a excelência do produto ou serviço para os clientes;

- tempo: a gestão da excelência do processo;

- custo: o lado econômico da excelência. 
$\mathrm{O}$ autor também considera a existência de um relacionamento entre as dimensões de desempenho. Estes relacionamentos correspondem à criação de valor para os clientes no caso do custo e qualidade. Já a qualidade e tempo juntos podem otimizar a execução e prestação do serviço.

Hronec descreve ainda três níveis, que são chamados na obra de "mobilização" das medidas de desempenho na organização como complemento a matriz Quantum de Medição de Desempenho. Os três níveis são: a) humano: as pessoas que executam as atividades, orientadas por um conjunto de medidas de desempenho, b) processo: a série de atividades que consomem recursos e fornecem saídas aos clientes internos ou externos e c) organização: compreensão dos níveis de desempenho das pessoas e do processo.

A matriz quantum de desempenho ilustra o uso das medidas de desempenho em toda a empresa em nível de hierarquia, processo e pessoal. Pode-se entender que existe um contexto para mostrar onde as pessoas se enquadram no processo de desenvolver, implementar e utilizar as medidas de desempenho. A matriz também apresenta o cruzamento das dimensões de desempenho (qualidade, tempo e custo) com os três níveis de mobilização das mesmas (humano, processo e organização) descritas acima, Tabela 2.4.

Tabela 2.4. Matriz Quantum de Medição de Desempenho.

\begin{tabular}{|c|c|c|c|}
\hline \multicolumn{4}{|c|}{ Desempenho Quantum } \\
\hline & \multicolumn{2}{|l|}{ Valor } & \multirow{2}{*}{\begin{tabular}{|l|} 
Serviço \\
Tempo
\end{tabular}} \\
\hline Níveis/Medidas & Custo & Qualidade & \\
\hline Organização & $\begin{array}{l}\text { Financeiro } \\
\text { Operacional } \\
\text { Estratégico }\end{array}$ & $\begin{array}{c}\text { Empatia } \\
\text { Produtividade } \\
\text { Confiabilidade } \\
\text { Credibilidade } \\
\text { Competência }\end{array}$ & $\begin{array}{c}\text { Velocidade } \\
\text { Flexibilidade } \\
\text { Responsabilidade } \\
\text { Maleabilidade }\end{array}$ \\
\hline Processo & $\begin{array}{c}\text { Inputs } \\
\text { Atividades }\end{array}$ & $\begin{array}{l}\text { Conformidade } \\
\text { Produtividade }\end{array}$ & $\begin{array}{c}\text { Velocidade } \\
\text { Flexibilidade }\end{array}$ \\
\hline Pessoas & $\begin{array}{c}\text { Remuneração } \\
\text { Desenvolvimento } \\
\text { Motivação }\end{array}$ & $\begin{array}{c}\text { Confiabilidade } \\
\text { Credibilidade } \\
\text { Competência }\end{array}$ & $\begin{array}{c}\text { Responsabilidade } \\
\text { Maleabilidade }\end{array}$ \\
\hline
\end{tabular}

Fonte: Hornec (1994). 
Para determinação das medidas de desempenho, dentro das áreas compreendidas na matriz, faz-se necessário o uso do processo chamado de " $\mathrm{O}$ modelo quantum de medição de desempenho", que fornece a estrutura básica para a medição de desempenho, Figura 2.7.

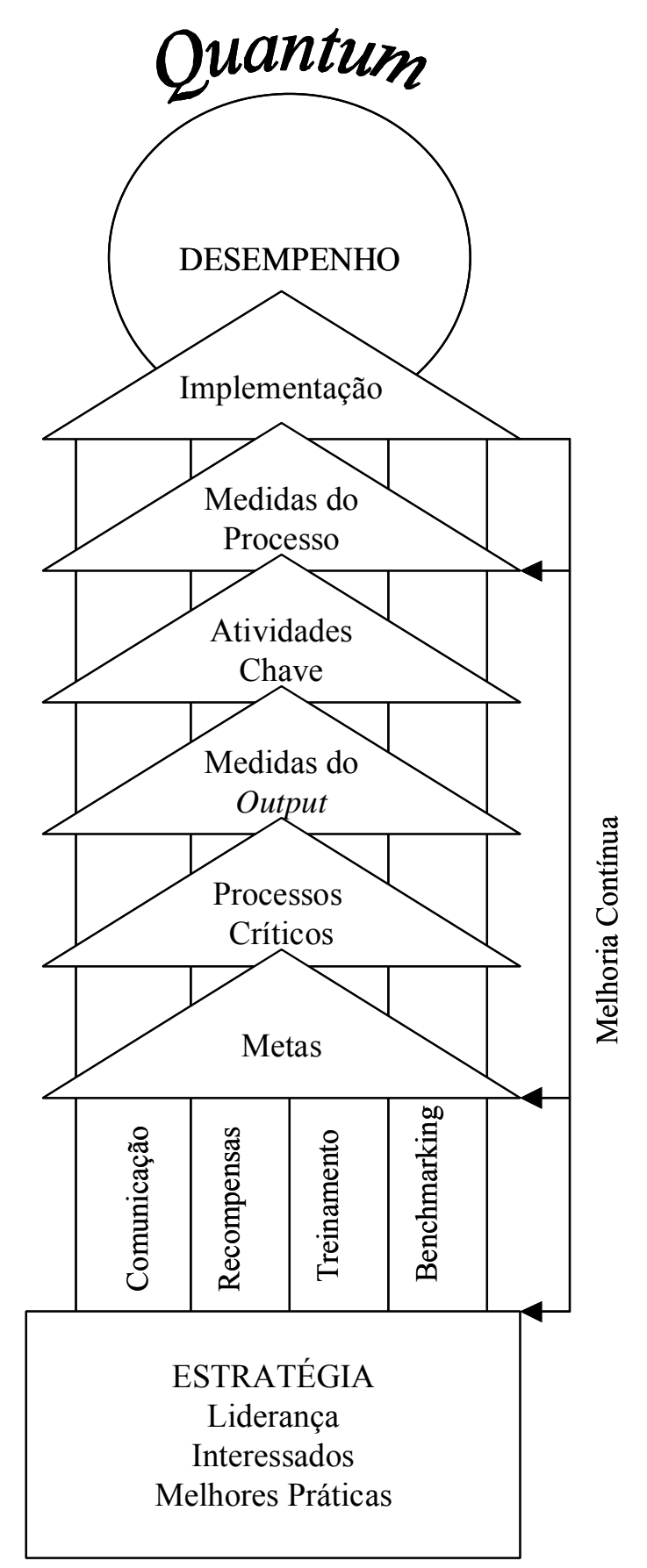

Figura 2.6. Modelo Quantum de medição de desempenho.

Fonte: Hronec (1994). 
Portanto, o modelo quantum consiste em quatro elementos distintos:

- Primeiro elemento (geradores): Estes levam em consideração a liderança da empresa, os interessados e as melhores práticas do ambiente;

- Segundo elemento (facilitadores): Eles dão apoio à implementação das medidas do desempenho por meio da comunicação. Os facilitadores são respectivamente: treinamento, recompensas e benchmarking;

- Terceiro elemento (o processo em si): É necessário que o entendimento dos processos críticos da organização para depois que as atividades chave dentro daqueles processos terem sido identificadas, empregar as medidas de desempenho de saídas. Após completar esta etapa, as medidas de desempenho do processo para controlar e monitorar as atividades chave podem ser desenvolvidas, e todas as medidas de desempenho podem ser implementadas;

- Quarto elemento (melhoria contínua): O modelo propõe feedback para a melhoria contínua, para o estabelecimento de novas metas e para o ajuste da estratégia.

A implementação é um processo composto de seis etapas, que deve incluir as pessoas envolvidas com as métricas a partir do processo do desenvolvimento, para garantir que novas medidas sejam aceitáveis, confiáveis e focalizadas. As etapas são: a) Desenvolver e validar a rotina dos relatórios; b) Obter o endosso da administração; c) Submeter o plano de implementação às pessoas do processo; d) Começar a medição e emitir os relatórios correspondentes; e) Avaliar a efetividade das medidas; f) Analisar e melhorar continuamente as medições de desempenho.

Ainda segundo Hronec (1994), esse modelo pode ser utilizado em cada nível e em cada parte da organização, já que cada área precisa de sua própria estratégia, suas próprias metas e medidas de saídas.

\subsection{Métodos de Desenvolvimento de Sistemas de Medição de Desempenho}

Apesar de a literatura apresentar várias recomendações e modelos conceituais para o desenvolvimento de sistemas de medição de desempenho, poucos são os trabalhos que tratam sobre como desenvolver um conjunto de indicadores ou um sistema de medição de desempenho. Neely et al (2000) apresentam uma proposta de método para o processo de desenvolvimento de sistemas de medição de desempenho, 
com seis fases, Figura 2.7, que é apresentado em um workbook, que endereça questões como quais indicadores são necessários, o custo/benefício do processo, o propósito da medição de desempenho para a aplicação, testes inter-funcionais, analise ambiental e definições de manutenções periódicas no sistema. Este modelo também apresenta um mapa detalhado com as fases essenciais no processo, Figura 2.8 .

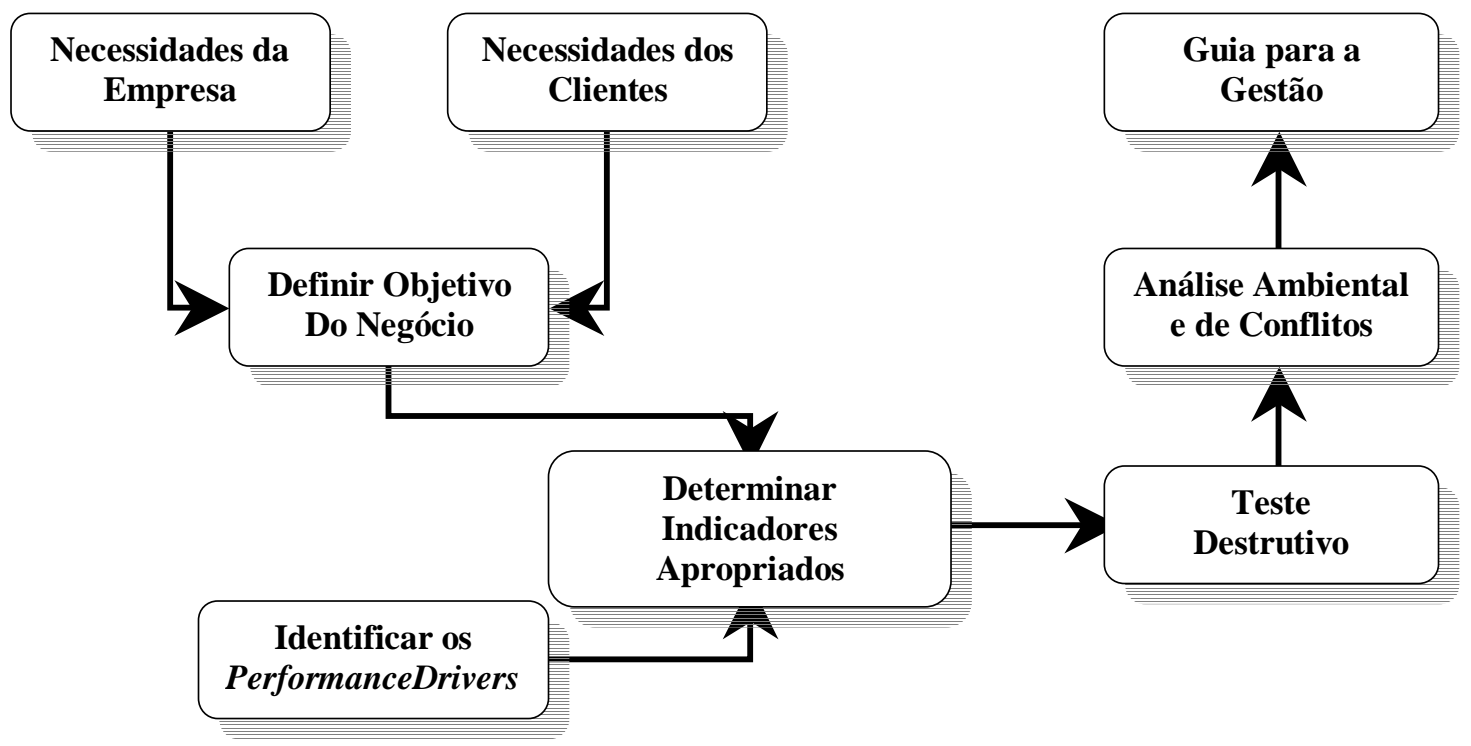

Figura 2.7. Fluxo do Processo.

Fonte: Neely et al. (2000)

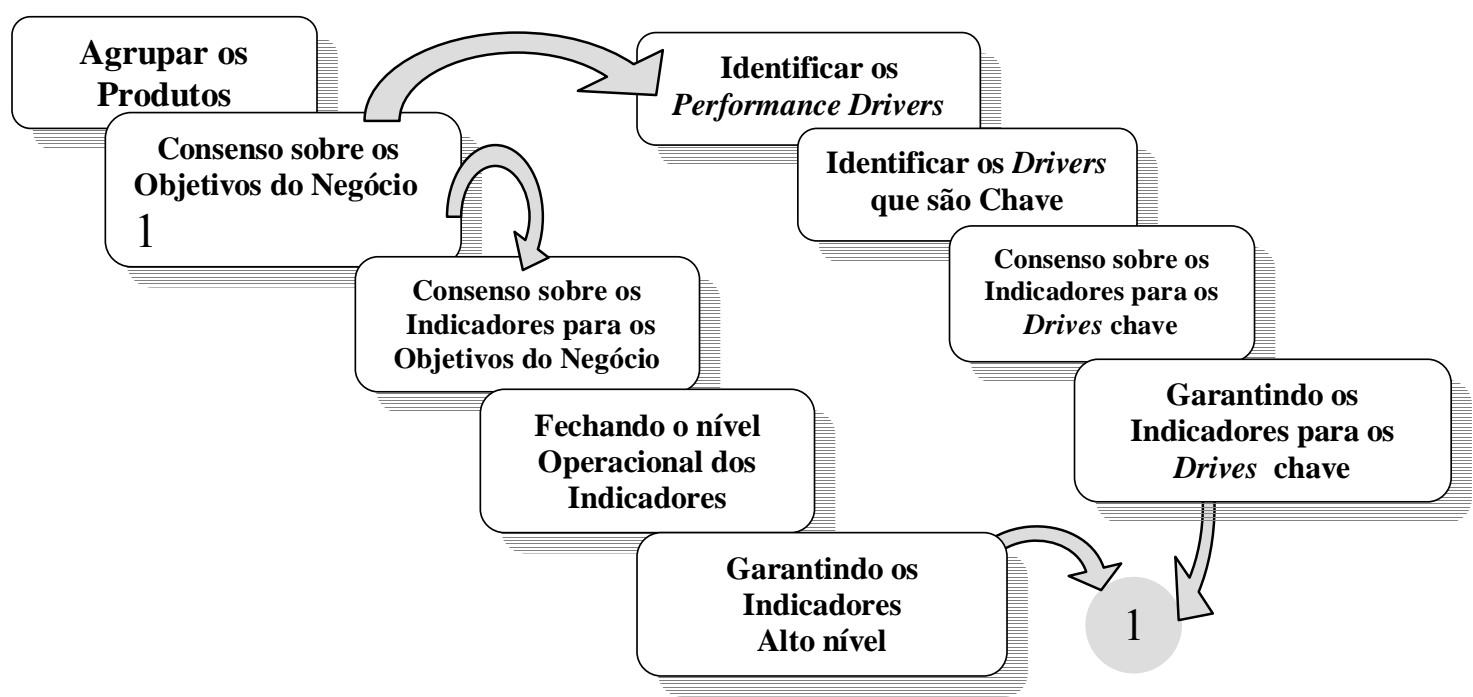

Figura 2.8. Mapa Detalhado da Proposta. 
Fonte: Neely et al. (2000)

Kiyan (2000) apresenta uma proposta para Desenvolvimento de Indicadores de Desempenho como Suporte Estratégico que incorpora duas importantes idéias que orbitam a área de MD:

- alinhamento dos esforços organizacionais, isto é, procura-se focar ações de melhorias em processos considerados críticos para alavancar a estratégia competitiva adotada, Carpinetti (2000), Figura 2.9.

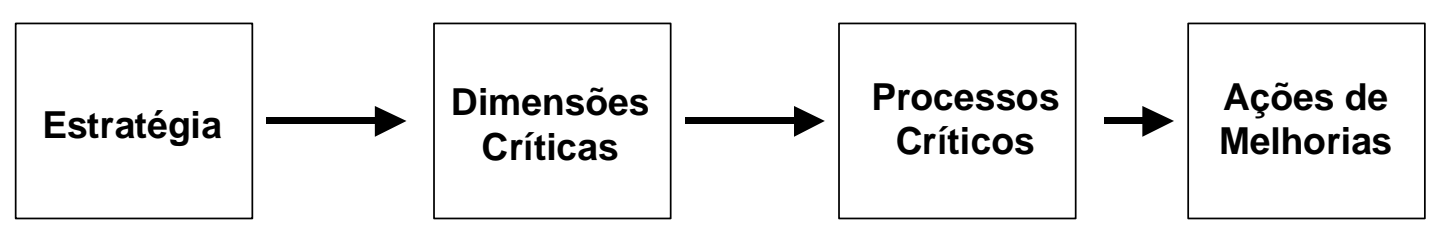

Figura 2.9. Modelo Conceitual de Carpinetti

Adaptado de Carpinetti (2000)

- trabalhar o conceito de MD não só em relação aos indicadores de uma forma isolada, mas também entender como eles relacionam entre si e, o quão aderente este conjunto de indicadores é em relação aos objetivos organizacionais (Neely et al. 1995).

A proposta foi estruturada de modo a ter um caráter abrangente, não se restringindo aos modelos de SMDs propostos na literatura, Figura 2.10. 


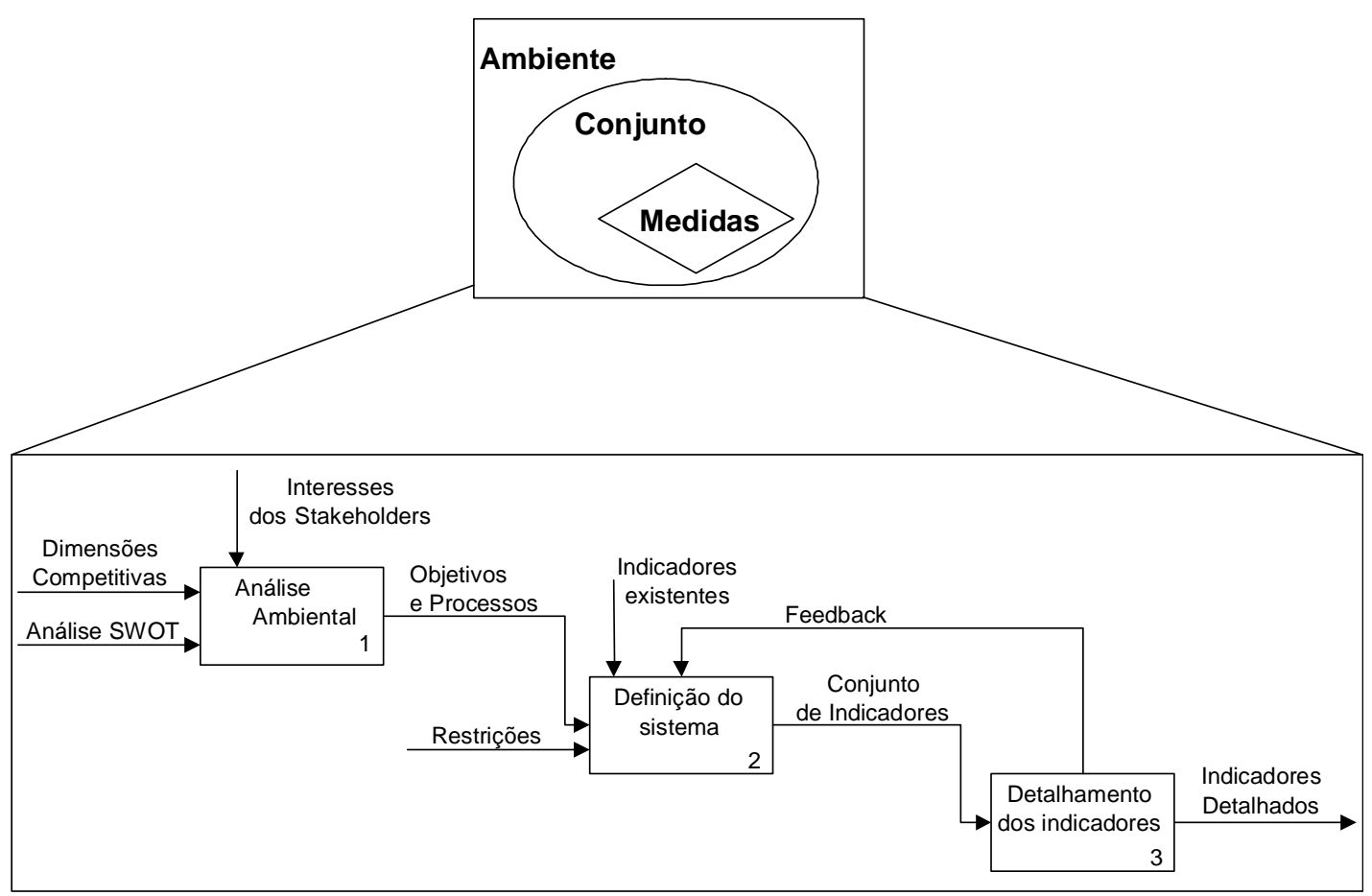

Figura 2.10. Estrutura Macro da Proposta

Fonte: Kiyan (2000)

Em cada nível de análise, ocorrem várias atividades que podem ser agrupadas em uma série de passos, conforme ilustrado na Figura 2.11.

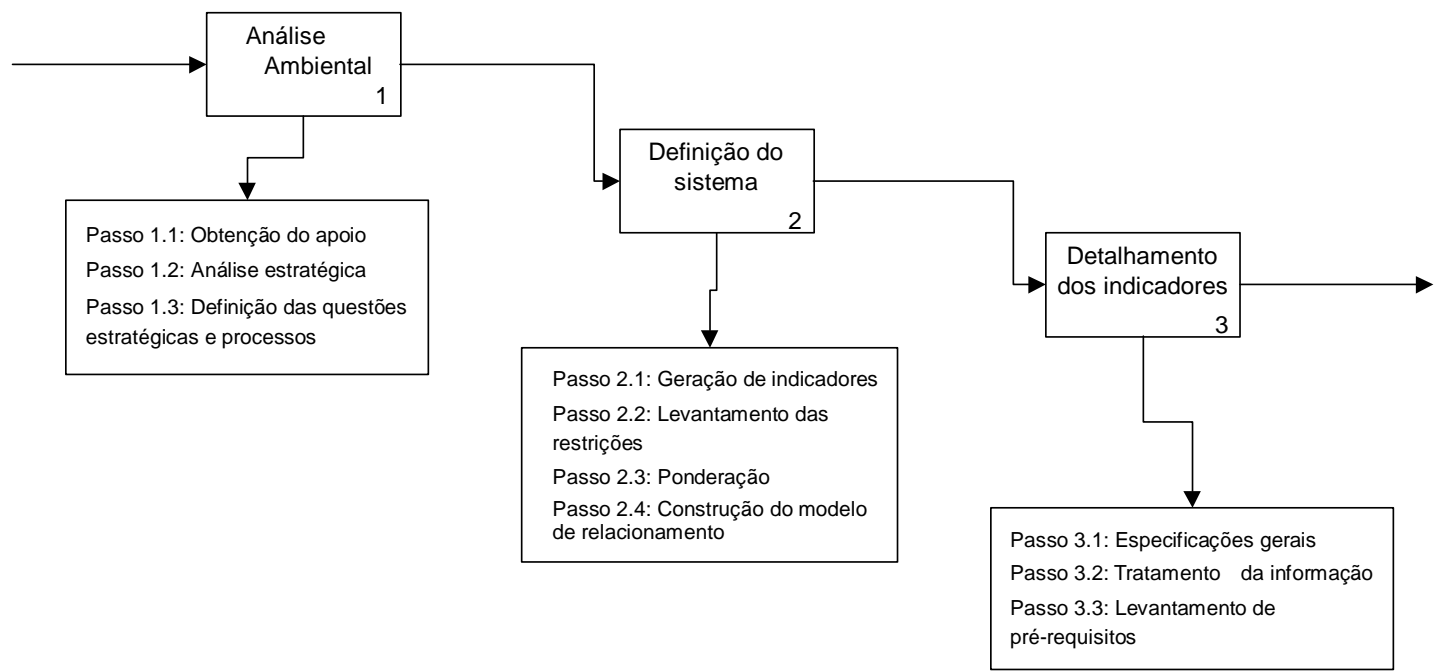

Figura 2.11. Estrutura Detalhada da Proposta

Fonte: Kiyan (2000) 
Rentes, Carpinetti e Van Aken (2002) apresentam um método de desenvolvimento de sistemas de medição de desempenho estruturado em um conjunto de sete passos, conforme ilustrado na Figura 2.12.

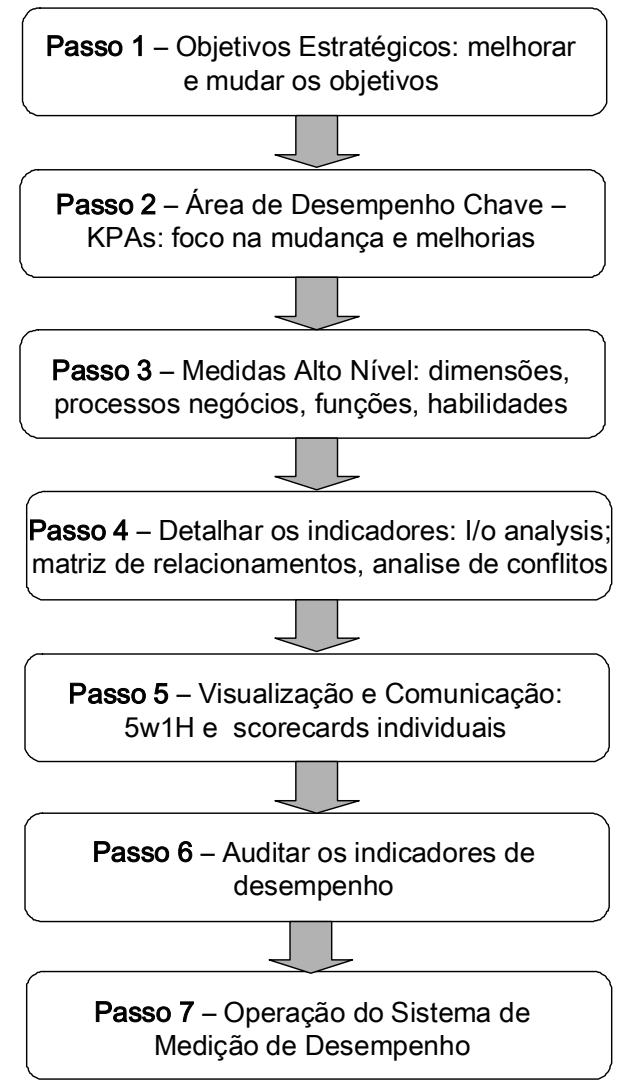

Figura 2.12. Passos para o desenvolvimento de um SMD.

Rentes, Carpinetti e Van Aken (2002)

\subsection{Considerações Sobre os SMDs}

Esta seção tem por objetivo elucidar que as práticas de medição de desempenho devem ser acompanhadas por uma série de cuidados e restrições que podem, de certa forma, prejudicar ou inviabilizar a sua implementação e apuração de resultados.

Para tal, iniciar um processo de medição de desempenho não pode se pensar em uma atividade de fácil execução. Brown (2000), afirma que a medição de desempenho é provida de regras difíceis que refletem inter-relações entre diferentes variáveis. O que pode ser perfeitamente normal hoje pode não ser amanhã. Além 
disto, existem importantes fatores que são de difícil avaliação objetiva e consistente, o que pode causar conflitos de interpretação a cerca dos resultados.

Este mesmo autor, levantou alguns erros comuns na medição de desempenho, que seque:

- Uso de indicadores que não se pode controlar ou influenciar: as ações da empresa para melhorar este tipo de indicador podem ser de difícil execução pela falta clara de ligação entre controle e resultados;

- Coletar informações que dizem o que a empresa já sabe: os indicadores devem ser selecionados para medir o que é desconhecido ou para testar hipóteses;

- Uso de relatórios para interesses específicos: os indicadores devem atender a um objetivo pré-determinado de atendimento a estratégia da empresa e não para mesurar ações especificas de alguns agentes;

- Confiar em todas as pesquisas sobre clientes: As pesquisas podem resultar em boas informações, porém podem ser de muito difícil interpretação e de resultados duvidosos;

- Indicadores para executivos: este nível hierárquico da empresa deve apenas receber informações agregadas para evitar a perda de tempo com extensos relatórios;

- Relatórios de difícil interpretação: um relatório confuso e de difícil análise pode por a perder todo o esforço de medição de desempenho. Os relatórios devem ser práticos e de rápida leitura;

- Indicadores que conduzem a desempenho deficitário: alguns indicadores podem ser enganadores por melhorar o desempenho de uma área ou processo em detrimento de outras.

Nesta mesma linha, Takashina \& Flores (1999), identificaram problemas decorridos do processo de gestão de indicadores e o que se deve evitar medir:

- somente o previsto em relação ao realizado (controle de prazos/cronograma de produção);

- apenas para monitoração (em vez de enfoque na melhoria);

- para descobrir erros, com objetivo de punir;

- características sem associação com as estratégias globais;

- apenas para cortar custos, em vez de melhorar a qualidade e o desempenho; 
- características não importantes;

- muitos indicadores, sem estabelecer a prioridade e hierarquia desses indicadores;

- sem considerar o comportamento da variabilidade dos resultados;

- sem considerar o progresso de forma sistemática e integrada;

- sem enfoque na satisfação das pessoas.

Outras considerações, com um caráter mais geral, também devem ser feitas para uma melhor compreensão das limitações da medição de desempenho. No caso do U.S. DOE (2000), foi observado que:

- pode existir a manipulação de resultados por funcionários que fazem seus indicadores parecerem estar em um bom nível, diminuindo a acurácia total;

- por vezes é avaliado somente o óbvio em vez do necessário;

- os resultados fracos não são necessariamente sinônimos de execução fraca;

- a medição de desempenho, por si só, não explica porque o desempenho está em um determinado patamar ou como melhorar;

- notações numéricas não corrigem processos defeituosos;

- indicadores de desempenho fornecem informações sobre o atendimento ou não de objetivos e metas, mas não define os objetivos que prioritariamente devem ser medidos;

- se o desempenho de alguns objetivos não está sendo alcançado, é obvio que alguma coisa está errada, mas as informações por si só, nem sempre fornecem a razão, apenas levanta a bandeira da investigação. A organização deve ser capaz de explicar os resultados e definir e apontar os fatores que contribuem para tal;

- pode ser difícil determinar quais indicadores são os mais importantes para atingir as metas e objetivos. Esta pode ser uma tarefa não trivial;

- os usuários é que devem solicitar informações além daquelas que estão utilizando para melhor entender a relação entre os relatórios e os agentes causadores dos resultados;

- existe um perigo no momento em que os objetivos da empresa se tornam uma notação numérica. Ao definir um objetivo e suas metas, não é garantido que ocorreram melhorias nos processos. Identificar os desafios e promover mudanças nos processos são elementos chaves para melhoria do desempenho e atingir resultados desejados. 


\subsection{Sistemas de Informação como Suporte a Medição de Desempenho}

Um dos elementos cruciais para a estratégia de manufatura no mundo é a habilidade de otimizar o uso da tecnologia da informação. Várias empresas tentam saltar a frente e antecipar as expectativas de seus clientes que são avaliadas e fundamentadas através da qualidade, tempo, serviços oferecidos, disponibilidade e eficiência.

Na medição de desempenho, McGee \& Prusak (1995), detectaram que a infra-estrutura de coleta, processamento e disponibilização da informação, são elementos importantes na implementação dos indicadores.

Ao longo dos anos, para Rao (2000) e Carajaville (2000), muito mudou desde os anos 60, quando as empresas começaram a usar os primeiros pacotes de softwares empresariais, que naquele momento eram construídos para a manipulação dos inventários.

Uma década depois, o foco se transportou para os sistemas denominados MRP (Material Requirement Planning), que ajudavam a planejar as necessidades de matérias primas e componentes nas empresas manufatureiras.

O conceito evoluiu até abranger, a partir dos anos 80 , a gestão das atividades de produção, distribuição, financeira, recursos humanos, compras e vendas. Foi dado então o nome de Planificação dos Recursos Empresariais, mais conhecido como ERP (Enterprise Resource Planning).

Além disto, para Filho (2001), a informação e, mais recentemente, o conhecimento tem sido o principal ativo com que a informática lida nas organizações. Todo sistema de informação pode ser visto, do ponto de vista técnico, como um conjunto de programas e de estruturas de dados.

Ainda segundo Filho (2001), os métodos de análise e projeto de sistemas historicamente focaram em dados e processos. Mas de uma ênfase inicial em algoritmos, programas e processos, típica da década de 60, as metodologias de desenvolvimento migraram para uma abordagem centrada nos dados.

Pode-se notar então que, paulatinamente as preocupações dos desenvolvedores e dos usuários foram passando dos dados estritamente operacionais 
para as informações agregadas envolvidas no processo de tomada de decisão. Os sistemas evoluíram para acompanhar a sofisticação da gerência de negócios.

Desta maneira, o mercado brasileiro e mundial de sistemas vem presenciando, nos últimos anos, uma demanda crescente no uso de pacotes de softwares destinados à gestão empresarial. Estes sistemas prontos, na forma de pacotes de software não são exatamente novidades, mas o fato é que, somente nos últimos anos, os grandes pacotes de software, que proclamam a capacidade de fornecer uma solução de sistemas única para a gestão de toda a organização, começaram a ser uma presença marcante em empresas no mundo todo.

Diversas são as razões apontadas por Bergamaschi \& Reinhard (2000) para o crescimento e busca de soluções na forma de pacotes de software, desde a incapacidade dos sistemas atuais em atender todas as necessidades da empresa, a falta de atualização de sistemas para acompanhar o "estado da arte" tecnológico, a não integração apropriada de dados e informações muitas vezes provenientes de uma grande variedade de sistemas.

Adicionando-se esses componentes à pequena quantidade de estudos acadêmicos sobre o assunto, obtém-se um cenário, que parece justificar a realização de estudos que possam auxiliar os diversos participantes deste mercado: fornecedores, consultores, empresas usuárias, e outros, em seus projetos.

Por outro lado, o fator custo de compra de licenças, implementação e treinamento associado à alta funcionalidade dos atuais sistemas de gestão, torna difícil o processo de seleção. Em alguns casos, a razão para que uma empresa considere a implementação de uma solução desta, vincula-se à necessidade de fazer ajustes em algumas funções corporativas centrais.

Para Carajaville (2000), os critérios de avaliação da escolha de um sistema de gestão, de acordo com a maioria dos experts, incluem os seguintes aspectos:

- Grau de integração entre os diferentes componentes do sistema;

- Nível de complexidade e adaptação requerida;

- Tempo de implementação;

- Tecnologia e segurança;

- Atualizações regulares;

- Custo Final. 


\subsubsection{Agilidade aos Sistemas de Medição de Desempenho}

Para Chung \& Snyder (2000), os sistemas de gestão tem se tornado uma tecnologia da informação popular na mudança do ambiente de negócios nos anos 90.

Para autores como Correa et al. (1997), Assem et al. (2000), Gupta (2000), Kappelhoff (1998), Rao (2000) e Chung \& Snyder (2000), os módulos que compõe os mais diversos sistemas de gestão geram integração de várias funções na organização, objetivando a melhor adaptação da indústria e práticas gerenciais para disponibilizar o produto certo, na hora adequada, no local correto com menor custo.

Além disto, os sistemas de gestão permitem que as empresas integrem informações de vários departamentos, de forma que seus procedimentos deixem de focar as áreas funcionais, passando a tratar dados por processo de negócio, ou seja, as aplicações dos sistemas tradicionais tratavam cada transação separadamente. Estes sistemas eram construídos em torno de grandes barreiras de funções especificas. Os sistemas de gestão param de tratar estas transações separadamente e as considera como parte de um processo interligado o qual é a base de negócio da empresa.

Segundo Gupta (2000), para muitos usuários, os sistemas de gestão podem ser vistos como um grande banco de dados com as mais variadas informações da empresa, sendo portanto, uma ferramenta de auxílio na formulação de sistemas de medição de desempenho. Neste contexto, Rao (2000) comenta que os objetivos destes sistemas são:

- fornecer suporte para todas variações das melhores práticas gerenciais;

- disponibilizar a implementação destas práticas para aumentar a produtividade;

- capacitar os consumidores a modificar a implementação dos processos de negócios de forma a respeitar suas necessidades.

Ainda segundo Rao (2000), a capacidade da gestão da cadeia de suprimentos aumenta nestes sistemas na medida em que a eficiência e produtividade dos usuários aumentam, através da ligação de aplicações para a cadeia de suprimentos com outros sistemas de negócios que podem reduzir o tempo de ciclo e os inventários.

Os usuários destes sistemas também possuem uma melhor conexão com os fornecedores, distribuidores e clientes. Desta maneira, pode-se observar que um dos grandes benefícios é coletar e disponibilizar informações com todos os elos da cadeia. 


\subsubsection{Data Warehouse}

O Data Warehouse (DW) pode ser visto como uma ferramenta que permite a recuperação de dados, através de ferramentas de produtividade, que agilizam os processo de gestão do negócio. Com a capacidade de armazenar dados dos sistemas de apoio à decisão, seus relatórios funcionam como "fotografias" de um momento específico da evolução da empresa.

Por possuir estas características, o DW pode ser utilizado como suporte ao processo de criação de indicadores de desempenho. Com ele é possível prover com confiabilidade, qualidade e facilidade de acesso às informações necessárias em várias das atividades envolvidas nos processos da empresa. Entretanto, de acordo com Inmon \& Hackathorn (1997), quanto mais perto estiver o processamento de informações do processo analisado, maiores são as chances de se obter bons resultados. Visto como um conjunto de dados, o DW possui as seguintes características:

- Orientado a assuntos: o DW está focado na modelagem dos dados e no projeto do banco de dados (Inmon \& Hackathorn, 1997);

- Integrado: segundo Inmon (1997), esta é a característica mais marcante do DW. A integração dos dados ocorre quando os dados são extraídos do ambiente operacional e inseridos no DW. Este processo é responsável por resolver as diferenças e inconsistências existentes nos dados do ambiente operacional;

- Não volátil: os dados são carregados no DW, normalmente em grandes quantidades, e são acessados, mas a atualização de dados não ocorre no ambiente do DW (a não ser em casos especiais, como correções de falhas no processo de carga dos dados) (Inmon, 1997);

- Variável em relação ao tempo: isto ocorre porque o horizonte de tempo de um DW (5 a 10 anos de dados) é bem maior que para um ambiente operacional (30 a 90 dias) (Inmon, 1997).

Uma questão central para o processo de Data Warehousing é o da qualidade de dados. A necessidade de qualidade consistente de dados se torna mais importante à medida que o tamanho e a complexidade das fontes de informação aumenta. 
Portanto, é preciso uma atenção especial à qualidade dos dados, por meio de métodos, técnicas e ferramentas específicas.

O conceito de qualidade de dados indica o quanto as fontes de dados atendem as demandas de informação das áreas de negócio. Isso envolve: (a) conhecer a qualidade de dados atual, (b) determinar a qualidade de dados desejada e (c) ajustar a qualidade atual em função da desejada.

Nesse processo de consistência dos dados em um DW, alguns aspectos são especialmente importantes: a integridade, a acurácia e a "completude". A integridade vai tratar da maneira em que os dados são mantidos na fonte. A acurácia indica o quanto que os dados da fonte representam a realidade. A "completude" indica a quantidade de dados necessários para atender a demanda do negócio que está presente na fonte.

Portanto, o DW é capaz de prover a organização com informações mais precisas para a tomada de decisão, em um ambiente que vivencia um aumento do volume de dados controlados e armazenados. 


\section{MEDIÇÃO DE DESEMPENHO NA CADEIA DE SUPRIMENTOS}

\subsection{Conceituação e Práticas da Gestão da Cadeia de Suprimentos}

A gestão da cadeia de suprimentos (Supply Chain Management-SCM), tem sua origem na função logística, como demonstram Wood \& Zuffo (1999) e Filho \& Hamacher (2000), que a definem como uma metodologia desenvolvida para alinhar todas as atividades de produção de forma sincronizada, visando reduzir custos, minimizar ciclos e maximizar o valor percebido pelo usuário final em busca de resultados superiores.

Em uma abordagem semelhante, Beamon (1999), define a SCM como um conjunto de processos integrados, através dos quais matérias-primas são manufaturadas em produtos finais e entregues aos consumidores.

Já, Cooper et al. (1997), Lambert et al. (1998) e Yoshizaki (2000), compartilham de uma mesma definição sugerida pelo Council of Logistics Management, onde a SCM é a integração de processos de negócio de várias empresas, que compreende o fornecedor original até o usuário final, proporcionando agregação de valor para os clientes.

Desta maneira, uma típica cadeia de suprimentos pode ser representada por fornecedores, empresas, distribuidores e consumidores finais. Sua complexidade está diretamente relacionada com o número de empresas envolvidas.

Para Pires (1998), também se pode atribuir a SCM uma visão expandida da administração de materiais tradicional, que abrange a gestão de toda a cadeia produtiva de forma estratégica e integrada, onde a competição passa a ocorrer entre unidades virtuais de negócios, Figura 3.1. 


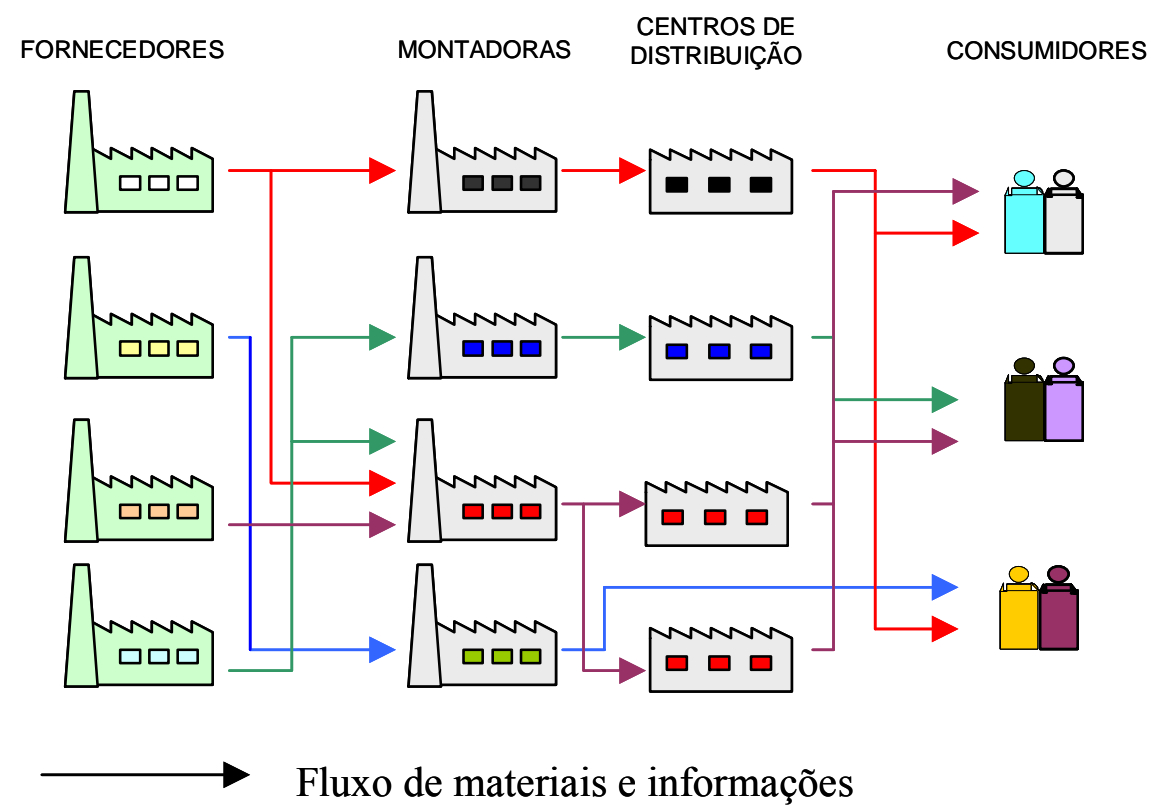

Figura 3.1. Concorrência entre unidades virtuais de negócios.

Fonte: Adaptado de Pires (1998).

Embora tenha origem na função logística, a SCM atua sobre outras funções empresariais, tais como: marketing, vendas, finanças, planejamento, P\&D (pesquisa e desenvolvimento), de todas as empresas participantes da cadeia, procurando alcançar um desempenho global superior, tanto em termos econômicos como em termos de satisfação dos clientes.

A implementação da SCM geralmente inicia a partir de uma empresa com grande poder econômico, pois esta condição confere a ela uma liderança natural para iniciar o uso da SCM. Esta empresa-líder, também chamada de elo forte da cadeia, no entanto, deve fazer investimentos, inspirar e desenvolver a confiança às outras empresas selecionadas.

À medida que a integração evolui para toda a cadeia de suprimentos, o poder da empresa-líder tende a diminuir, em contra-partida, a complexidade da SCM cresce cada vez mais. Para entender esta evolução da complexidade é preciso analisar o papel da Cadeia de Suprimentos.

Vollmann \& Cordon (1996) afirmam que um dos objetivos básicos da SCM é a maximização das potenciais sinergias entre os elos da cadeia produtiva, de forma a atender o consumidor final com maior eficiência, tanto pela adição de valor e redução dos custos dos produtos finais. 
Por outro lado, a implementação de uma série de práticas eficazes da SCM tem visado sobretudo a simplificação e a obtenção de cadeias produtivas mais eficientes. Dentre essas práticas, Pires (1998) destaca:

- reestruturação e consolidação do número de fornecedores e clientes, implicando sua redução e aprofundamento das relações com o conjunto de empresas com as quais realmente se deseja desenvolver relacionamentos colaborativos e com resultado sinérgico;

- divisão de informações e integração da infra-estrutura com clientes e fornecedores, propiciando entregas just-in-time e redução dos níveis de estoques;

- resolução conjunta de problemas e envolvimento dos fornecedores desde os estágios iniciais do desenvolvimento de novos produtos;

- concepção de produtos que facilitem o desempenho da logística da cadeia produtiva e escolha de um operador eficiente para administrá-la;

- compatibilização da estratégia competitiva e das medidas de desempenho da empresa à realidade e aos objetivos da cadeia produtiva.

A SCM ainda oferece grandes perspectivas de ganhos para quem a utiliza, na medida que exista um aumento de escala nos volumes transacionados entre os participantes e transferência de tecnologias para as empresas menos desenvolvidas, com isso, possibilitando menores custos operacionais, menores ciclos de produção e melhorias na qualidade dos produtos fabricados (Savoi, 1998). Desta maneira, as variações e pressões do mercado e os benefícios esperados são os melhores argumentos para a utilização desta metodologia.

\subsection{Medição de Desempenho na Cadeia de Suprimentos}

\subsubsection{Importância}

Ao medir o desempenho de uma cadeia de suprimentos, onde o controle não é baseado somente em uma empresa, mas em interfaces ao longo de uma cadeia de processos, o SMD reflete uma realidade por vezes complexa devido às dificuldades em se integrar os processos das várias empresas que fazem parte da cadeia. 
Essa nova situação é descrita por Hoek (1998), que concluiu em suas pesquisas que a complexidade de uma cadeia de suprimentos vem do fato de:

- serem compostas de múltiplas camadas de empresas;

- existir um envolvimento parcial de algumas empresas na cadeia;

- como a integração não é baseada em grandes investimentos e em integrações verticais, mas em interfaces, a rede de trabalho se torna momentânea, portanto, barreiras à entrada e saída são baixas;

- o formato de uma cadeia de suprimentos muda ao longo do tempo;

- nem todas as interfaces possuem o mesmo nível de integração e coordenação. A determinação do nível de gerenciamento necessário depende de uma grande combinação de fatores.

Desta maneira, todas estas novas características das organizações têm seu efeito na medição de desempenho das atividades da cadeia.

Segundo Beamon \& Ware (1998), os indicadores de desempenho possuem o papel de abrangência (incluir a medida de todos os aspectos pertinentes), universalidade (permitir a comparação sob várias condições operacionais), mensurabilidade (garantir que os dados necessários são mensuráveis) e consistência (garantir medidas consistentes com os objetivos da organização).

Para Lapide (2000), algumas razões da importância de se medir as cadeias de suprimentos são:

- Métricas são importantes para controlar diretamente o comportamento e indiretamente o desempenho;

- Algumas métricas irão direcionar a empresa a longo prazo atingindo os objetivos de melhorias da SCM;

- Métricas erradas podem guiar a SCM para a degradação;

- Não é aconselhável dirigir uma cadeia de suprimentos baseada apenas em medias chamadas "após o fato", como perda de clientes importantes ou desempenho financeiro pobre.

No caso específico de um sistema de avaliação de desempenho para a SCM, faz-se necessário que haja compatibilidade das medidas utilizadas, ao longo de toda a cadeia, ou seja, as medidas individuais, para uma determinada unidade de negócios da cadeia, devem ser interpretadas e comparadas com todo o restante. Pode-se então 
representar a estrutura de um sistema de avaliação de desempenho para a cadeia de suprimentos conforme a Figura 3.2.

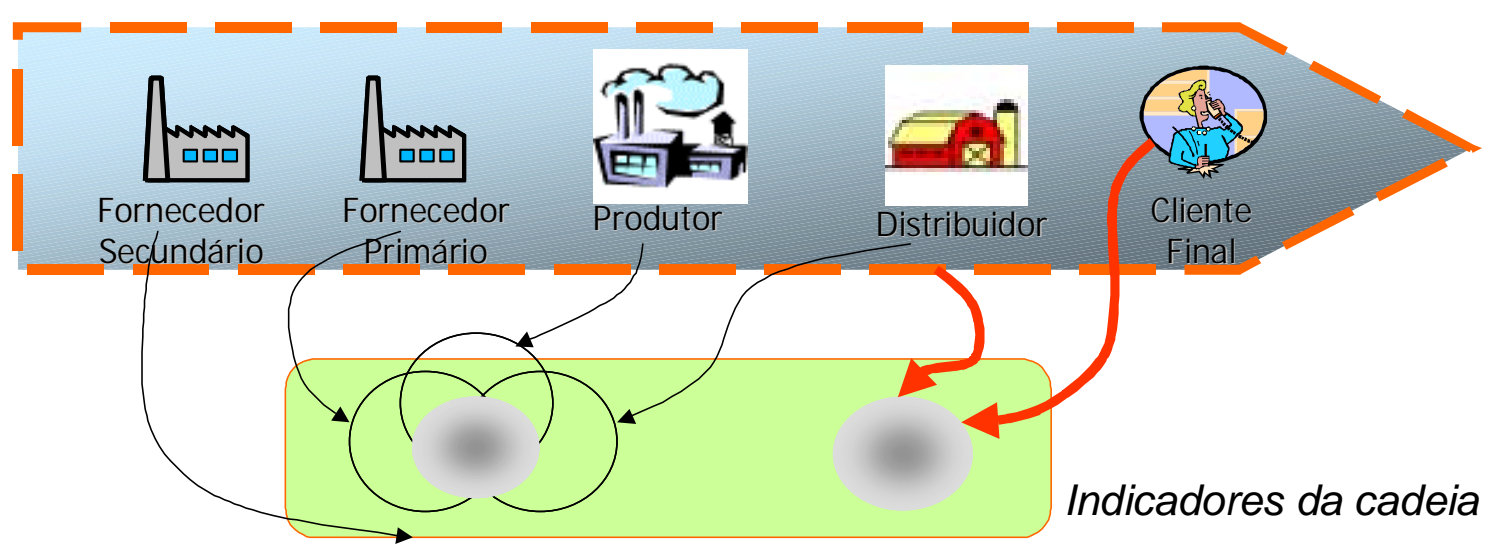

Figura 3.2. Estrutura de um SMD para cadeias de suprimentos.

\subsubsection{Os Indicadores na Cadeia de Suprimentos}

Pode-se entender que SMDs tradicionais, como os descritos nos itens 2.8.1 e 2.8.2, podem ser, de certa forma, adaptados para a cadeia de suprimentos. Porém, em algumas situações, esses modelos podem não servir como suporte para definição de métricas para a cadeia.

O motivo por traz desta constatação reside no princípio fundamental destes modelos, que vêem na estratégia de cada empresa a pedra fundamental para o desdobramento dos indicadores (Keebler et al., 1999).

Porém, no trabalho de Lapide (2000), a estratégia para cadeia de suprimentos difere de empresa para empresa, por esta ser baseada em suas competências e do estágio de desenvolvimento, que irão ditar os tipos e níveis de métricas. Dentro deste contexto, os indicadores poderão ser direcionados por estágio, exigindo o alinhamento dos SMDs a esta nova situação, como descrito abaixo:

- Excelência nas funções: o estágio no qual a empresa necessita desenvolver excelência dentro de cada unidade operacional como manufatura, atendimento ao cliente, ou unidades logísticas. As métricas neste estágio irão focar em funções departamentais; 
- Ampla integração: é uma situação na qual a empresa deve desenvolver excelência em processos em detrimento a visão departamental. Neste caso, as métricas serão baseadas nos processos;

- Integração estendida: estágio no qual a empresa desenvolve excelência em processos entre empresas.

Ainda segundo Lapide (2000), historicamente, muitas empresas têm focado seus indicadores de desempenho para atingir excelência funcional. Nestes sistemas, cada indicador vai tratar da habilidade de se atingir objetivos departamentais.

Nesta situação, as métricas podem guiar os funcionários a se preocuparem em melhorar apenas suas próprias áreas, situação que pode causar problemas na consecução dos objetivos da empresa, Figura 3.3.

\section{Indicador de Processo}
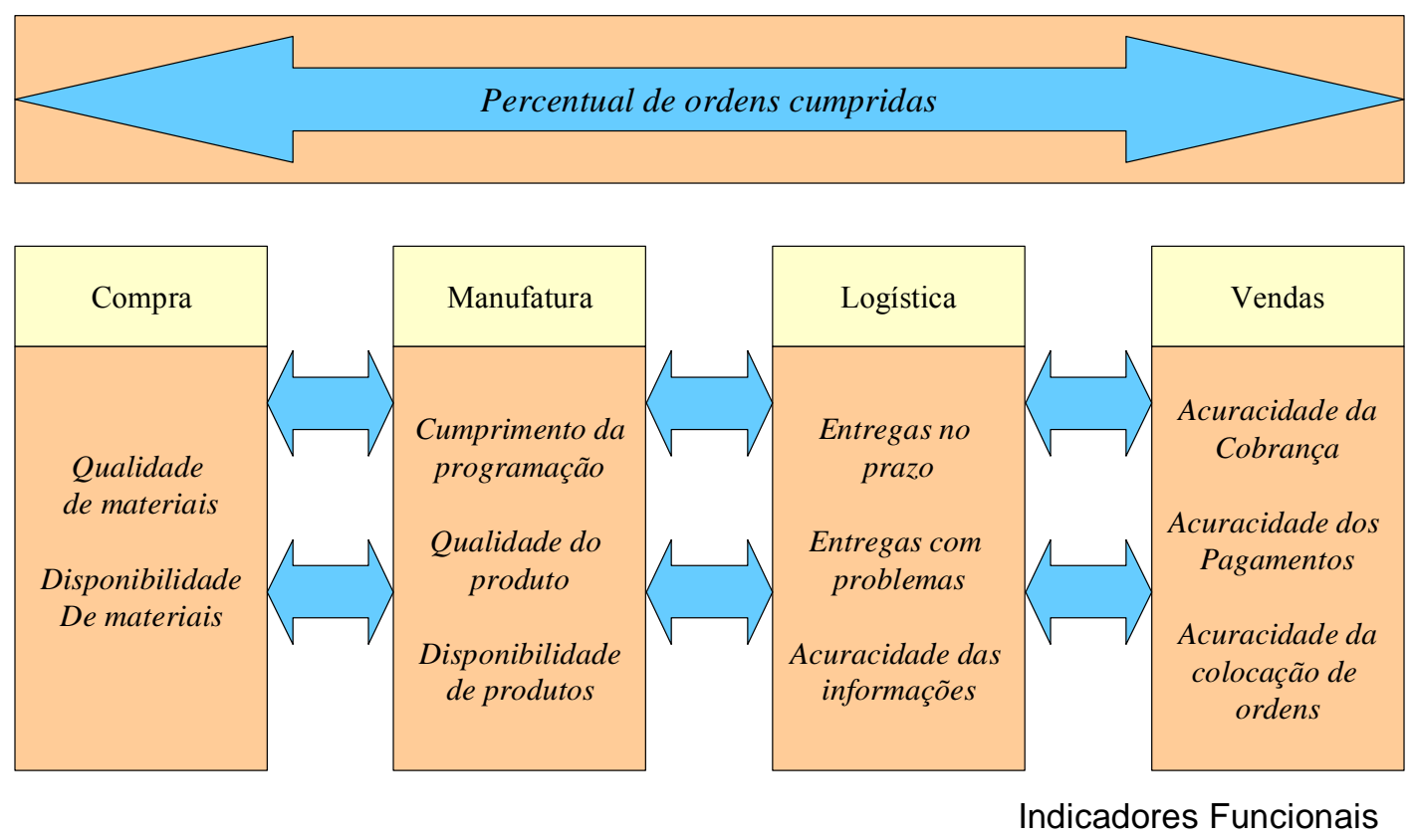

Figura 3.3. Indicadores funcionais versus indicadores de processos.

Fonte: Lapide (2000).

A Figura 3.3 apresenta em parte um conjunto de indicadores funcionais típicos. Estes tipos de métricas usadas isoladamente, tendem a criar conflitos entre os departamentos como segue: 
- Compras: Os indicadores são focados em custo de materiais e desempenho da entrega dos fornecedores. Esta situação pode levar os compradores a fazerem grandes compras a fim de conseguir descontos em altos volumes, além de aumentarem a carteira de possíveis fornecedores para garantir o baixo preço. Este comportamento resulta em excesso de compras e uma provável baixa qualidade de materiais;

- Manufatura: Os indicadores medem em geral a produtividade. Neste contexto, a tentativa de se produzir grandes lotes para evitar paradas que comprometam os índices de velocidade, resultando em uma demora em atender clientes, principalmente aqueles que adquiriram pequenos lotes;

- Logística: As métricas são relacionadas com custos de armazenagem e níveis de inventários. A tendência natural é que estes funcionários queiram receber cargas com maiores volumes, para reduzir o custo de transporte e armazenagem, resultando em um aumento de estoques;

- Vendas e atendimento aos clientes: Os indicadores vão medir a habilidade em manter altos níveis de atendimento aos clientes o que pode induzir um aumento de inventário em vários locais, para se reduzir o tempo de atendimento.

É aparente que pelos comportamentos descritos acima, os funcionários podem conduzir a empresa para caminhos contraditórios, reforçando barreiras funcionais e reduzindo o potencial de muitas cadeias de suprimentos.

Por outro lado, o natural amadurecimento das empresas que convivem em ambientes de cadeias de suprimentos, podem e devem levá-las, a se organizarem por processos de negócios. Isto pode ser feito através da criação de responsabilidade de todos na execução, por exemplo de uma ordem perfeita ${ }^{6}$ ou na responsabilidade de todos no tempo de ciclo.

Um facilitador é a introdução de indicadores de desempenho para processos. Apesar desta situação não significar o descarte total dos indicadores funcionais, o foco da medição se transfere para os processos, transformando os funcionais apenas em suporte para algumas atividades específicas, como pode ser visto na Tabela 3.1.

\footnotetext{
${ }^{6}$ Ordem perfeita é um indicador de processo, que desdobrado, vai incluir métricas que se relacionam com várias funções e áreas da empresa.
} 
Tabela 3.1. Lista de possíveis métricas para a cadeia

\begin{tabular}{|c|c|c|}
\hline \multicolumn{3}{|c|}{ Cumprimento de uma ordem } \\
\hline CLIENTES & PROCESSOS & EMPRESA ESTENDIDA \\
\hline $\begin{array}{l}\text { - } \quad \text { taxa de cumprimento de } \\
\text { ordem } \\
\text { - } \quad \text { taxa de cumprimento do } \\
\text { item na linha de produção } \\
\text { - } \quad \text { retorno de clientes } \\
\text { - } \quad \text { acurácia de uma nova } \\
\text { ordem }\end{array}$ & $\begin{array}{l}\text { - } \quad \text { acurácia da previsão } \\
\text { - } \quad \text { percentual de ordens } \\
\text { perfeitas } \\
\text { - } \quad \text { tempo de execução do } \\
\text { planejamento } \\
\text { - } \quad \text { mudança da programação }\end{array}$ & $\begin{array}{l}\text { - } \quad \text { percentual de fornecedores } \\
\text { solicitando previsões } \\
\text { - } \quad \text { inventário total da cadeia } \\
\text { de suprimentos } \\
\text { - } \quad \text { transações via EDI } \\
\text { - } \quad \text { percentual de clientes que } \\
\text { fornecem previsões }\end{array}$ \\
\hline COMPRAS & MANUFATURA & LOGÍSTICA \\
\hline $\begin{array}{l}\text { - desempenho da entrega } \\
\text { - } \quad \text { qualidade de materiais e } \\
\text { componentes } \\
\text { - custo por unidade } \\
\text { - custo de aquisição de } \\
\text { - materiais } \\
\text { - gasto com atividades de } \\
\text { compra }\end{array}$ & $\begin{array}{l}\text { - } \quad \text { qualidade do produto } \\
\text { - } \quad \text { cumprimento da } \\
\text { - } \quad \text { rogramação } \\
\text { - } \quad \text { número de paradas } \\
\text { - } \quad \text { custos de segurança } \\
\text { - } \quad \text { horas extras } \\
\text { - } \quad \text { tempo de ciclo } \\
\text { - } \quad \text { produtividade }\end{array}$ & $\begin{array}{l}\text { - } \quad \text { entregas no prazo } \\
\text { - } \quad \text { entregas com problema } \\
\text { - } \quad \text { custo da logística } \\
\text { - } \quad \text { acurácia da } \\
\text { documentação } \\
\text { - } \quad \text { custo de estocagem } \\
\text { - } \quad \text { utilização de armazéns }\end{array}$ \\
\hline FINANCEIRO & MARKETING & OUTROS \\
\hline 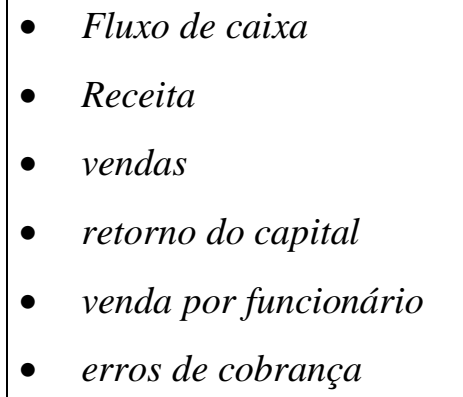 & $\begin{array}{l}\text { - } \quad \text { participação no mercado } \\
\text { - } \quad \text { percentual de vendas de } \\
\text { - } \quad \text { time-to-market } \\
\text { - } \quad \text { clientes que retornam } \\
\text { - } \quad \text { novos clientes }\end{array}$ & $\begin{array}{l}\text { - } \quad \text { Patentes adquiridas ou } \\
\text { registradas } \\
\text { - } \quad \text { rotatividade de } \\
\text { funcionários } \\
\text { - } \quad \text { taxa de treinamento de } \\
\text { funcionários }\end{array}$ \\
\hline
\end{tabular}

Fonte: Lapide (2000).

Uma outra etapa para melhorar a aplicação dos SMDs para as cadeias de suprimentos, ainda segundo o trabalho de Lapide, é a utilização da integração estendida. 
A SCM tipicamente inclui a agregação de valor que é dividida por vários parceiros. A integração estendida pode gerar benefícios por tornar mais acurada e sincronizada a integração dos processos.

Para então ter a certeza da efetividade dos processos entre empresas, é necessária a criação de indicadores de desempenho que monitorem a execução do processo. O que pode ser observado também é que a não utilização de indicadores de processos, pode mascarar uma deficiência na cadeia de suprimentos, o que resulta na falta ações endereçadas a estas falhas.

Da mesma forma, Lapide (2000) afirma que existem empresas que implementaram programas de SCM que extrapolam o seu controle. Estes programas e os indicadores relacionados estão listados na Tabela 3.2.

Desta maneira, Keebler et al. (1999) listaram alguns benefícios da medição de desempenho na cadeia de suprimentos:

- Informações objetivas apóiam iniciativas de melhorias;

- Indicadores efetivos são críticos para o sucesso: as empresas em uma cadeia de suprimentos devem compartilhar objetivos similares a fim de se obter confiança mutua e controle. Neste sentido, deve-se compartilhar indicadores da cadeia que apontem os responsáveis e o resultado de suas atividades;

- Permite o esclarecimento da real situação dos processos;

- Ilustra o que deve ser feito ou não agora;

- Ajuda as empresas a ficarem competitivas;

- Ajuda a melhorar a cultura organizacional;

- Ajuda a confirmar os valores dos clientes;

- Indicadores são a única forma de se controlar o processo logístico.

Portanto, Chow et al. (1994) afirmam que quando uma empresa vai medir o desempenho de uma cadeia de suprimentos, a incorporação de novos indicadores de desempenho vai refletir o resultado dos objetivos traçados para a cadeia de suprimentos. Dentre estes objetivos, pode-se encontrar:

- Crescimento das vendas;

- Satisfação dos clientes;

- Disponibilidade de produtos;

- Lucratividade; 
- Responsabilidade Social;

- Entregas no prazo;

- Flexibilidade;

- Atendimento pós-venda.

Tabela 3.2. Programas de controle externo

\begin{tabular}{|c|c|}
\hline Programa & Indicadores \\
\hline Vendor Management Inventory (VMI) & $\begin{array}{l}\text { - } \quad \text { nível de vendas } \\
\text { - } \quad \text { disponibilidade em estoque } \\
\text { - } \quad \text { giro do inventário }\end{array}$ \\
\hline Continuous Replenishment Programs (CRP) & $\begin{array}{l}\text { - } \quad \text { nível de vendas } \\
\text { - } \quad \text { disponibilidade em estoque } \\
\text { - giro do inventário }\end{array}$ \\
\hline Iniciativas de resposta rápida & $\begin{array}{l}\text { - } \quad \text { nível de vendas } \\
\text { - } \quad \text { gisponibilidade em estoque } \\
\text { - giro do inventário }\end{array}$ \\
\hline Compartilhamento de previsão & $\begin{array}{l}\text { - } \quad \text { acurácia da previsão } \\
\text { - } \quad \text { taxa de cumprimento de ordens } \\
\text { - giro do inventário }\end{array}$ \\
\hline Compartilhamento de programação de produção & $\begin{array}{l}\text { - } \quad \text { aderência à programação } \\
\text { - } \quad \text { tempo de ciclo }\end{array}$ \\
\hline Gerenciamento de categorias & $\begin{array}{l}\text { - } \quad \text { categorias de clientes } \\
\text { - disponibilidade em estoque }\end{array}$ \\
\hline
\end{tabular}

Fonte: Lapide (2000).

\subsection{Modelos de Medição de Desempenho em Cadeias de Suprimentos}

\subsubsection{Processo Integrado da Cadeia de Suprimentos}

Para Bowersox \& Closs (1996), um esforço tem sido aplicado para melhorar a qualidade da informação que as empresas têm a sua disposição para medir, comparar e guiar o desempenho de uma cadeia. No lugar de relatórios rígidos, hoje 
administradores requerem uma maior flexibilidade de informações para facilitar a visualização e prevenção dos problemas e prover repostas rápidas para as oportunidades que surgem.

Para se desenvolver e implementar um SMD em cadeias de suprimentos, este modelo trata de três objetivos: controlar, monitorar e direcionar as operações da cadeia de suprimentos. Monitorar, neste caso, significa disponibilizar o histórico para clientes e administradores. Controlar traduz o desempenho realizado no percurso da cadeia e é utilizado para refinar o processo de controle logístico. Direcionar está relacionado com a motivação das pessoas, Bowersox \& Closs (1996).

Desta maneira, para os autores, um ponto importante está nas possibilidades de criação de indicadores que podem variar desde métricas por atividades até por processos. As métricas por atividades vão focar em desempenhos individuais requeridos para um processo de negociação, execução, transporte e entrega de uma ordem. Já as métricas de processo devem considerar a satisfação do cliente observando toda a cadeia de suprimentos. Deve ser examinado o tempo de ciclo total ou qualidade total dos serviços comparando com o requerido para satisfazer os clientes.

Dentro deste contexto, este modelo vai tratar internamente de medidas que devem comparar atividades e processos com operações previamente executadas com os objetivos. As medidas internas são utilizadas para os administradores entenderem a fonte da informação e são consideradas de mais fácil acesso. No trabalho dos autores, é sugerido que medidas internas tenham as categorias:

- Custo: vai demonstrar o quanto à expectativa dos custos é a essência de um processo de orçamentação;

- Produtividade: vai mostrar o resultado da relação entre as entradas e as saídas do processo;

- Administração de Ativos: é a visão da utilização do capital investido em equipamentos e outros assim como o capital aplicado em inventário para atingir o objetivo da cadeia;

- Qualidade: são medidas mais orientadas as avaliações do processo, e são designadas para determinar a efetividade de uma série de atividades em detrimento das atividades individuais. 
No ambiente externo, este modelo tenta monitorar, entender e sustentar o foco no cliente e ganhar uma percepção inovativa em relação a outras empresas, já que é considerado importante medir a percepção dos clientes. Tais métricas podem ser obtidas através de pesquisas de mercado ou de uma extensa monitoração das ordens. Outra ferramenta considerada importante para validar estas medidas é a prática de benchmarking.

Para então desenvolver um conjunto integrado de medidas para a cadeia, é sugerido quatro tipos de métricas:

- Custo: é incluso o total de gastos com a cadeia de suprimentos passando pelo custo de cumprimento de uma ordem, aquisição de materiais, inventário, produção e overhead;

- Tempo: métricas de tempo refletem a habilidade da cadeia em responder a demanda. Ex: tempo de ciclo, tempo de resposta da cadeia e percentual atingido do planejamento da produção;

- Ativos: medidas sobre ativos basicamente levam em consideração o nível de vendas que pode ser suportado por um nível específico de ativos. Ex: obsolescência do inventário e capacidade de utilização dos ativos;

- Qualidade/Satisfação de Clientes: mede a capacidade da empresa em atingir a satisfação dos clientes. É mensurado o cumprimento da "ordem perfeita" que significa produto ou serviço entregue dentro do prazo, com documentação correta e em prefeitas condições. Outras medidas são referentes à satisfação do cliente e qualidade do produto.

\subsubsection{Modelo de Benita Beamon}

Em função dos objetivos da SCM (redução de custo e aumento do valor do produto percebido pelo consumidor final), se faz necessário uma revisão de algumas prioridades competitivas bem como a adição de outras dimensões relevantes.

Assim, Beamon (1999), sugere que uma boa avaliação do desempenho da cadeia de suprimentos, passa por uma adaptação de modelos de medição de desempenho existentes, por focarem apenas em unidades produtivas isoladas, a algumas novas métricas, que seriam responsáveis por uma melhor leitura da cadeia. 
Em seu trabalho, é sugerido que um modelo de medição de desempenho para a cadeia de suprimentos, deve estar baseado nas dimensões de desempenho tratadas por Neely et al. (1995) (tempo, qualidade e flexibilidade), e em três tipos de medidas: recursos (níveis de eficiência), saídas (níveis de serviço ao consumidor) e flexibilidade (habilidade de responder a mudanças no ambiente). Cada um destes tipos de indicador de desempenho é discutido logo abaixo:

1 - Recursos: Na busca de altos níveis de eficiência, as medidas relacionadas aos recursos são aquelas que geralmente possuem o objetivo de serem minimizadas ao longo do processo. Inclui níveis de inventário, necessidade de pessoal, utilização de equipamentos e custos. Abaixo são listados alguns exemplos citados pela autora:

- Custo total: total dos custos dos recursos;

- Custos de distribuição: total dos custos de distribuição com transporte e manuseio;

- Custos de manufatura: total dos custos de manufatura, com processamento, manutenção e re-trabalho;

- Custos de inventário: investimento em estoques, obsolescência de inventário, estoques obsoletos, trabalho em processo, estoque em processo, produtos finais, estoque de produtos acabados;

- Retorno sobre investimentos (ROI): indicador da lucratividade da organização.

2 - Saídas: Com o objetivo de se conhecer os níveis de serviços ao consumidor, muitos desses indicadores podem facilmente ser representados de maneira quantitativa, tais como: número de itens produzidos, tempo necessário para a produção de um determinado item e número de entregas no prazo. Por outro lado, alguns indicadores, como satisfação dos clientes e qualidade do produto devem possuir uma análise qualitativa, e de difícil compreensão em alguns casos para algumas pessoas, por não possuírem uma conotação numérica. Incluem-se indicadores de resposta aos consumidores, qualidade e volume da produção. Indicadores de saída podem ser de:

- Vendas: total de vendas;

- Lucro: total de vendas menos as despesas; 
- Fill rate: proporção de pedidos atendidos imediatamente: fill rate alvo; taxa média de fill rate; fill rate agregado dividido pelo número de itens;

- Entregas no prazo: atraso de produto, data da entrega menos data devida (due date), atraso médio dos pedidos, atraso agregado dividido pelo número de pedidos, antecipação média dos pedidos, antecipação agregada dividida pelo número de pedidos, porcentagem de entregas no prazo, porcentagem das entregas realizadas na data prometida ou antecipadamente;

- Devolução de pedidos/falta em estoque: número de pedidos devolvidos devido à falta em estoque, número de faltas no estoque, número de requisições de itens em falta no estoque, nível médio de devolução de pedidos;

- Tempo de resposta ao consumidor: tempo entre a colocação e entrega do pedido;

- Tempo de processamento pela da manufatura (lead time): tempo total necessário para a produção de um item ou lote;

- Erros de entrega: número de entregas erradas realizadas;

- Reclamação dos consumidores: número registrado de reclamações dos clientes.

3 - Flexibilidade: Apesar da necessidade de se ter a habilidade de reposta a mudanças no ambiente, estes indicadores são raramente utilizados em análises de cadeias de suprimentos. Neste item se pode medir a habilidade de se trabalhar com volumes e flutuações de programação de fornecedores, produtores e consumidores. Alem disto, a flexibilidade é elemento importante em uma cadeia de suprimentos devido à incerteza existente neste ambiente (Beamon, 1999).

Indicadores de flexibilidade em uma cadeia podem incluir:

- número de pedidos devolvidos;

- número de vendas perdidas;

- número de pedidos atrasados;

- satisfação dos clientes;

- habilidade de responder a variações de demanda (sazonalidade);

- habilidade de responder a baixos desempenhos da manufatura (quebra de equipamentos);

- habilidade de responder a baixo desempenho de fornecedores;

- habilidade de responder a baixo desempenho de entregas; 
- habilidade de responder a novos produtos, novos mercados ou novos competidores.

\subsubsection{Modelo SCOR (Supply Chain Operations Reference Model)}

O Supply Chain Council foi fundado em 1996 por Pittiglio Rabin Todd juntamente com o AMR (Advanced Manufacturing Research). No mesmo ano, foi desenvolvida a primeira versão do modelo SCOR. Atualmente, o conselho tem o interesse em disseminar este modelo, para formar uma base de relacionamentos, a fim de possuir um vocabulário de termos comuns, e reconhecer e adotar rapidamente as melhores práticas.

O modelo SCOR apresenta como configurar e medir uma cadeia de suprimentos, contendo diversas seções organizadas em torno de quatro processos preliminares que são: planejar, fornecer, produzir e entregar, como mostra a Figura 3.4. O modelo pode ser usado para descrever uma cadeia de suprimentos simples ou complexa usando um conjunto comum de definições. Também pode-se descrever e fornecer uma base para a melhoria da cadeia para projetos globais, assim como para projetos locais e específicos. Neste modelo, a medição de desempenho assume o papel de facilitador.

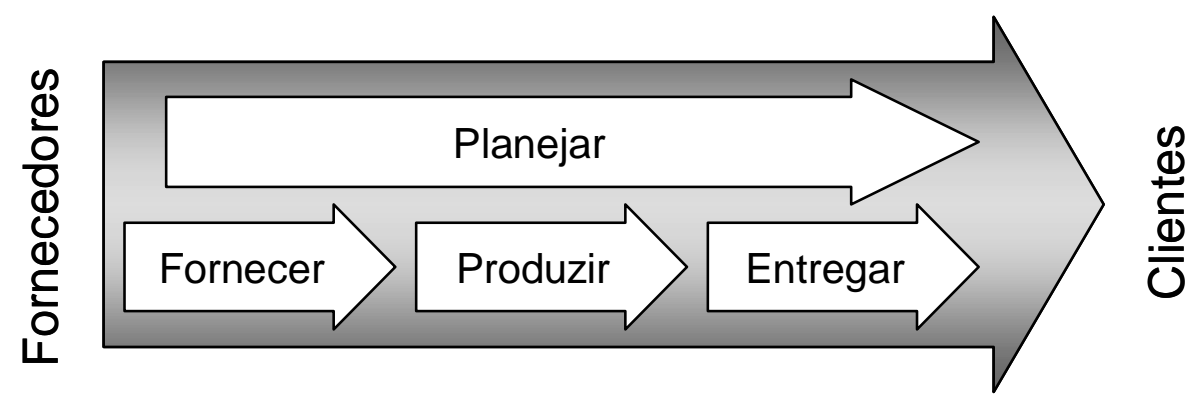

Figura 3.4. Referência das operações da cadeia de suprimentos.

Fonte: Lapide (2000).

Segundo Lapide (2000), o modelo SCOR, sugere um guia de indicadores balanceados. O SCOR advoga a utilização de um grupo de indicadores para a SCM compreendendo uma combinação de métricas de tempo de ciclo, de custo, de serviço/qualidade e de ativos (Figura 3.5). 


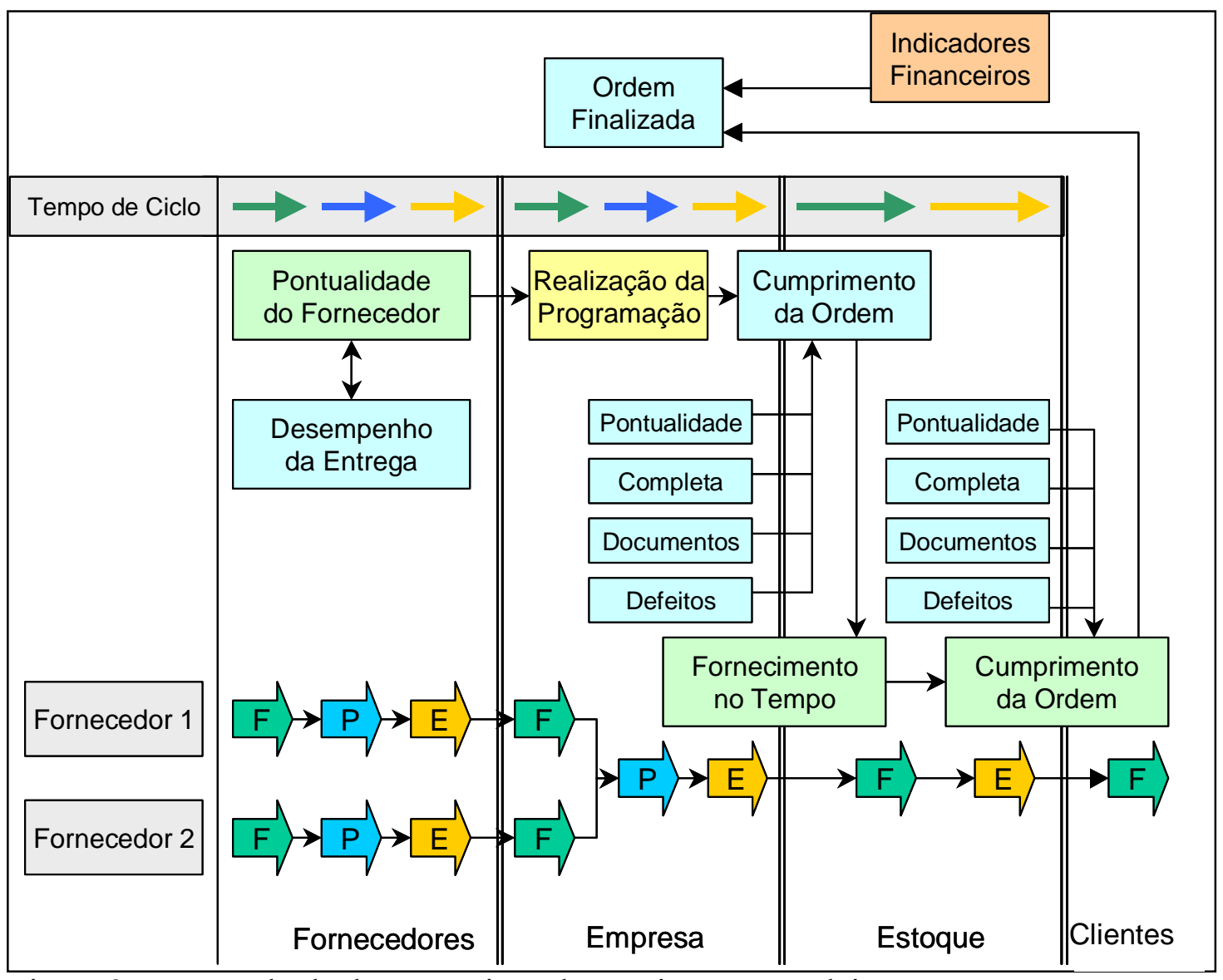

Figura 3.5. Exemplo de decomposição de métricas para cadeia.

( $\mathrm{F}=$ Fornecer, $\mathrm{P}=$ Produzir, $\mathrm{E}=$ Entregar)

Fonte: Supply Chain Council (2001).

O processo de análise para implementação do modelo contempla três níveis de detalhamento onde é definido desde o produto até a capacidade de competir e formar alianças. Além disto, o conselho focalizou em três níveis e não tenta descrever como uma empresa particular deve conduzir seu negócio ou construir seus sistemas de fluxo de informação. Cada uma deve entender seu modelo, ao menos ao nível 4 (Figura 3.6). 


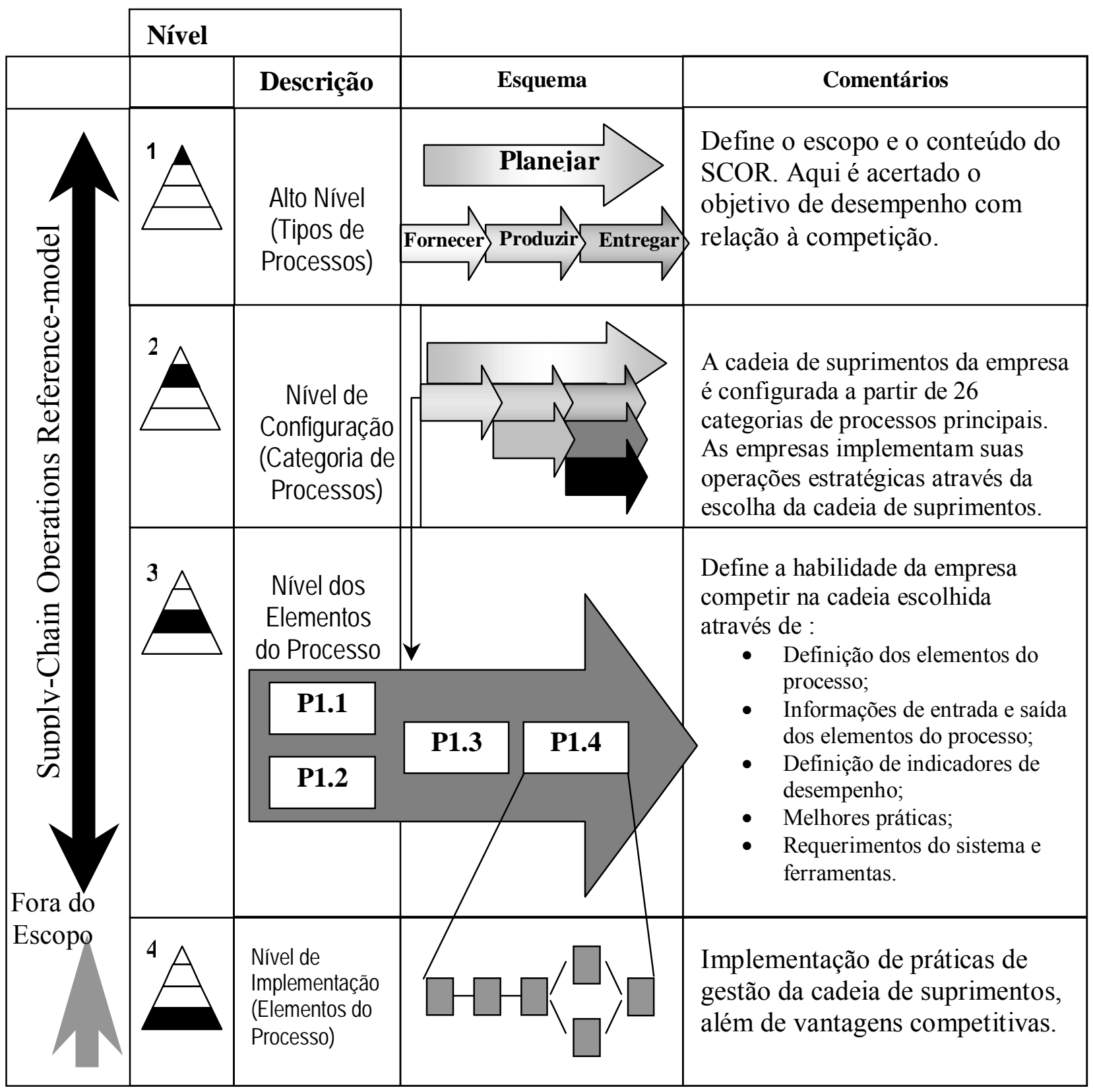

Figura 3.6. Modelo Hierárquico

Fonte: Supply Chain Council (2001).

Além dos quatro processos básicos da gerência (planejar, fornecer, produzir e entregar), que fornece a estrutura organizacional do SCOR, deve-se distinguir o processo de planejamento, já que neste caso, este processo alinha os recursos às exigências da previsão da demanda. É feito um balanceamento da demanda agregada através de um horizonte determinado do planejamento, o que ocorre em intervalos regulares e podem contribuir para o tempo de resposta da cadeia. O planejamento 
também muda o estado dos produtos, inclui programas e arranja a seqüência de materiais e serviços.

Durante todo o modelo um jogo de notações padrão é usado. P descreve elementos do planejamento, $\mathrm{F}$ descreve elementos do fornecimento, $\mathrm{P}$ descreve elementos da produção e E descreve a entrega. Um H que precede alguma das outras (por exemplo, HP), indica que o processo está habilitado, ou seja, o planejamento está disponível.

Finalmente, os indicadores de desempenho assuem um processo hierárquico, embora não explícito no modelo. As métricas do nível 1 (planejar a cadeia de suprimentos), são endereçadas e desdobradas para o nível 2 (métricas de diagnóstico), para o planejamento e execução dos elementos. 


\section{MEDIÇÃO DE DESEMPENHO PARA O PROJETO IPROS}

\subsection{O Projeto IPROS}

No final de 1999, o NUMA (Núcleo de Manufatura Avançada), localizado na USP São Carlos, apresentou em um evento promovido pela SAPTM América, o projeto intitulado IPROS (Integrated Production And Supply Chain Management), que foi o vencedor na categoria "Pesquisa e Aplicação".

O NUMA agrega pesquisadores da UFSCar, UNICAMP, UNIMEP e da Universidade de Aachen (Alemanha). Este núcleo é composto de pessoas de diferentes áreas de conhecimento, permitindo o desenvolvimento de trabalhos interdisciplinares.

Esse projeto é usado para demonstração e fins educacionais criando um ambiente sinérgico, onde é possível ilustrar e avaliar diversos projetos de pesquisa como: medição de desempenho, controle e sistemas de informação, monitoramento de chão de fábrica, desenvolvimento de produtos, gestão da demanda e gerenciamento da cadeia de suprimentos.

O grupo de medição de desempenho, no qual o autor desta dissertação estava incluído, foi formado justamente para desenvolver um conjunto de indicadores de desempenho descrito aqui neste trabalho. Os grupos da gestão da demanda e da cadeia de suprimentos tiveram participação na medição de desempenho através das definições do cenário. O grupo de sistemas de informação teve a incumbência de desenvolver um Data Warehouse para melhorar a visualização e disponibilização das métricas, e parte deste trabalho também é descrito aqui.

Já o grupo de monitoramento de chão de fábrica foi responsável pela captação dos dados do chão de fábrica. O pessoal do desenvolvimento de produtos apresentou novas técnicas do assunto para o produto "redutores". 


\subsection{Cenário da Cadeia de Suprimentos do Projeto IPROS}

A proposta do IPROS é o desenvolvimento de um cenário, onde uma cadeia de produção usará as soluções de um sistema informatizado, para a gestão da cadeia de suprimentos.

O cenário adotado pelo projeto é o de uma empresa de manufatura de redutores, que passou por uma série de transformações até se dividir em uma empresa especializada na fabricação de eixos e em outra empresa que fabrica engrenagens e monta os redutores (Figura 4.1)

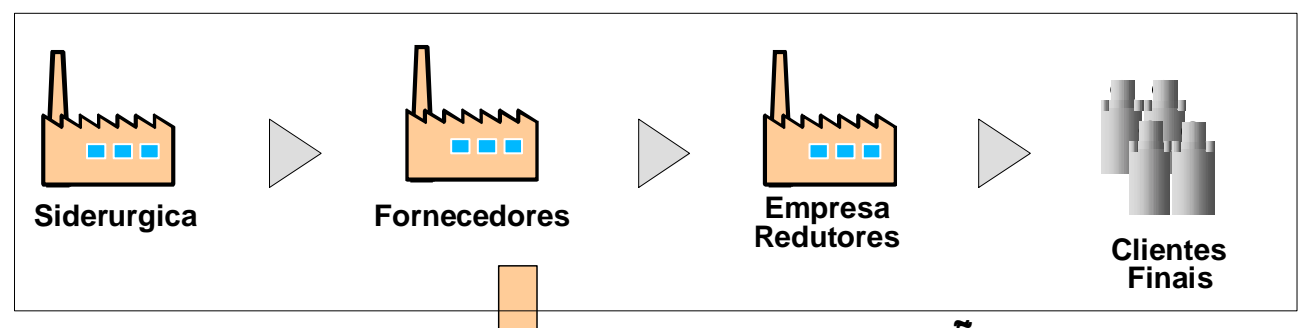

TRANSFORMAÇÃO

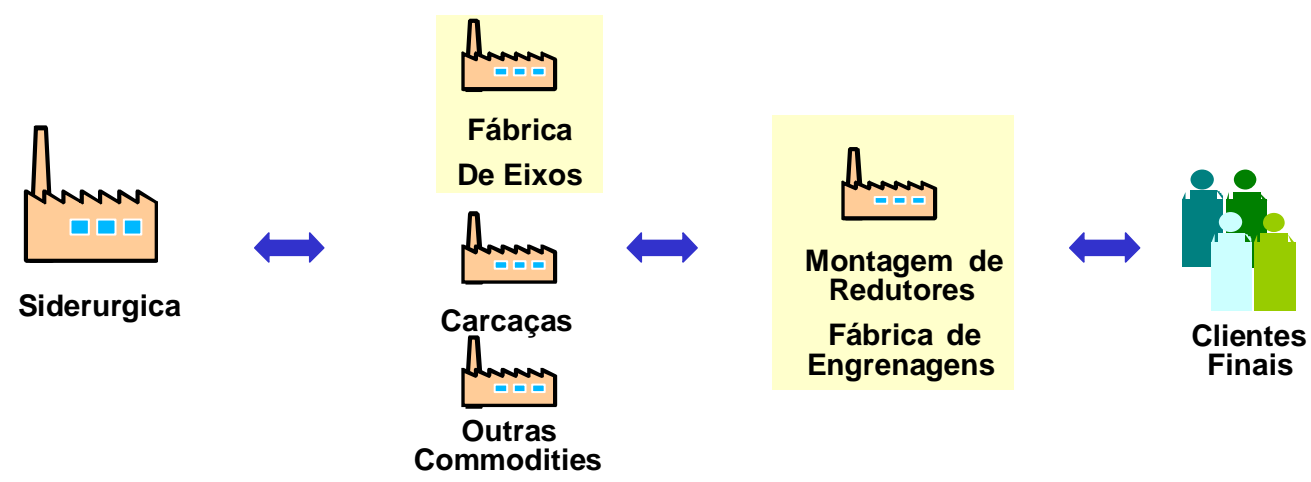

Figura 4.1. Transformação da Cadeia de Suprimentos.

A fábrica de eixos é uma empresa composta de um torno, centro de usinagem e retífica. Sua matéria prima básica são barras em aço, as quais são adquiridas de uma siderúrgica. Estas barras, tão logo são compradas, vão diretamente para um parceiro que as corta e as trata termicamente.

Essa fábrica possui clientes divididos em dois grupos. O primeiro é composto pela própria montadora de redutores, que é atendida prioritariamente, com uma programação de produção. O segundo grupo de clientes, que são diversos, são 
atendidos contra pedido, ou seja, eles entram com o pedido, e somente assim a ordem é processada (Figura 4.2).

A cadeia de suprimentos da montadora de redutores é composta por fornecedores que a suprem com commodities (parafusos, porcas, etc.) e carcaça. Os eixos são fornecidos pela produtora de eixos, a qual a atende com alta prioridade, enquanto que as engrenagens são produzidas dentro da própria montadora.

Seus clientes são divididos em três grupos. O primeiro grupo são os dos setores de bebidas e alimentícios, os quais necessitam de redutores para suas linhas de produção. Eles demandam uma grande quantidade em relação ao volume, mas seus pedidos não são colocados constantemente. O segundo grupo é composto de clientes que produzem linhas de tratores. Os pedidos destes clientes são de um volume mais baixo, mas pode ser observada uma relativa constância na sua demanda. O terceiro grupo são clientes que, de forma esporádica, solicitam produtos da montadora (Figura 4.2).

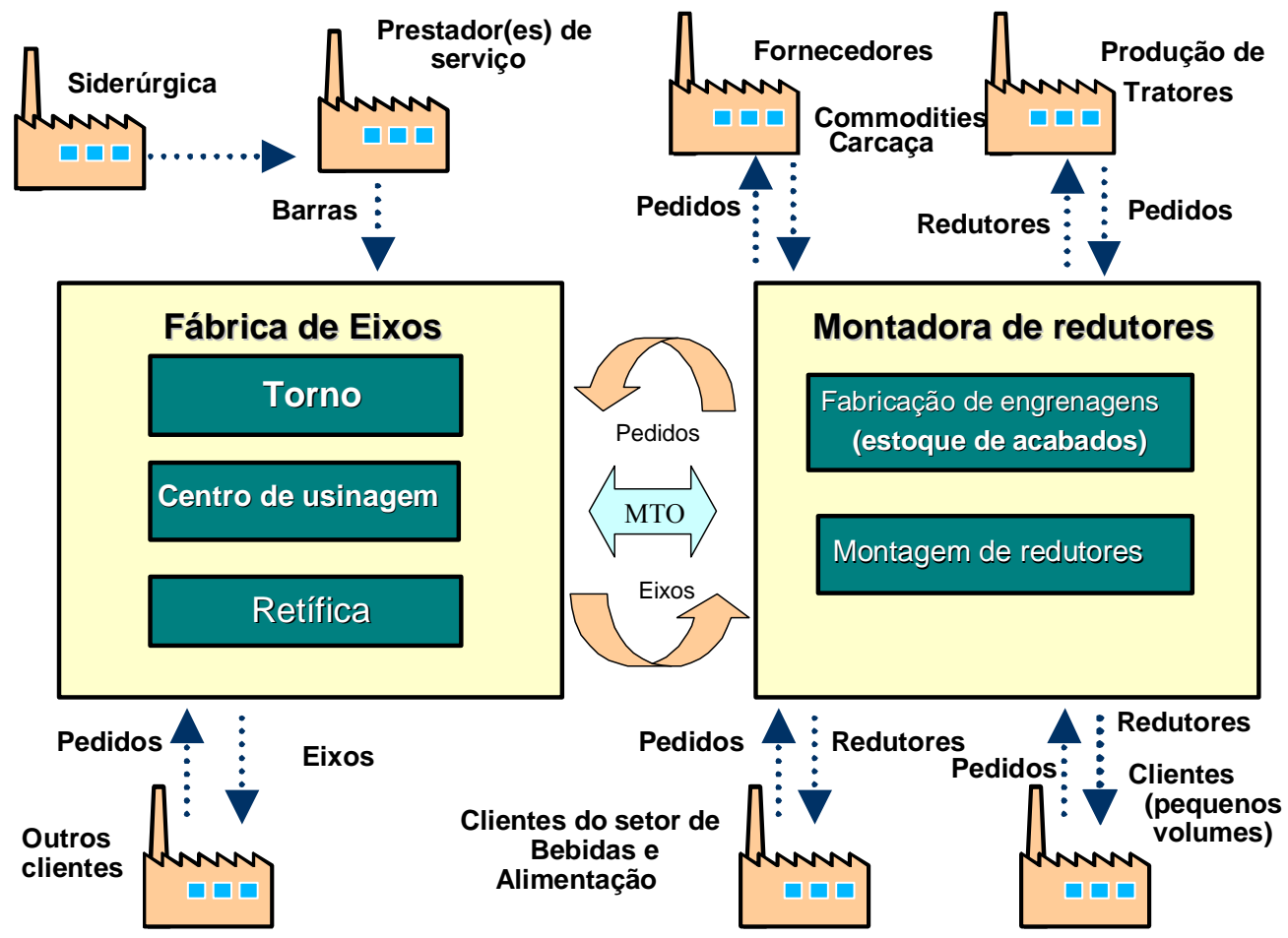

Figura 4.2. Relações entre clientes e fornecedores das fábricas de eixos e redutores. 


\subsection{Proposição de um conjunto de Indicadores de Desempenho}

\subsubsection{Conceitos Envolvidos}

O objetivo dessa parte do projeto era definir um conjunto de indicadores de desempenho para o gerenciamento da empresa correspondente ao elo mais forte da cadeia de suprimentos, ou seja a montadora de redutores.

Para a proposição de um conjunto de indicadores de desempenho nesta dissertação, partiu-se das teorias sobre medição de desempenho apresentadas nos capítulos de revisão bibliográfica. A literatura mostra um conjunto de recomendações, segundo a visão de vários autores, que foram usados como base para a definição dos indicadores, conforme apresentado na Tabela 2.1 na seção 2.6.

Particularmente, as seguintes recomendações serviram de base para a estruturação da proposta:

a) Balanceamento dos indicadores de desempenho: conforme proposto por Kaplan e Norton, os indicadores de um sistema de desempenho devem refletir um adequado balanceamento entre diferentes visões ou perspectivas. Conforme apresentado na seção 2.8.1, as perspectivas financeiras, do cliente, dos processos internos e de aprendizado e crescimento organizacional devem ser consideradas. Ainda, uma quinta perspectiva, a dos fornecedores, deve ser adicionada, especialmente considerando o contexto de cadeia de suprimentos. Desse modo, o conjunto de indicadores de desempenho propostos são estruturados em cinco perspectivas, conforme ilustrado na Figura 4.3.

b) Identificação das áreas chave de desempenho: a literatura em desenvolvimento de sistemas de medição de desempenho faz várias referências à necessidade de se identificar as áreas chave de desempenho do negócio. As áreas chave de desempenho de um negócio estão relacionadas com os fatores de valor para os clientes. Alternativamente, a literatura faz referência a critérios ou dimensões competitivas de um negócio, e processos e atividades críticas para o desempenho nas dimensões competitivas. Neste texto, o termo área chave de desempenho é entendido como a combinação entre dimensões competitivas e os processos ou atividades necessários para se atingir o desempenho esperado. Ainda um outro ponto importante a destacar 
é que as áreas chave de desempenho são definidas a partir de um processo iterativo de definição de produtos, segmentos de mercado e estratégias de atuação para atender os segmentos de mercado alvo. Na próxima seção, as áreas chave de desempenho, para as diferentes perspectivas, serão detalhadas;

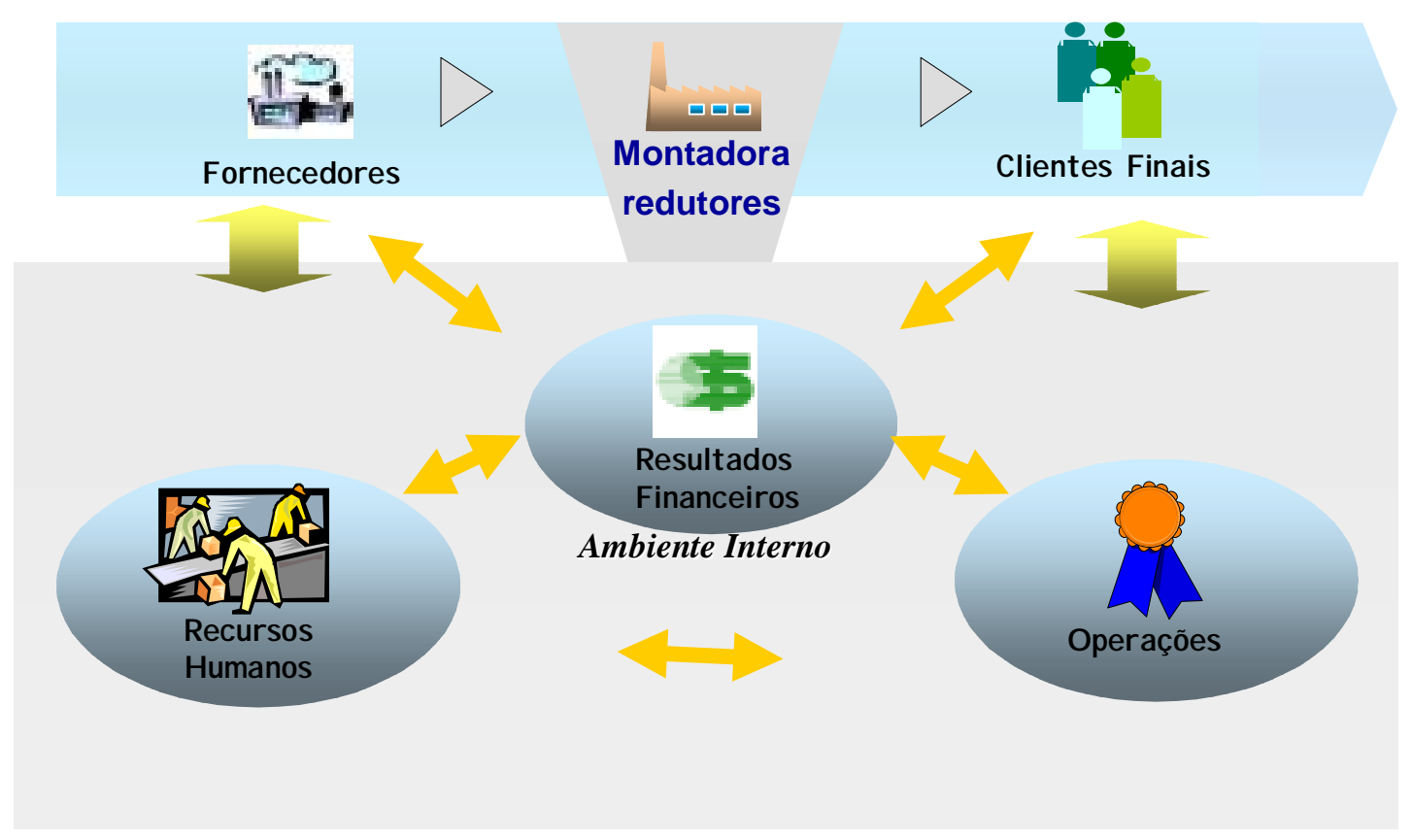

Figura 4.3. Perspectivas do conjunto de indicadores do projeto IPROS.

c) Processos de Negócio da Cadeia de Suprimentos: um terceiro aspecto considerado para a estruturação do conjunto de indicadores de desempenho é o que se refere à definição de indicadores focados nos processos de negócio da cadeia de suprimentos. Para isso, adotou-se como referência, o modelo SCOR, conforme ilustrado na Figura 4.4.

Assim, fazendo referência ao modelo de 5 perspectivas de medição de desempenho da Figura 4.3, percebe-se que a perspectiva das operações deve contemplar os processos internos e também aqueles que atravessam a organização, na interface com clientes e fornecedores. Assim, a representação da Figura 4.3 pode ser redesenhada conforme ilustrada na Figura 4.5. Ainda um outro aspecto a ser observado é que o sistema de medidas de desempenho de qualquer uma das empresas da cadeia deve conter medidas de desempenho da cadeia propriamente dita assim 
como medidas de desempenho do cliente final, conforme ilustrado na Figura 4.6. Nesse sentido, pode-se considerar ainda uma nova perspectiva, que é a de gerenciamento da cadeia como um todo.
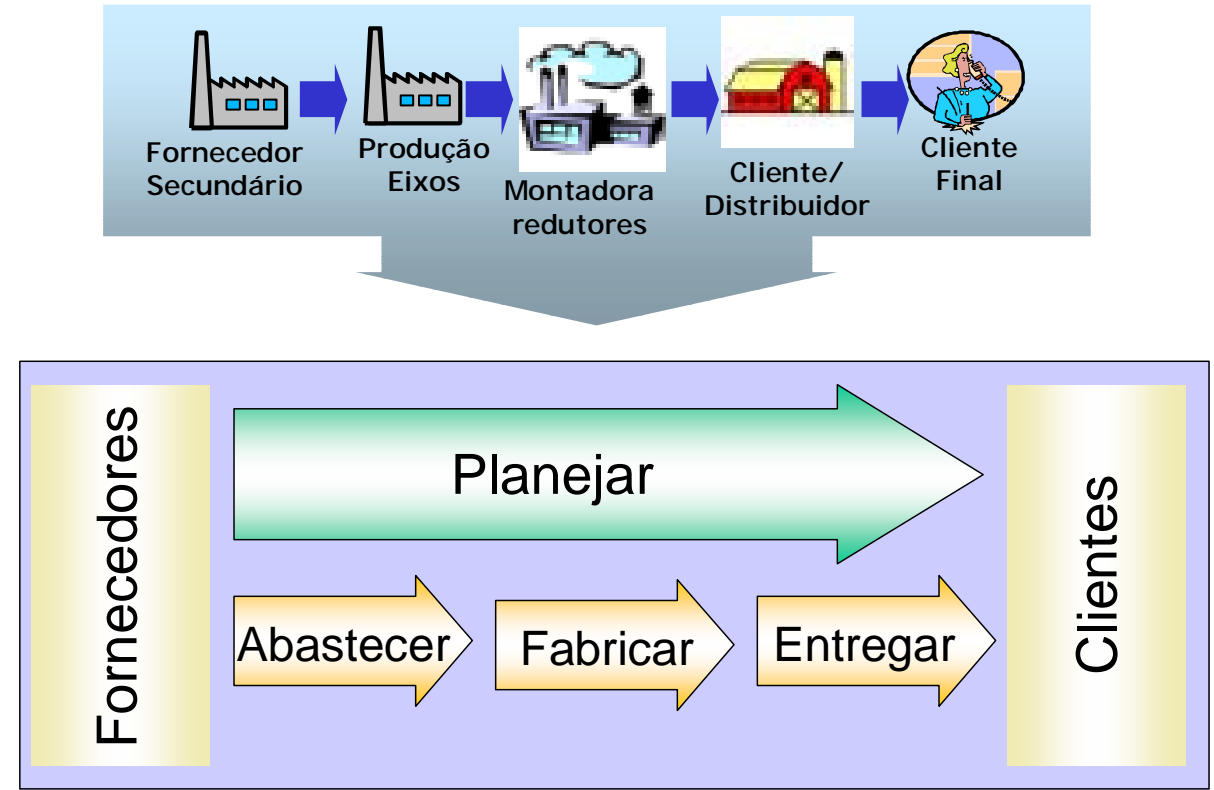

Figura 4.4. O modelo SCOR de processos de negócio na cadeia de suprimentos Fonte: Adaptado de Lapide (2000).

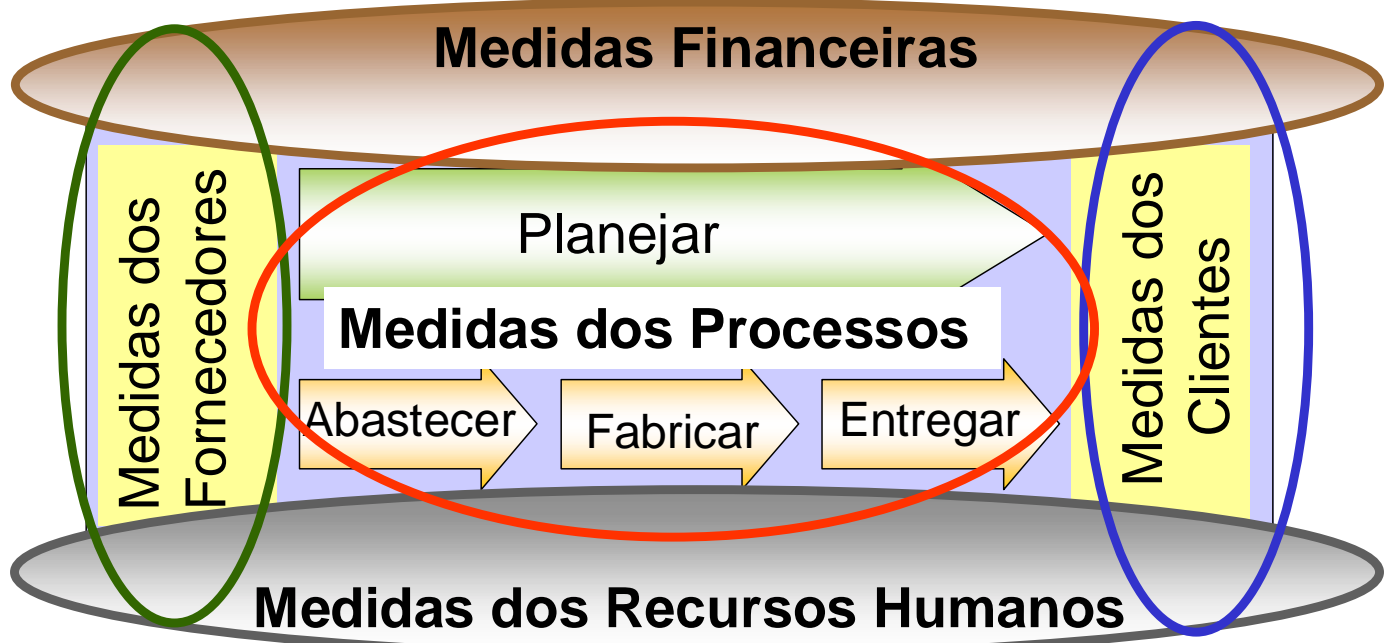

Figura 4.5. Integração entre o modelo SCOR e as perspectivas de desempenho ilustradas na Figura 4.3. 
d) Desdobramento das Medidas de Desempenho: um último conceito usado na definição dos indicadores de desempenho é aquele que se refere ao desdobramento das medidas a partir das áreas chave de desempenho. Ou seja, as medidas a serem focadas em processos e atividades chave para o sucesso do negócio, e relacionadas àquelas dimensões de desempenho que contribuam para a geração de valor para os clientes e acionistas. Ou seja, os drivers, ou vetores de desempenho do negócio. $\mathrm{Na}$ próxima seção, são detalhados os indicadores desdobrados a partir das áreas chave de desempenho consideradas.

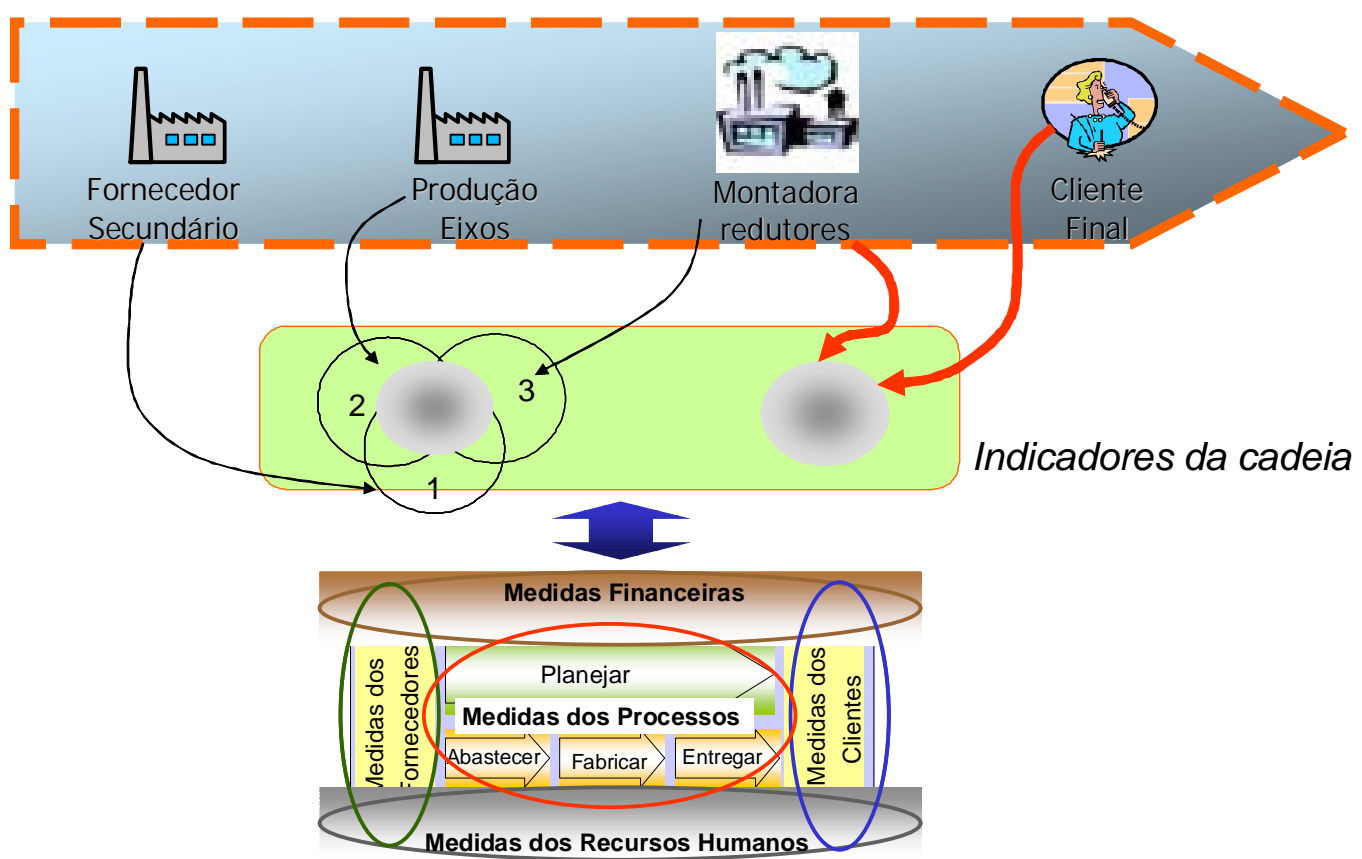

Figura 4.6. Medidas da cadeia de suprimentos.

\subsubsection{Método de Desdobramento dos Indicadores do Projeto IPROS}

Para a definição dos indicadores de desempenho adotados para o gerenciamento da montadora do projeto IPROS, além dos conceitos e recomendações adotados, conforme descrito na revisão e nas seções anteriores, procurou-se adotar um método de definição dos indicadores.

A definição dos indicadores adotou como referência o método proposto por Rentes, Carpinetti e Van Aken (2002). Algumas simplificações foram feitas 
considerando-se que os indicadores foram definidos para um cenário e não para um caso real, ou seja, sem implementação do sistema.

Assim, os seguintes passos foram adotados:

- Passo 1 - Identificar objetivos estratégicos de melhoria e mudança: No cenário do projeto IPROS, a situação simulada é que não existe no momento oportunidade de crescimento de mercado e, portanto, os objetivos estratégicos estão mais relacionados a temas como redução de custos, melhoria da qualidade do produto, aumento de produtividade e melhor utilização dos ativos;

- Passo 2 - Identificar áreas chave de desempenho: para a identificação das áreas chave de desempenho, partiu-se das perspectivas do Balanced Scorecard adicionada a perspectiva dos fornecedores, conforme ilustrado nas Figuras 4.3 e 4.5. Assim, para cada uma das perspectivas, detalhou-se as áreas chave de desempenho, conforme apresentado na próxima seção;

- Passo 3 - Definir as métricas relacionadas às áreas chave de desempenho: para cada uma das áreas chave de desempenho, foi definido um conjunto de indicadores de desempenho, conforme apresentado na próxima seção;

- Passo 4 - Desdobrar indicadores de primeiro nível: neste passo, indicadores das perspectivas dos clientes, operações, fornecedores e recursos humanos foram desdobrados e indicadores de tendência, conforme apresentado na próxima seção;

- Passo 5 - Visualização e Comunicação das métricas: este passo não foi desenvolvido, dado a natureza da aplicação (cenário);

- Passo 6 - Auditoria do Sistema: neste passo, construiu-se um diagrama de relações entre os indicadores de forma a facilitar a identificação de indicadores não associados a uma relação de causa-efeito ou mesmo indicadores conflitantes.

- Passo 7 - Planejamento da Operação do sistema: no desenvolvimento do projeto IPROS, este passo foi aplicado pelos grupos de sistemas de informação e de chão de fábrica, apenas no que se refere, respectivamente, à especificação dos recursos de tecnologia de informação e à infra-estrutura de coleta de dados, conforme apresentado na seção 4.4. 


\subsubsection{Indicadores de Desempenho do Cenário IPROS}

A seguir, são detalhados os indicadores propostos, agrupados por perspectivas e áreas chave de desempenho.

\section{Perspectiva Financeira}

Considerando-se os objetivos estratégicos de redução de custos, aumento de produtividade e melhor utilização dos ativos, para a perspectiva financeira, as áreas chave de desempenho podem ser sumarizadas como (Tabela 4.1):

- Retorno sobre o investimento;

- Redução dos custos: vai tratar de como ao longo do tempo a empresa vem diminuindo os custos com programas de melhoria ou intervenção de novos equipamentos mais produtivos.

As medidas de desempenho desdobradas a partir dessas áreas chave de desempenho são:

- Taxa de redução de custos: índice que acusa quanto se diminui de custos de um período atual em relação a um anterior. Calculado por:

$$
\% \text { red_custo }=\left(\frac{C P A n-C P A t}{C P A n}\right) \times 100
$$

onde:

$C P A n$ : Custo total do período anterior;

CPAt: Custo total do período atual;

- Taxa de aumento da receita por funcionário: índice que quantifica a variação da receita por funcionário. Calculado por:

$$
\% \text { receita }=\left(\frac{R P A t-R P A n}{R P A n}\right) \times 100
$$

onde:

$R P A n$ : Receita por funcionário no período anterior;

$R P A t$ : Receita por funcionário no período atual; 
- Taxa de Retorno de Investimento (TROI):

$$
\text { TROI }=\left(\frac{\text { Lucro }}{\text { Total dos ativos }}\right) \times 100
$$

Tabela 4.1. Áreas chave e medidas de desempenho da perspectiva financeira.

\begin{tabular}{|c|l|l|}
\hline Áreas chave & \multicolumn{1}{|c|}{ Medidas de desempenho } \\
\cline { 1 - 1 } $\begin{array}{c}\text { Retorno sobre o investimento } \\
\text { Redução de custos } \\
\text { Produtividade }\end{array}$ & $\begin{array}{l}\text { Taxa de redução de custos } \\
\text { Taxa de aumento de receita por funcionário } \\
\text { TROI }\end{array}$ \\
\hline
\end{tabular}

\section{Perspectiva dos Clientes:}

No projeto IPROS, conforme descrito na seção 4.2, a carteira de clientes da montadora de redutores é formada principalmente por indústrias que utilizam equipamentos com redutores, e também montadora de veículos pesados. Para esses clientes, além do custo, as dimensões qualidade do produto e desempenho das entregas são aquelas que mais geram satisfação (ou insatisfação) aos clientes. Portanto, as áreas chave de desempenho a partir da perspectiva dos clientes são:

- Qualidade do produto: a qualidade do produto aqui está associada ao bom desempenho durante a vida útil prevista para o produto e também à disponibilidade do produto em operação;

- Desempenho da entrega: o desempenho da entrega está relacionado mais fortemente ao cumprimento dos prazos de entrega contratados, ou seja a pontualidade das entregas; mas também inclui outros aspectos geradores de insatisfação, como velocidade e acurácia das entregas .

As medidas de desempenho desdobradas a partir dessas áreas chave são:

- Taxa de falhas na garantia: relação entre o número de falhas no período de garantia (NFPG) e o número total de falhas (NTF). Calculado por:

$$
T F G=\left(\frac{N F P G}{N T F}\right) \times 100
$$


- Disponibilidade do equipamento: quantificada pela relação entre Tempo médio até a falha (MTTF - Mean time to failure) e tempo médio de reparos (MTTR Mean time to repair), conforme segue:

$$
\text { disponibilidade }=\frac{M T T F}{M T T F+M T T R}
$$

- Taxa de pedidos perfeitamente atendidos: indicativo da porcentagem de pedidos entregues que completamente atenderam as expectativas dos clientes. É calculado como:

$$
\% \text { pedidos_corretos }=\left(\frac{N P P A}{N T P}\right) \times 100
$$

onde:

NPPA: Número de pedidos perfeitamente atendidos;

$N T P$ : Número total de pedidos.

Tabela 4.2. Áreas chave e medidas de desempenho da perspectiva dos clientes.

\begin{tabular}{|c|l|}
\hline Áreas chave & \multicolumn{1}{|c|}{ Medidas de desempenho } \\
\cline { 1 - 1 } $\begin{array}{c}\text { Qualidade do produto } \\
\text { Desempenho da entrega }\end{array}$ & $\begin{array}{l}\text { Taxa de falhas na garantia } \\
\text { Disponibilidade } \\
\text { Taxa de pedidos perfeitamente atendidos }\end{array}$ \\
\hline
\end{tabular}

\section{Perspectiva das Operações}

No projeto IPROS, as áreas chave de desempenho das operações são aquelas relacionadas aos processos e dimensões críticas para a satisfação dos clientes e atingimento dos objetivos financeiros do negócio. Os macro-processos críticos são aqueles representados no modelo SCOR, ou seja, fornecimento, fabricação e entrega. Já as dimensões de desempenho relacionadas às áreas chave são:

- Qualidade de fabricação: a qualidade de fabricação impacta diretamente no desempenho do produto durante o uso, assim como na probabilidade de ocorrência de falhas durante o uso; 
- Tempo: a dimensão tempo nos processos de fornecimento, fabricação e entrega, ainda que tenha impacto direto na satisfação dos clientes, também é uma medida da eficiência de utilização dos recursos;

- Custo: o bom desempenho nessa dimensão leva a um melhor resultado do negócio e portanto está relacionado aos objetivos financeiros. Além disso, ainda que custo não seja explicitamente considerado como um critério de satisfação do cliente, um dos critérios mais importantes na decisão de compra é aquele relacionado ao custo do ciclo de vida do produto. Em produtos manufaturados, especialmente o produto considerado no projeto IPROS, os custos de produção (fixos e variáveis) e as despesas indiretas são significativos e portanto um bom desempenho nessa dimensão pode resultar em maior competitividade.

As medidas de desempenho desdobradas a partir dessas áreas chave de desempenho são:

- Índice de rejeição: porcentagem de peças fora das especificações ou, no caso de produto acabado, porcentagem de produtos que não passem nos testes finais. Calculado como:

$$
\% \text { rejeição }=\left(\frac{Q I D}{Q T I P}\right) \times 100
$$

onde:

$Q I D$ : quantidade de itens defeituosos;

QTIP: quantidade total de itens produzidos.

- custo da não qualidade (CNQ): A quantidade monetária de trabalho e material desprendido para processar refugo ou re-trabalho. Calculado por:

$$
C N Q=C M O+C M
$$

onde:

$C M O$ : custo da mão de obra em processamento de material refugado ou re-trabalho em horas trabalhadas;

$C M$ : custo do material desperdiçado em refugo. 
- Lead time total (LTT): é tempo total de processamento de um pedido, incluindo o lead-time comercial, de produção e de entrega. É calculado por:

$$
L T T=L T C+L T P+L T E
$$

onde:

LTC: lead time comercial;

LTP: lead time de processamento;

LTE: lead time de entrega.

- Pontualidade: uma medida da porcentagem de pedidos atendidos dentro do prazo previamente programado. Calculado por:

$$
\% \text { pontualidade }=\left(\frac{Q E P}{Q T E}\right) \times 100
$$

onde:

$Q E P:$ quantidade de entregas no prazo;

QTE: quantidade total de entregas.

- Eficiência do ciclo de produção (ECP): é uma medida da eficiência do ciclo produtivo, aplicado aos recursos restritivos da produção, em que os tempos não produtivos precisam ser minimizados. Calculado por:

$$
E C P=\left(\frac{T P}{T T C P}\right) \times 100
$$

onde:

$T P:$ tempo de processamento;

TTCP: tempo total do ciclo de produção.

- Despesas indiretas: a soma das despesas administrativas, de suporte à produção e pós-venda.

- Custo unitário de produção (CUT): apuração do custo para se produzir uma unidade de determinado produto. Inclui os custos de materiais, mão de obra e insumos. Calculado por:

$$
C U T=\frac{C F+C V}{N P P}
$$

onde: 
$C F$ : custo fixo total;

$C V$ : custo variável total;

$N P P$ : número de peças produzidas.

Tabela 4.3. Áreas chave e medidas de desempenho da perspectiva das operações.

\begin{tabular}{|c|c|}
\hline Áreas chave & Medidas de desempenho \\
\hline & \% de rejeição \\
\hline & Custo da não qualidade \\
\hline Qualidade & Lead time total \\
\hline Tempo & Pontualidade \\
\hline \multirow[t]{3}{*}{ Custo } & ECP \\
\hline & Despesas indiretas \\
\hline & Custo unitário de produção \\
\hline
\end{tabular}

\section{Perspectiva dos fornecedores:}

As áreas chave de desempenho dos fornecedores são diretamente relacionadas com as dimensões de desempenho das operações, ou seja:

- qualidade: refere-se à qualidade do material fornecido;

- tempo: relacionada ao tempo de fornecimento dos materiais;

- custo: relacionado ao custo do material fornecido.

As medidas de desempenho desdobradas a partir dessas áreas chave de desempenho são:

- Índice da qualidade do fornecedor (IQF): uma medida da qualidade do fornecedor. A qualidade do fornecedor é avaliada não só pela qualidade do material fornecido como também pelo cumprimento dos prazos e acurácia da entrega. Este índice varia numa escala de zero a dez, onde dez representa aqueles fornecedores qualidade "assegurada", cujos materiais fornecidos não passam por inspeção de recebimento e entram direto na linha. A expressão de cálculo desse indicador é dada por: 


$$
I Q F=0,5 \times Q P F+0,5 \times Q E
$$

onde:

$Q P F$ : qualidade do produto fornecido, variando de zero a dez, em função da necessidade de inspeção no recebimento;

$Q E$ : qualidade da entrega, variando de zero a dez, em função do atendimento de prazos ou tempos e acurácia da entrega.

- Taxa de custo do material fornecido (TCMF): taxa que indica a variação no custo final do produto adquirido junto ao fornecedor, incluindo o custo de aquisição e outros custos relacionados à necessidade de inspeção de recebimento. Índice calculado para cada fornecedor, a partir da expressão:

$$
T C M F=\left(\frac{C T A t-C T A n}{C T A n}\right) \times 100
$$

onde:

CTAt: Custo total de fornecimento no período atual;

CTAn: Custo total de fornecimento no período anterior;

Tabela 4.4. Áreas chave e medidas de desempenho da perspectiva dos fornecedores.

\begin{tabular}{|c|c|l|}
\hline Áreas chave & \multicolumn{1}{|c|}{ Medidas de desempenho } \\
\hline Qualidade & & Índice da qualidade do fornecedor \\
Tempo & Taxa de Custo do material fornecido \\
Custo & \\
\hline
\end{tabular}

\section{Perspectiva dos Recursos Humanos}

Para a perspectiva dos recursos humanos, as áreas chave de desempenho relacionam-se àqueles aspectos que mais afetam a qualidade de resultados gerados pelos recursos humanos da empresa, ou seja, capacitação, motivação e organização, conforme segue:

- capacidade: a gestão efetiva de pessoal é necessária para a devida alocação dos funcionários em respectivos cargos. Para isto, existe a necessidade de um plano de qualificação de cada posto e funcionário; 
- motivação: vai tratar do quanto à empresa possui pessoas com disposição e motivação, que resulta em uma ambiente com melhor produtividade;

- organização: avaliar o ambiente com relação a seu visual, sua praticidade e segurança, são itens que refletem nas boas condições do trabalho, por isso, a preocupação com um local adequado para a execução das tarefas impacta diretamente na produtividade e satisfação dos funcionários.

As medidas de desempenho desdobradas a partir dessas áreas chave de desempenho são:

- Matriz de capacitação: matriz que mapeia a relação entre a capacitação necessária para cada função e o estágio de capacitação de cada funcionário. Nesta matriz, pode-se atribuir notas para cada funcionário, sendo que estas notas vão traduzir a verdadeira qualificação de cada um em determinada função.

- índice de satisfação dos funcionários: pesquisa realizada para avaliar o nível de satisfação dos funcionários com relação a encargos e salário, condições de trabalho e segurança oferecida pela empresa.

- número de deméritos: é a avaliação das condições de trabalho da empresa em geral. Os deméritos são calculados a partir da organização, ou seja, itens guardados nos locais corretos, limpeza, reduzindo a geração de resíduos e garantindo um destino correto para os mesmos, segurança do local de trabalho, reduzindo os riscos e prevenindo acidentes.

Tabela 4.5. Áreas chave e medidas de desempenho da perspectiva dos recursos humanos.

\begin{tabular}{|c|c|}
\hline Áreas chave & Medidas de desempenho \\
\hline Capacidade & Matriz de capacitação \\
\hline motivação & Índice de satisfação dos funcionários \\
\hline organização & Número de deméritos \\
\hline
\end{tabular}


A seguir, é apresentada na Tabela 4.6 todos os indicadores, suas áreas chave e respectivas perspectivas. Nesta forma de apresentação, foi adotado um sistema mais rígido para avaliar a relação entre indicadores e áreas chave, sendo que está apresentado a dimensão que mais tem relacionamento com determinado indicador, não descartando a possibilidade de um indicador possuir mais de uma área chave. 
Tabela 4.6. Indicadores de desempenho e suas perspectivas.

\begin{tabular}{|c|c|c|c|c|c|}
\hline Perspectivas & \multirow[b]{2}{*}{ Financeira } & \multicolumn{2}{|l|}{ Clientes } & \multirow[b]{2}{*}{ Fornecedores } & \multirow[b]{2}{*}{$\mathbf{R H}$} \\
\hline & & & Operações & & \\
\hline Custo & $\begin{array}{l}\text { - Taxa redução de } \\
\text { custos } \\
\text { - Taxa de aumento de } \\
\text { receita } \\
\text { - TROI }\end{array}$ & $\begin{array}{l}\text { - Taxa de defeitos na } \\
\text { garantia }\end{array}$ & $\begin{array}{l}-\quad \text { Custo da não qualidade } \\
-\quad \text { Despesas indiretas } \\
-\quad \text { Custo unitário da } \\
\text { produção }\end{array}$ & $\begin{array}{l}\text { - Taxa do custo do } \\
\text { fornecimento }\end{array}$ & \\
\hline Qualidade & & & - Índice de rejeição & $\begin{array}{l}\text { - Índice da qualidade } \\
\text { do fornecedor }\end{array}$ & \\
\hline Tempo & & $\begin{array}{l}\text { - } \quad \text { Disponibilidade } \\
\text { - } \quad \text { Taxa de pedidos } \\
\text { perfeitamente atendidos }\end{array}$ & $\begin{array}{l}\text { - } \quad \text { Lead-time total } \\
\text { - } \quad \text { pontualidade }\end{array}$ & & \\
\hline Produtividade & & & $\begin{array}{l}\text { - Eficiência do Ciclo de } \\
\text { Produção }(E C P)\end{array}$ & & $\begin{array}{l}\text { - } \quad \text { Matriz de capacitação } \\
\text { - Índice satisfação } \\
\text { funcionários } \\
\text { - } \quad \text { Deméritos }\end{array}$ \\
\hline
\end{tabular}


A Tabela 4.7 apresenta uma sugestão de freqüência de medição de desempenho para as métricas individualmente.

Tabela 4.7. Plano de medição

\begin{tabular}{lc}
\hline Perspectivas & Freqüência \\
\hline Financeira & \\
\hline$\bullet \quad$ Taxa de redução de custos & Mensal \\
$\bullet \quad$ Taxa aumento receita por funcionário & Trimestral \\
- TROI & Anual \\
\hline Clientes & Mensal \\
\hline$\bullet \quad$ Taxa de falhas em garantia & Mensal \\
$\bullet \quad$ Disponibilidade & Semanal \\
\hline Taxa de pedidos perfeitamente atendidos & \\
\hline Processos & Por ordem \\
\hline Índice de Rejeição & Mensal \\
$\bullet \quad$ Custos da não qualidade & Quinzenal \\
$\bullet \quad$ Lead Time Total & Mensal \\
$\bullet \quad$ Pontualidade & Mensal \\
$\bullet \quad$ Eficiência do ciclo de produção & Mensal \\
$\bullet \quad$ Despesas indiretas & Mensal \\
$\bullet \quad$ Custo unitário da produção & \\
\hline Fornecedores & Semanal \\
\hline Índice da qualidade do fornecedor & Mensal \\
\hline Taxa de custo de material fornecido & \\
\hline Recursos Humanos & Anual \\
\hline$\bullet \quad$ Matriz de Capacitação & Semestral \\
$\bullet \quad$ Taxa da satisfação dos funcionários & Mensal \\
\hline
\end{tabular}

Finalmente, é apresentado na Figura 4.7, um modelo de relacionamento das métricas do projeto IPROS. Esse modelo serve como forma de testar a integração e eliminar qualquer conflito entre eles. Desta maneira, tentou-se provar que todos as métricas do projeto IPROS não conduzem a objetivos assíncronos, mas sim ao melhor retorno sobre o investimento, uma estrutura de custos mais enxuta com qualidade superior e tempos otimizados. 


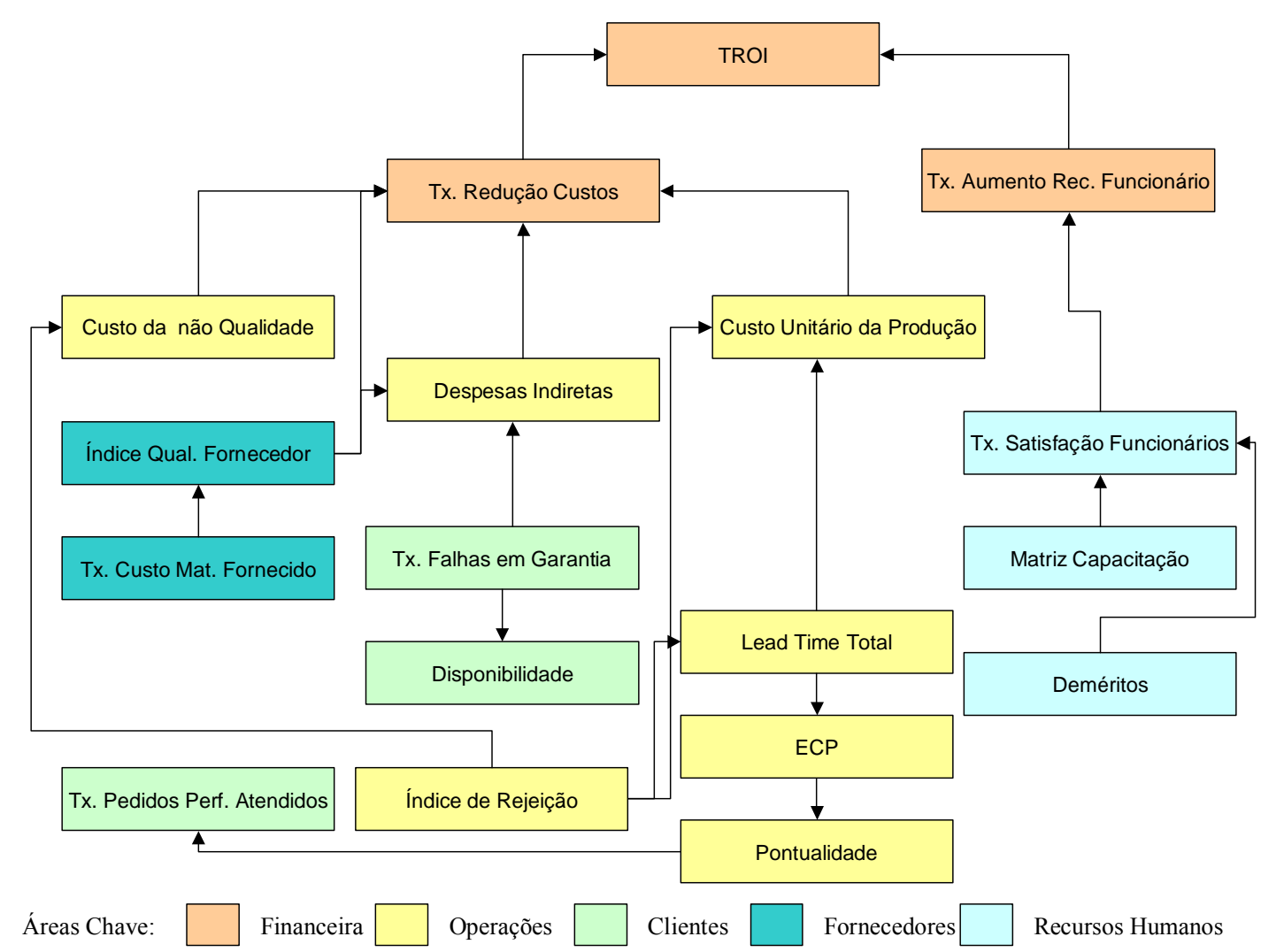

Figura 4.7. Modelo de relacionamento das métricas do projeto IPROS.

\subsection{Infra-estrutura de Coleta de Dados e Tratamento da Informação}

Em princípio, o grupo do chão de fábrica adotou a utilização da tecnologia da informação, por meio de sensores, uma rede tipo fieldbus interligando as máquinas e um software chamado SCADA, que é um aplicativo típico para análises gráficas (Figura 4.8). Esta configuração permite que as informações, antes desconhecidas ou de difícil acesso, fossem disponibilizadas através de consultas SQL (Structured Query Language).

Contudo, foi observado que somente esses dados ou esses relatórios obtidos por consultas SQL não bastam para um administrador do chão de fábrica, pois as consultas SQL não conseguem obter facilmente um relatório indicando fatores de perda de produção de um chão de fábrica, por exemplo. Além disso, foi observado que os dados obtidos pelos sensores também cresciam exponencialmente com o tempo. 


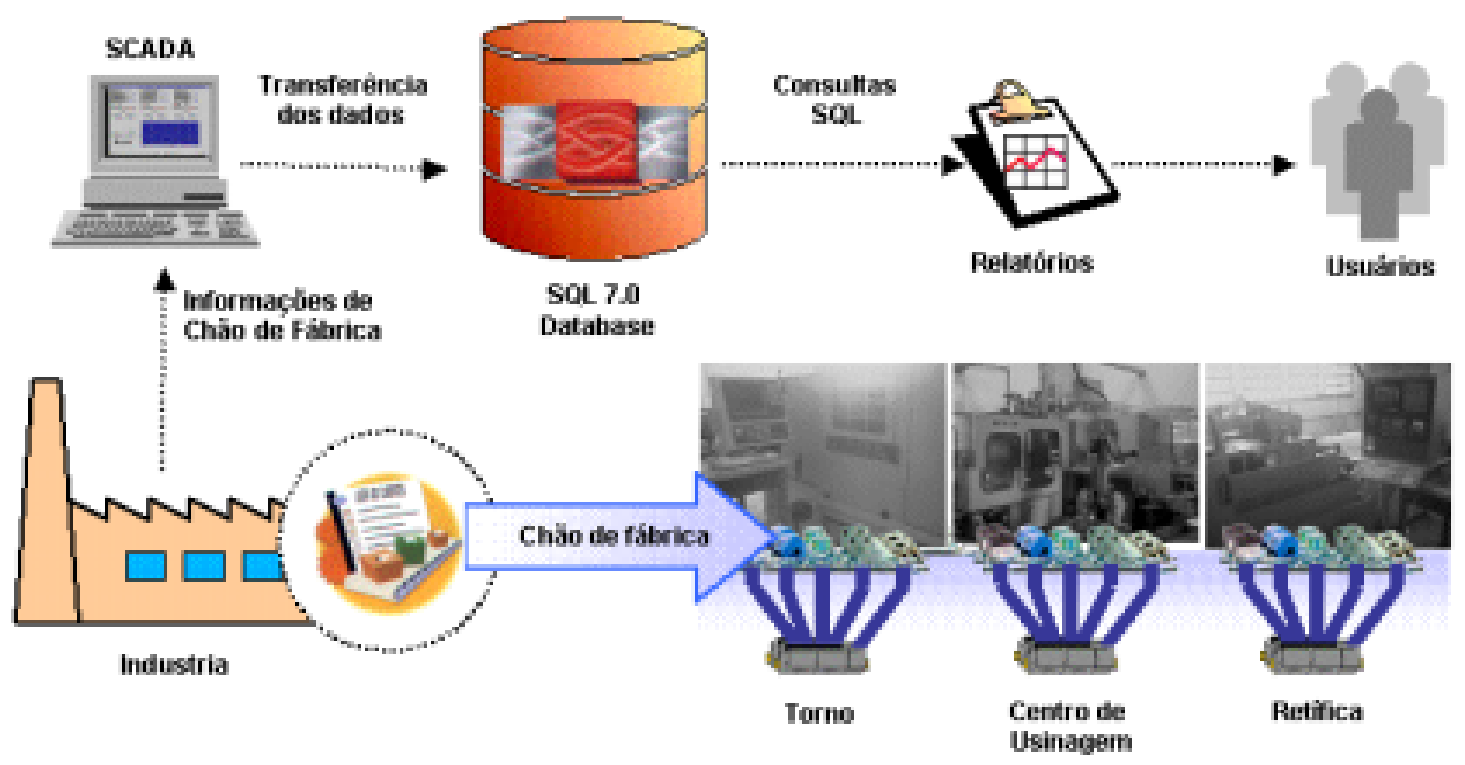

Figura 4.8. Processo de coleta de informações do chão de fábrica.

Desta maneira, entrou em operação o grupo de sistemas de informação que adotou a solução Data Warehouse (DW) para os dados no IPROS, que foi construído utilizando-se o Microsoft Data Warehouse Framework ${ }^{\mathrm{TM}}$.

Esta estrutura agrupa ferramentas para construção e utilização, como o SQL Server e o OLAP Services da Microsoft ${ }^{\mathrm{TM}}$. No OLAP Services foram construídos os cubos dimensionais do DW, que posteriormente são utilizados no Microsoft Office ${ }^{\mathrm{TM}}$, que serve de front-end para as consultas $\mathrm{OLAP}^{7}$ (On-Line Analytical Processing) elaboradas pelos administradores. Esta base de dados e o DW possibilitam uma melhor visão dos dados existentes e, por conseguinte, uma melhor coordenação, por exemplo, de um chão de fábrica, por possibilitar relatórios operacionais mais detalhados conforme mostrado na Figura 4.9.

\footnotetext{
${ }^{7}$ OLAP é uma nova tecnologia de software a visualização dos dados de uma forma mais rápida. Essa tecnologia permite calcular e modelar por meio de dimensões as informações que uma empresa possui.
} 


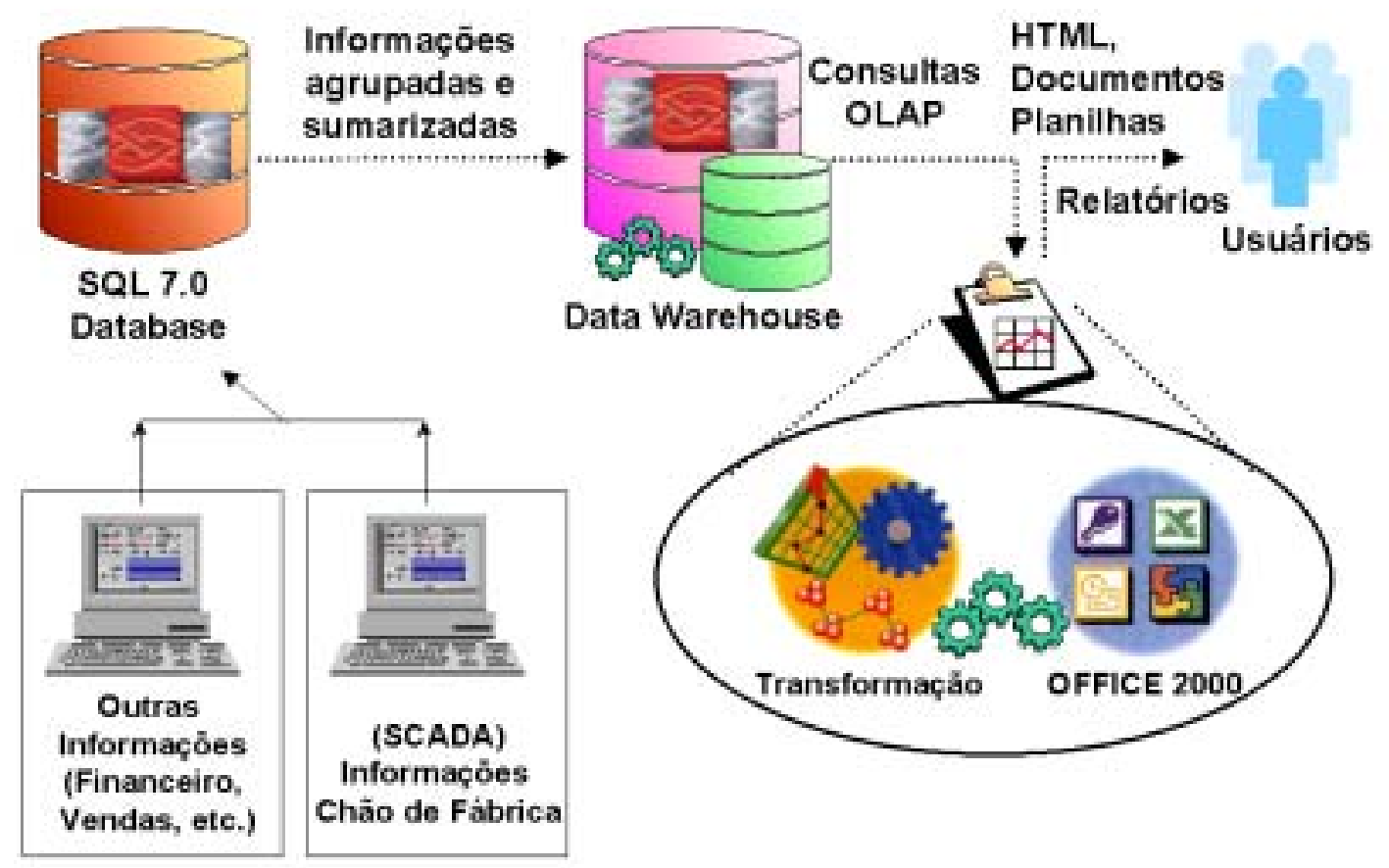

Figura 4.9. Data Warehouse para o Projeto IPROS.

Com o DW construído pelo OLAP Services no SQL Server, o próximo passo foi a utilização do mesmo por meio de consultas OLAP. Essas consultas acessam estruturas hierárquicas dimensionais denominadas de cubos dimensionais que são responsáveis em consolidar todas as informações contidas na base de dados do chão de fábrica. Desse modo, dentro do DW existem cubos dimensionais que devem conter informações a respeito do desempenho da produção, por exemplo.

No IPROS, a ferramenta utilizada para a geração de relatórios por meio de consultas OLAP foi o Excel $^{\mathrm{TM}}$, devido à característica de permitir a conexão direta com os cubos dimensionais do DW no OLAP Services, Figura 4.10.

A partir desta arquitetura, administradores podem, executar consultas dinâmicas a partir de parâmetros como: tempo de ciclo, tempo de setup, tempo de fila, tempo de outras paradas, perdas eventuais, etc. Desta maneira, o usuário pode configurar o tipo de relatório de acordo com a sua necessidade, otimizando, desta maneira, a imensa quantidade de informações. 


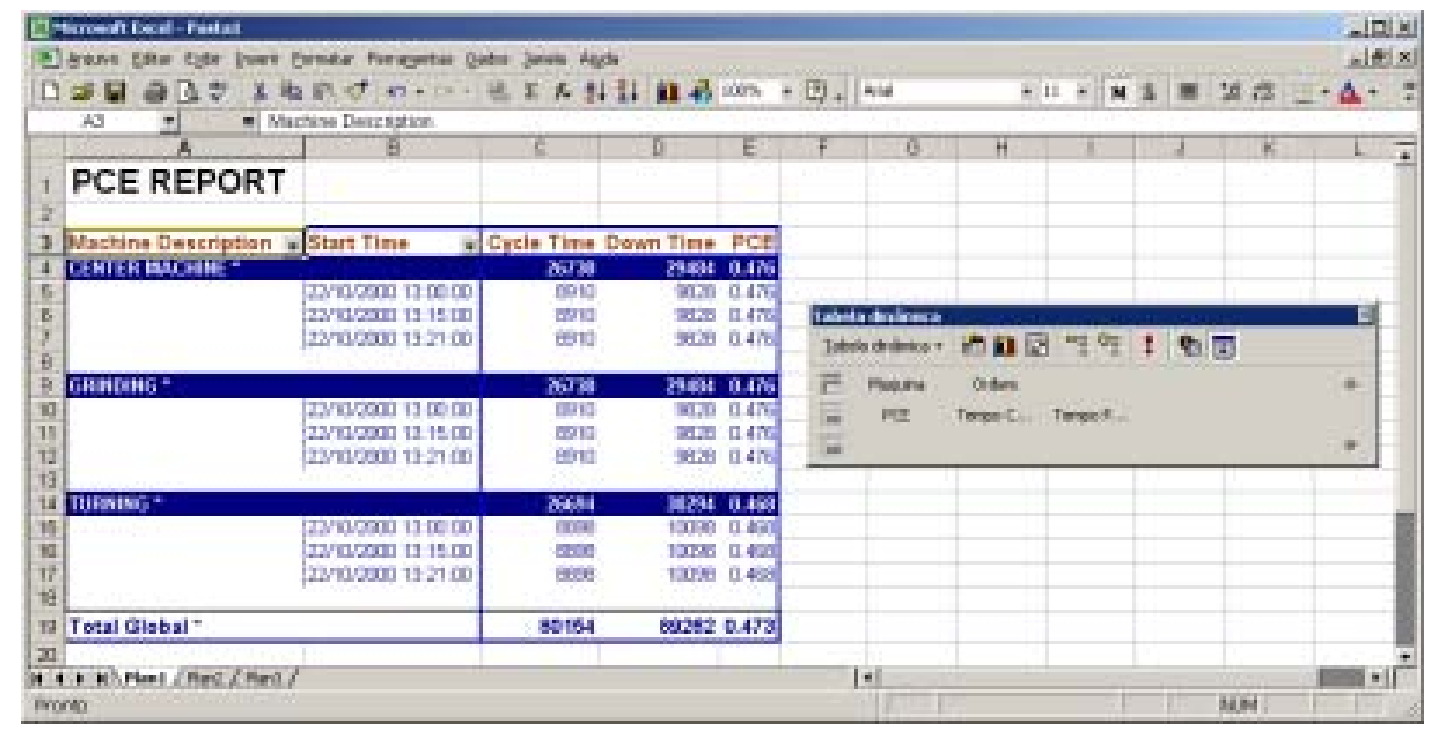

Figura 4.10. Exemplo de Consulta OLAP no Excel 2000.

\subsection{Considerações Finais}

Este capítulo apresentou o conjunto de indicadores de desempenho propostos para o projeto IPROS, baseados nos conhecimentos descritos nos capítulos 2, 3 e 4 deste trabalho

Por meio desta proposição de um conjunto de indicadores, foi possível mostrar como uma empresa pode obter informações mais rápidas e acuradas, principalmente no chão de fábrica. Também foi possível ilustrar a utilização de indicadores de desempenho balanceados e divididos em áreas chave da empresa, o que permite um melhor foco em processos e atividades críticas para a competitividade do negócio.

Outro ponto importante a se destacar é que o conjunto de indicadores de desempenho também contempla a cadeia de suprimentos, onde se pode obter algumas informações do ambiente externo a empresa, melhorando o fornecimento de materiais e otimizando o foco nos clientes, melhorando a sua competitividade no segmento de mercado em que atua.

As restrições ficam a cargo da aplicação dos indicadores de desempenho do modelo de relacionamento nas empresas de serviços, o qual requer um total redesenho, e o uso do modelo em empresas que não possuem eficientes sistemas de captação e armazenamento de informações. 


\section{ESTUDO DE CASO}

\subsection{Introdução}

Este capítulo apresenta o desenvolvimento do estudo de caso, proposto na seção 1.2, com o objetivo de se estudar os indicadores de desempenho de uma empresa que esteja inserida em uma cadeia de suprimentos similar ao projeto IPROS e que possua um bom SMD.

Este estudo de caso foi desenvolvido em uma empresa localizada na cidade de Valinhos, interior do Estado de São Paulo, no mês de novembro de 2001.

A escolha da empresa se deveu a identificação da utilização dos conceitos do BSC para formulação do seu sistema de indicadores de desempenho, além do produto final desta empresa, que é caracterizada pela produção de redutores. Desta maneira, entendeu-se que este seria um exemplo para ser estudado, levando em consideração o escopo apresentado e discutido até aqui nesta dissertação.

Assim, a próxima seção apresenta uma breve caracterização da empresa estudada e o detalhamento de seu SMD. Finalmente, é feita uma discussão sobre as conclusões obtidas, em resposta às questões de pesquisa.

\subsection{Procedimentos de Pesquisa}

Dentre os principais métodos de pesquisa, pode-se afirmar que os principais, segundo Gil (1991) e Bryman (1995), são: a pesquisa experimental, a pesquisa-ação e o estudo de caso.

O estudo de caso é um método utilizado para examinar detalhadamente um ou pequeno número de casos em unidades organizacionais, podendo ser uma seção ou departamento da organização, ou mesmo redes inter-organizacionais (Conti, 2001).

Para Gil (1991), o estudo de caso envolve um estudo profundo e exaustivo de um ou poucos objetos de maneira que se permita o seu amplo e detalhado 
conhecimento. Existe também a ressalva que o estudo de caso pode ser tratado como uma pesquisa qualitativa, mas a quantificação pode ser usada em conjunto para descrever adequadamente o método da pesquisa do estudo de caso.

\subsection{Escolha da Empresa}

Os critérios para a seleção da empresa foram: representativa do cenário nacional, que atue na produção de redutores, além de estar situada em uma cadeia de suprimentos que seja similar a do projeto IPROS; que a empresa apresente características de preocupação e aplicação de conceitos de medição de desempenho e gerenciamento da cadeia de suprimentos.

A empresa estudada, denominada Eaton, é uma empresa de grande porte, com operações espalhadas por mais de 24 países, contando com aproximadamente 59.000 funcionários e um faturamento de US\$ 8.3 bilhões no ano de 2000. Seus negócios são subdivididos em quatro grandes áreas:

- Grupo caminhões;

- Grupo automotivo;

- Grupo de controle comercial e industrial;

- Grupo de fluídos.

No Brasil, a unidade estudada se localiza na cidade de Valinhos-SP, chamada de Eaton Ltda (Divisão Transmissões). São 1.960 funcionários com um faturamento de R\$ 550 milhões no ano de 2000. Os seus produtos são transmissões mecânicas para: veículos de passeio, pick ups, caminhões (leves/médios/pesados) e tratores agrícolas, peças para reposição de transmissões, embreagens, produtos para pneus e serviços. Seus principais clientes são a GM, Volkswagen, Daimler Chrysler, International, Ford, New Holland, Valtra, Agco, etc.

O sistema de produção adotado é o de montagem contra pedido (MTO - make to order). Ou seja, a empresa trabalha com contratos de fornecimento junto às montadoras.

Suas operações são integradas com o restante do mundo, fornecendo também parte de sua produção para o mercado mundial. Desta maneira, no que tange a desenvolvimento de projetos e montagem, a empresa no Brasil tem importante 
participação no desenvolvimento de projetos de transmissão leve para o mercado de montadoras, e atua fortemente na montagem, exceto da de transmissão pesada (Tabela 5.1).

Tabela 5.1. Projeto e Montagem no Brasil

\begin{tabular}{|l|c|c|c|c|c|}
\cline { 2 - 6 } \multicolumn{1}{c|}{} & $\begin{array}{c}\text { Transmissão } \\
\text { leve }\end{array}$ & $\begin{array}{c}\text { Transmissão } \\
\text { média }\end{array}$ & $\begin{array}{c}\text { Transmissão } \\
\text { pesada }\end{array}$ & $\begin{array}{c}\text { Tratores } \\
\text { agrícolas }\end{array}$ & $\begin{array}{c}\text { Carro de } \\
\text { passeio }\end{array}$ \\
\hline Projeto & Brasil & $\begin{array}{c}\text { Estados } \\
\text { Unidos }\end{array}$ & Opel & Montadoras & $\begin{array}{c}\text { Estados } \\
\text { Unidos }\end{array}$ \\
\hline Montagem & Sim & Sim & Não & Sim & Sim \\
\hline
\end{tabular}

\subsection{Questões de Pesquisa}

As questões de pesquisas elaboradas a seguir, tiveram como objetivo esclarecer da melhor forma a proposta de estudo de caso deste trabalho.

- O conjunto de indicadores é balanceado?

- O conjunto de indicadores é relacionado às áreas chave de desempenho derivadas da estratégia?

- O conjunto de indicadores foca nos processos da cadeia de suprimentos?

- Os indicadores de resultado são desdobrados em indicadores de tendência?

- O sistema de medição de desempenho é integrado ao sistema informatizado de gestão?

\subsection{O Instrumento de Pesquisa}

$\mathrm{O}$ instrumento de pesquisa utilizado, um questionário (anexo B), foi desenvolvido para auxiliar na condução das entrevistas para a coleta de dados.

Por se tratar de um estudo de caso, o questionário será preparado baseado nas questões de pesquisa, que leva em consideração os conceitos desenvolvidos neste trabalho.

\subsection{Resultados do Estudo de Caso}

As entrevistas realizadas foram individuais contando sempre com a presença do pesquisador. O objetivo principal foi levantar as principais atividades, 
informações e recursos do SMD da empresa estudada. Além disto, foi também objeto da entrevista, mesmo que de uma forma não estruturada, ou seja, através do questionário, o levantamento de aspectos como o produto, o mercado, os processos de negócios existentes e a estratégia da empresa.

Ao todo, para esta unidade de negócio, foram realizadas cinco entrevistas, com as seguintes áreas:

- Qualidade (1 entrevista);

- Informática (1 entrevista);

- Produção (2 entrevistas);

- Gestão Estratégica (1 entrevista);

Então, através do questionário e da percepção geral dos fatos, foi logo no início levantado que a empresa passou por um passado recente onde as práticas de medição de desempenho também eram adotadas, porém com uma configuração muito diferente da atual.

Para tal, era adotado uma matriz de medição de desempenho, onde existia a tentativa de se cruzar informações, do que se era chamado de tema estratégico (Strategic Issue), com os processos de negócio chave. Com relação aos indicadores de desempenho, as medidas consideradas "chave" estavam relacionados com os temas estratégicos e as medidas de processos estavam diretamente vinculadas aos processos de negócio (Tabela 5.2).

Porém, algumas pessoas criticavam a matriz com relação a sua difícil introdução de novos indicadores e de uma análise mais profunda de algumas áreas de negócio. Também era criticado que novas ações no Brasil não eram incluídas na matriz, já que o formato e a grande maioria dos indicadores eram criados nos Estados Unidos. 
Tabela 5.2. Matriz de medição de Desempenho

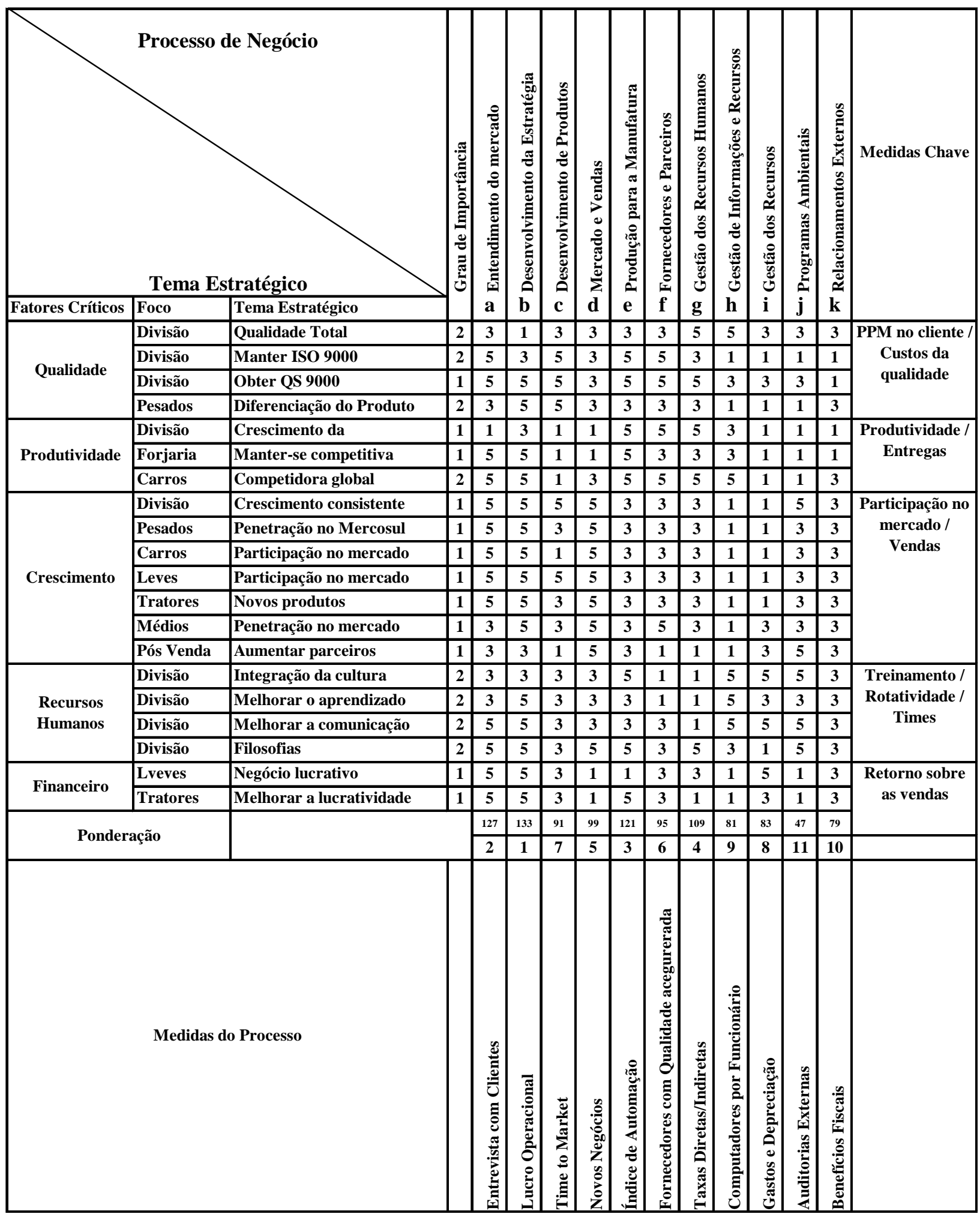


Partiu-se então para o estudo e a viabilização de um novo SMD, no qual os indicadores da antiga matriz fossem contemplados, bem como novas métricas que pudessem ser incluídas em um modelo mais flexível.

Após estudos preliminares, a empresa decidiu pela implementação do BSC, para toda a empresa no mundo, com relativa flexibilidade de alteração nas divisões.

No Brasil, a empresa solicitou a ajuda de um especialista que detinha o conhecimento do assunto, que introduziu o conceito e a forma de elaboração e adaptação do BSC mundial para a realidade brasileira.

Dentre os conceitos abordados, a empresa decidiu que algumas características deveriam fazer parte de seu SMD como:

- Ser fácil de se entender;

- Com definições claras;

- Ser derivado da estratégia;

- Fazer parte de um processo gerencial;

- Com garantia de retorno acurado;

- Se relacionar a metas específicas;

- Refletir os processos de negócio;

- Focado na melhoria;

- Baseado em tendências.

Portanto, a empresa decidiu pela situação na qual a análise de indicadores deveria abranger a situação atual, tendências e comparação (benchmarking). Para tal, foram feitas reuniões especificas para: a escolha das estratégias a serem alcançadas, a definição das perspectivas que deveriam cobrir o desmembramento das estratégias, a freqüência de medição e de apresentação de relatórios e a formulação de um plano de implementação. Desta maneira, ficou acertado que mensalmente seriam apresentados os resultados, e que anualmente seria feito uma reavaliação e manutenção do sistema, que segue a mesma sistemática de definição dos indicadores.

Desta forma, as perspectivas escolhidas e os respectivos indicadores, que são chamados de "chave", foram:

\section{Perspectiva do Impacto Ambiental}

- $\%$ dos programas ambientais executados; 
- Acompanhamento dos resultado dos programas ambientais;

\section{Perspectiva Financeira}

- Break Even Point (BEP);

- Days of Sales Outstanding (DSO);

- Inventário;

- Lucro operacional;

- Produtividade.

\section{Perspectiva da Inovação}

- $\%$ das vendas de novos produtos;

- Pesquisa e desenvolvimento como \% das vendas;

- "Time to Market".

\section{Perspectiva da Manufatura}

- Desempenho da entrega com relação a prazos e tempos cumpridos.

\section{Perspectiva do Mercado}

- $\quad \%$ de clientes com níveis confidenciais $\geq$ a 60 ;

- Satisfação dos clientes;

- Participação no mercado.

\section{Perspectiva das Pessoas}

- $\%$ dos objetivos pessoais atingidos no curto prazo;

- Satisfação dos funcionários;

\section{Perspectiva da Qualidade}

- Rejeição na linha de produção dos clientes;

- Falhas - PPM;

- Custos da não qualidade. 


\section{Perspectiva da Responsabilidade social}

- Investimentos em programas sociais.

\section{Perspectiva dos Fornecedores}

- Redução do custo com materiais;

- Desempenho da entrega do fornecedor com relação a prazos e tempos cumpridos;

- Problemas na linha de produção da própria empresa.

Em um segundo nível, decidiu-se pela criação de indicadores para servir como apoio para o detalhamento de planos de ação, ou também chamado pela empresa de processos. Desta maneira foram criados os denominados "Drives" para os planos de ação, que são descritos abaixo:

Definir planos de tecnologia da informação e arquitetura

- Taxa de usuários finais;

- Número de chamas ao Help Desk;

- Taxa de computadores e estações de trabalho;

- Pesquisa de satisfação com o Help Desk.

\section{Desenvolvimento de novos produtos}

- Custo alvo do produto.

\section{Desenvolvimento da estratégia e visão}

- \% dos indicadores de desempenho "chave" atingidos;

- $\%$ Objetivos atingidos no curto prazo.

\section{Gerenciamento dos programas ambientais}

- Emissão de afluentes e tratamento de água.

\section{Gerenciamento das relações externas}

- Conformidade com as leis e regulamentações. 
Gerenciamento dos recursos financeiros

- Realização do plano de capital;

- Investimento e depreciação;

- Folha de pagamentos/Vendas.

Gerenciamento dos recursos humanos

- $\%$ de promoções + Alto potencial;

- Absenteísmo;

- Benefícios;

- Nível formal de educação;

- Índice de rotatividade do trabalho;

- Taxas de aprendizes e "Trainees" contratados;

- Horas de treinamento / Funcionário;

- Investimento em treinamento;

- Rotatividade;

- Acidentes de trabalho.

\section{Gerenciamento da melhoria e mudança}

- Pontuação no PNQ.

\section{Gerenciamento das compras e parcerias}

- $\%$ de fornecedores qualidade assegura;

- \% do custo de inspeção no recebimento e custos industriais;

- Custo recuperado - Compra de materiais;

- Rejeição na linha de produção de clientes devido a materiais comprados.

Produce After Market

- \% de máquinas $\mathrm{CNC}$;

- Índice de automação;

- Eficiência;

- Refugo como \% das vendas. 


\section{Partes forjadas da produção}

- \% de máquinas $\mathrm{CNC}$;

- Índice de automação;

- Eficiências;

- Refugo como \% das vendas.

\section{Produção na OEM}

- \% de máquinas $\mathrm{CNC}$;

- Índice de automação;

- Eficiências;

- Refugo como \% das vendas.

\section{Vendas e produtos negociados}

- Nível de retenção de clientes;

- Desempenho da entrega- OEM;

- Vendas líquidas;

- Taxa de acessibilidade do item da pesquisa dos clientes.

\section{Entendimento do mercado e dos clientes}

- Nível de conhecimento do mercado;

- Participação nas reuniões do Sindipeças.

Em um terceiro nível, existia também a preocupação em utilizar indicadores que servissem como suporte a determinadas atividades que a empresa entendia como relevantes, mas que isoladamente não foram contempladas no desenho do BSC. Aqui se pode observar que os indicadores, na sua maioria, são apenas indicativos de níveis de certificação, financeiros de produtividade dentre outros, que a empresa entendeu como importantes e que deveriam ser mensurados. Estes indicadores, que são chamados de suporte pela empresa, são apresentados abaixo:

- $\%$ de fornecedores com ISO/QS-9000

- Utilização da capacidade 
- Cost Out

- Taxa de clientes auditados

- Índice de confiabilidade dos clientes

- Entrevistas com clientes

- Material direto como \% das vendas

- Mão de obra direta/indireta

- Exportações e mercado doméstico

- Custo por hora

- Manutenção do prêmio ABRINQ e certificação FUNCEF

- Lucratividade da manufatura como \% das vendas

- Número de Green Belts and Black Belts

- Número de pessoas treinadas nas concessionárias

- Comparação técnica do produto

- Rejeição na linha de produção da empresa

- Retorno sobre as vendas

- Vendas por funcionário

- Evolução das horas padrão

- Taxas estaduais

- Custos de suporte (\% das vendas)

- Garantia / vendas líquidas

Por outro lado, a empresa também possui uma preocupação com sua cadeia de suprimentos, e atua fortemente na medição de desempenho de seus fornecedores.

A empresa trabalha com um sistema de seleção de fornecedores através de indicadores de desempenho que inicialmente são avaliados quanto a atributos de qualidade, preço, atendimento e condições de entrega.

No atributo qualidade, é conduzida uma avaliação simplificada do sistema da qualidade, considerando informações quanto a certificações (ISO 9000 e QS 9000), limpeza, organização, instalações, máquinas e equipamentos, qualificação dos recursos humanos e planejamento da qualidade. Portanto, tendo o fornecedor 
apresentado perfil adequado aos atributos citados acima, pode-se considerá-lo como potencial para o fornecimento.

A avaliação completa do sistema da qualidade é feita no fornecedor com o objetivo de avaliar se o mesmo atende aos requisitos básicos do sistema da qualidade, considerando a QS 9000. Fornecedores certificados na QS 9000 são dispensados da avaliação completa do sistema da qualidade

Em caso de não conformidades detectadas na avaliação completa do sistema da qualidade, o fornecedor deve elaborar um plano de ações corretivas e preventivas, baseando nessa avaliação, e enviar para a empresa com os respectivos prazos para implementação conforme estabelecido.

Além do Sistema da Qualidade, o fornecedor tem seu desempenho avaliado por deméritos, que são somados e compilados na Tabela 5.3. Os parâmetros para esta avaliação são:

- Qualidade

a) Inspeção de recebimento:

Quando esta atividade ocorre, o fornecedor é avaliado a cada lote que entrega com nota 0 (zero) a 10 (dez). Para fornecedores isentos de inspeção, em função de sua classificação esta nota é 10 (dez).

O critério de notas para a inspeção de recebimento é:

0 - Fornecedor com lotes com seleção/retrabalho/devolução;

5 - Fornecedor com lotes aprovados com desvio reincidente;

5 - Fornecedor que não enviou os registros de inspeção solicitados;

7,5 - Fornecedor com lotes aprovados com desvio após inspeção;

10 - Fornecedor com lotes aprovados ou dispensados de inspeção.

b) Homologação de Processos:

O processo deve ser homologado conforme as atividades descritas anteriormente.

Os problemas apresentados na Homologação de Processos serão avaliados com deméritos de 0 (zero) a 2 (dois), em função da gravidade. 
c) Linhas de produção/montagem:

Os problemas apresentados nas linhas de produção e/ou montagem serão avaliados com deméritos de 0 (zero) a 2 (dois), em função da gravidade.

d) Linhas dos clientes

Os problemas apresentados nas linhas de produção dos clientes serão avaliados com deméritos de 0 (zero) a 3 (três), em função da gravidade

e) Desempenho no campo:

Os problemas apresentados no campo serão avaliados com deméritos de 0 (zero) a 4 (quatro), em função da gravidade.

- Problemas de entrega

É exigência fundamental da é que o fornecedor atenda um padrão de entrega $100 \%$ no prazo. O desempenho de entrega do fornecedor é monitorado, incluindo o acompanhamento do volume de carga em excesso ou custos acima previsto.

$\mathrm{Na}$ avaliação completa do sistema da qualidade, é analisado o sistema de ação corretiva dos fornecedores para problemas que impossibilitem o atendimento das entregas no prazo.

O fornecedor será avaliado quanto ao prazo de entrega e por problemas de embalagens, com deméritos que variam de 0 (zero) a 2 (dois).

- Atendimento técnico/comercial

Considera-se o comportamento do fornecedor nas negociações comerciais, alterações nos programas de entrega, colaboração no desenvolvimento de novos itens e na resolução e prevenção de problemas. A avaliação será com deméritos de 0 (zero) a 2 (dois). 
- Ações corretivas

O fornecedor fica sujeito a demérito de 0 (zero) a 1(um) ponto caso não envie o relatório de ação corretiva e preventiva solicitado, incluindo as ações decorrentes da avaliação do sistema da qualidade.

- Avaliação do desempenho dos itens fornecidos

A nota final de desempenho é dada pela nota de inspeção de recebimento ( 0 a 10 - zero a dez pontos).

Tabela 5.3. Classificação dos Fornecedores

\begin{tabular}{|l|c|c|}
\hline \multicolumn{1}{|c|}{ Classe do Fornecedor } & $\begin{array}{c}\text { Avaliação do Sistema da } \\
\text { Qualidade }\end{array}$ & $\begin{array}{c}\text { Avaliação do Desempenho } \\
\text { dos Itens Fornecidos }\end{array}$ \\
\hline Qualidade Assegurada & $\geq 7,5$ & $\geq 9$ \\
\hline $\begin{array}{l}\text { Com potencial para } \\
\text { Qualidade Assegurada }\end{array}$ & $\geq 6$ & $\geq 7,5$ \\
\hline Problemático & $<6$ & $<7,5$ \\
\hline
\end{tabular}

\subsection{Discussão Sobre as Questões de Pesquisa}

O estudo de caso descrito até aqui revelou características de uma empresa que possui um SMD estruturado. Foi apresentado o processo de evolução, criação e manutenção do sistema. Agora será feito uma análise deste processo frente às questões de pesquisa propostas neste trabalho, com o intuito de se esclarecer à proposta de estudo de caso.

Questão de Pesquisa 1: O conjunto de indicadores é balanceado?

O sistema de medição de desempenho desenvolvido pela empresa adota o conceito de balanceamento de indicadores de diferentes perspectivas, como proposto por Kaplan e Norton (1996). Além disso, de acordo com os relatos dos entrevistados, o processo de criação de novos indicadores de desempenho segue um processo anual de revisão, no qual é realizada uma reunião para avaliação do sistema vigente, além 
de todas as métricas que compõe este sistema. Nesta oportunidade, são retiradas aquelas métricas que são consideradas obsoletas, e inseridas aquelas que são consideradas importantes para o futuro da empresa.

Porém, pode ser observado que as áreas de negócio possuem liberdade para criar paralelamente indicadores que se julguem necessários. Esta ação pode às vezes ser facilitadora para o controle, principalmente para o chão de fábrica, de ações que por ventura não estão sendo contempladas no sistema de medição original, mas que são relevantes no contexto da área de negócio. Mas é importante ressaltar que estes indicadores quando criados a esmo, podem criar uma estrutura conflitante e que pode deixar o conjunto total de medição de desempenho não balanceado.

No que tange as perspectivas utilizadas pela empresa, os criadores do SMD entenderam que eles possuíam total liberdade para criação de novas perspectivas dentro do BSC. Assim, foram criadas além da financeira, manufatura, pessoas e clientes as de impacto ambiental, inovações, responsabilidade social e de fornecedores.

Neste ponto, a criação de tantas perspectivas pode ser avaliada como desnecessário, na medida em que se pode estar sendo redundante. Talvez a criação das mesmas perspectivas do BSC, com apenas uma ou outra adaptação, seria suficiente, pois desta maneira, a garantia de balanceamento fica mais consistente devido os indicadores de desempenho estarem em baixo de uma mesma estrutura.

Mesmo assim, pode se observar que o conjunto de indicadores é relativamente balanceado, pela estrutura de medição de desempenho que foi criada em torno de indicadores não conflitantes e que seguem a criação da estratégia da empresa.

Questão de Pesquisa 2: $\mathbf{O}$ conjunto de indicadores é relacionado às áreas chave de desempenho derivadas da estratégia?

É sabido que o Balanced Scorecard deve ser construído por meio de um processo sistemático que busque consenso e clareza sobre como traduzir a missão e estratégia da unidade de negócios em objetivos e medidas operacionais, servindo como estrutura comum para a organização do processo de planejamento dos 
departamentos corporativos de apoio, permitindo que esses departamentos compreendam as estratégias de toda a corporação e das unidades individuais afim de se alcançarem seus objetivos estratégicos

Desta maneira, como apresentado na questão de pesquisa anterior, o conjunto de indicadores de desempenho é desenvolvido a partir de conceitos de balanceamento das diferentes perspectivas do BSC. Desta maneira, durante a entrevista foi discorrida a estratégia global da empresa e como esta se desdobrava em estratégias para as diferentes áreas de negócio.

Foi comentado que as estratégias traçadas pela empresa para os próximos anos seguem o caminho de redução de custos e aumento da participação no mercado de algumas linhas consideradas estratégicas. Para a linha principal de produtos, é seguido fortemente à qualidade do projeto de produto, o preço e a pontualidade da entrega. Para atender a estes requisitos, as dimensões das operações priorizam a conformidade com as especificações, a flexibilidade do volume, a pontualidade da entrega e o menor custo.

Pode-se observar então que através de uma forma sistemática, as reuniões de delineamento de estratégias seguem um conjunto de passos que culminam em revisão ou criação de novas estratégias para os próximos anos, além da definição de indicadores de alto nível. Seqüencialmente ocorre a validação e detalhamento destes indicadores na reunião de reavaliação e manutenção do SMD.

Portanto, os indicadores de desempenho são derivados das estratégias traçadas pela empresa, e são relacionados com as áreas chave de desempenho.

Questão de Pesquisa 3: O conjunto de indicadores foca nos processos da cadeia de suprimentos?

$\mathrm{Na}$ cadeia de valor, os indicadores de desempenho focam em geral em todos os processo primários e de suporte e gestão. Nos processos primários pode-se observar que são fortemente direcionados para o entendimento do mercado e fornecedores, no projeto de produtos e na produção e entrega. Os processos de suporte e gestão são focados no gerenciamento de relacionamentos externos, na execução de programas de meio ambiente e gerenciamento financeiro. 
Desta maneira, ao focar em elos da cadeia de fornecimento, pode-se perceber a preocupação da empresa em mensurar e conhecer melhor os relacionamentos que acontecem na cadeia de suprimentos em que estão envolvidos, e para tal, foram criadas duas perspectivas no BSC que é a do mercado, com a preocupação de tentar monitorar, entender e sustentar o foco no cliente, já que a empresa considera importante medir a percepção dos clientes e de que forma ela participa e os atende, e dos fornecedores, com um grande sistema de avaliação e qualificação que tenta selecionar e categorizar os mais confiáveis, importantes e eficientes.

Por outro lado, quando se construiu o projeto IPROS, o pensamento sobre a cadeia de suprimentos provocou uma mudança funcional, que levou à adoção de novos métodos de controle, como por exemplo de clientes e fornecedores. Já barreiras externas poderiam decorrer da distância física dos fornecedores ou do mercado consumidor, do tipo de relacionamento da empresa com as demais, de interferências governamentais ou até mesmo de dificuldades de infra-estrutura do país.

Assim, pode-se dizer que à medida que as empresas integram seus esforços para oferecer aos clientes mais do que a entrega da mercadoria no local e na hora certa; as mesmas estão procurando otimizar a cadeia, que em linhas gerais, pode ser resumido como uma metodologia desenvolvida para alinhar todas as atividades de produção de forma sincronizada, visando reduzir custos, aumentar a qualidade, proporcionar uma maior velocidade de distribuição, minimizar ciclos e maximizar o valor percebido pelo cliente final, ganhando sua confiabilidade.

Desta forma, as perspectivas criadas para o projeto IPROS tentaram deixar claro que as medidas financeiras e não-financeiras devem fazer parte do sistema de informações para funcionários de todos os níveis da organização e em alguns casos, para as empresas que compõe a cadeia de suprimentos, visando justamente atender aos conceitos e premissas que se aplicam a cadeia de suprimentos.

Portanto, pode se considerar que o conjunto de indicadores de desempenho tanto da empresa estudada quanto do projeto IPROS focam nos processos internos da empresa como também nos processos da cadeia suprimentos. 


\section{Questão de Pesquisa 4: Os indicadores de resultado são desdobrados em indicadores de tendência?}

A inclusão dos indicadores de resultado e de tendência permite que os executivos identifiquem fatores operacionais como investimentos estratégicos, pesquisas de mercado, produtos e serviços inovadores, reciclagem de funcionários e melhores sistemas de informação, que devem ser criados para viabilizar o atingimento de metas financeiras.

$\mathrm{Na}$ empresa estudada, foi constatado que existe para alguns indicadores que se desdobram em outros que fazem parte na verdade de uma rede de relacionamentos. Além disto, pode-se também observar que indicadores operacionais, em alguns casos, servem tanto para identificar problemas, quanto para preveni-los.

Desta maneira, a empresa utiliza algumas medidas genéricas que são essenciais aos resultados e que refletem as metas comuns de algumas estratégias. Essas medidas genéricas tendem a ser indicadores de ocorrência. Por outro lado, os indicadores de tendência utilizados são geralmente específicos para uma determinada unidade de negócios.

Porém, não foi identificado um relacionamento sistemático de validação dos indicadores de tendência, que são definidos pela média gerência, para as operações departamentais, e que eventualmente podem possuir metas departamentais táticas e de curto prazo, em detrimento da criação de capacidades que permitam a realização de metas estratégicas a prazos mais longos.

Estas constatações foram alvo de uma discussão com uma das gerências, o que nos faz acreditar, que os indicadores de resultado, em alguns momentos, podem não ser desdobrados em indicadores de tendência. Entretanto, esta afirmação precisa ser melhor investigada. 
Questão de Pesquisa 5: O sistema de medição de desempenho é integrado ao sistema informatizado de gestão?

A coleta e armazenagem das informações e feita através de um sistema integrado de gestão no qual está todo o BSC. O sistema intitulado Operational Performance Management System (OPMS), possui interface WEB, e se contra disponível na Intranet da empresa para consulta de qualquer funcionário autorizado. O sistema contempla o plano estratégico, os planos de ações e toda a base de indicadores de desempenho.

Desta maneira, os indicadores de desempenho podem ser visualizados no principal sistema de gestão da empresa, exceto aqueles indicadores que são criados em virtude de necessidades das áreas de negócio, que utilizam planilhas eletrônicas para tal controle.

Também, na maioria dos casos os relatórios são sumarizados a partir de uma base de dados única. Desta forma, pode-se afirmar que o SMD está relativamente bem integrado ao sistema informatizado de gestão da empresa. 


\section{CONCLUSÃO}

\subsection{Introdução}

Este trabalho teve como objetivo principal a proposição de um conjunto de indicadores de desempenho das operações de produção de uma empresa de manufatura inserida no contexto de uma cadeia de suprimentos.

Este objetivo principal foi desenvolvido por meio de:

a) Revisão da literatura, buscando identificar as características fundamentais e as boas práticas dos modelos de medição de desempenho organizacional, inclusive quando se considera a gestão da cadeia de suprimentos.

b) Proposição de um conjunto de indicadores de desempenho para o cenário da cadeia de suprimentos de moto redutores desenvolvido para o projeto IPROS focados tanto no desempenho dos processos internos de uma empresa elo da cadeia, principalmente no gerenciamento do chão de fábrica, quanto no relacionamento desse elo com o desempenho da cadeia de suprimentos auxiliados por sistemas de gestão;

c) Estudo de Caso, com o objetivo de avaliar os indicadores de desempenho de uma empresa que se encontre em uma cadeia de suprimentos similar ao projeto IPROS e que utilize indicadores de desempenho como instrumento gerencial.

O trabalho descrito nos capítulos anteriores atingiu satisfatoriamente os objetivos propostos. No entanto, alguns comentários conclusivos sobre os resultados obtidos podem ser feitos para finalizar esta dissertação. 


\subsection{Discussão Final}

A primeira conclusão básica deste trabalho é justamente a importância dos indicadores de desempenho dentro do ambiente empresarial, e a expansão dos mesmos para as empresas que fazem parte de uma determinada cadeia de suprimentos. Outro ponto fundamental para o sucesso ou não da criação e o desenvolvimento dos SMDs, é justamente a utilização de uma metodologia, como foi discutida neste trabalho.

Tratando do projeto IPROS e do estudo de caso, pode-se observar nos dois casos que existiu a preocupação quando da criação dos indicadores, em se manter um sistema balanceado, desenvolvido a partir de conceitos do BSC, além de existir um processo anual de revisão, no qual são realizadas reuniões periódicas para avaliação do sistema e de todas as métricas, avaliando se as mesmas estão alinhadas com a estratégia da empresa.

Além disto, ambos sistemas primaram pela criação de métricas relacionadas com a cadeia de suprimentos, principalmente na empresa estudada, que apresenta um formalizado sistema de avaliação de fornecedores. Da mesma forma, ambos SMDs apresentam métricas relacionadas com o entendimento do mercado e com o atendimento aos seus clientes. Desta maneira, apesar de indicadores diferentes para avaliar a cadeia de suprimentos, ambos SMDs apresentaram foco nos processos ligados a cadeia de suprimentos.

Do ponto de vista dos clientes, deve-se ter uma idéia clara dos segmentos alvo de clientes e negócios, e dispor de um conjunto de medidas essenciais para tal. Essas medidas de resultados representam metas para as operações, logística, marketing e desenvolvimento de produtos e serviços das empresas e que podem ser observadas tanto no estudo de caso quando no projeto IPROS.

Já os processos internos, ou as operações, procuram avaliar custos, qualidade e tempos de resposta como atributo crítico de desempenho. Muitos clientes dão extremo valor a tempos de desenvolvimento curtos, medidos como o tempo transcorrido desde o momento em que é feito o pedido até o momento em que o produto ou serviço desejado é recebido. Neste item, a empresas estudada e o projeto 
IPROS apresentaram uma vasta quantidade de indicadores que tentam atender minimamente este assunto.

Por outro lado, um elemento importante no processo de um SMD é a identificação das atividades funcionais exercidas em nível corporativo. Uma das importantes funções neste nível é oferecer mecanismos pelos quais as oportunidades de sinergia do negócios possam ser percebidas e exploradas, e especificamente na empresa estudada, esta característica se mostrou presente.

Finalmente, existiu a preocupação com a máxima centralização das informações em bases concisas e de fácil acesso, a fim de deixar o SMD mais ágil com relação ao acesso aos dados. Por isso a integração ao sistema de gestão faz, nos dois casos, que os SMDs sejam mais flexíveis do ponto de vista de futuras integrações com sistemas de fornecedores e clientes, mais rápidos com relação ao processamento de informações, com uma maior confiabilidade e maior flexibilidade com relação a exclusão e inclusão de indicadores.

Desta maneira, indicadores de resultado e tendência são utilizados nos dois casos, o que mostra uma boa disposição para que os sistemas consigam refletir a realidade atual, como uma foto, e também mostrar o caminho para o qual das duas situações estão progredindo.

Portanto, os dois casos apresentaram uma grande semelhança no que tange aos conceitos de derivação da estratégia, balanceamento dos indicadores, identificação das áreas chave de desempenho e a percepção da necessidade de inclusão de métricas relacionadas com a cadeia de suprimentos.

Desta maneira, fica claro de que o caminho traçado pelo trabalho mostrou indícios claros de estar seguindo na direção correta. Por outro lado, deve ficar claro que o cenário do projeto IPROS possuía limitações que não possibilitaram a implementação de todos os indicadores propostos.

Uma das dificuldades encontradas foi o uso da tecnologia de informação na implementação do projeto IPROS, já que nem todas as ferramentas propostas inicialmente foram disponibilizadas, o que afetou no produto final do cenário como atrasos e a redução do escopo inicial da proposta. 
Outro reflexo importante foi incapacidade de se implementar um número maior de indicadores de desempenho para a toda a cadeia, o que privou de certa maneira uma análise mais profunda do impacto dos mesmos no cenário.

Apesar disto, pode-se concluir que o SMD criado para o IPROS foi um bom exemplo que contemplou o uso das boas práticas e ferramentas da medição de desempenho sugeridas pela literatura abordada.

\subsection{Trabalhos Futuros}

Finalmente, como trabalhos futuros decorrentes desta dissertação, pode-se pensar na criação de metodologias para que se garanta com efetividade o alinhamento entre as possíveis diferentes estratégias das empresas que compõe as cadeias de suprimentos, e como a competição entre participantes de diferentes cadeias pode afetar nos objetivos.

Também fica aberta a criação de novos sistemas de medição de desempenho que tratem da cadeia de suprimentos, até mesmo pela escassez de trabalhos científicos desta natureza, e a criação de sistemas de gestão que facilitem a manutenção de indicadores de desempenho e que consigam agrupar todas as informações em bases únicas ou com grande poder de troca de informações.

Por fim, o estudo e desenvolvimento de SMDs que contemplem o gerenciamento do desempenho dos processos da empresa mais representativa de uma cadeia, decorrente do gerenciamento do desempenho de dimensões da cadeia como um todo. 


\section{ANEXO A - Questões de Pesquisa e o Questionário}

A Tabela A.1, apresenta o relacionamento entre as questões de pesquisa definidas no item 6.3 , e as respectivas perguntas apresentadas no questionário (Anexo B).

Tabela A.1. Relação entre questões de pesquisa e o questionário.

\begin{tabular}{cc}
\hline Questões de Pesquisa & Questões Relacionadas \\
\hline A - O Conjunto de indicadores é balanceado? & $1,2,3,4$ e 5 \\
\hline
\end{tabular}

$\mathrm{B}$ - $\mathrm{O}$ conjunto de indicadores é relacionado às áreas $\quad 6,7,8,9,10,11$ e 12 chave de desempenho derivadas da estratégia?

$\mathrm{C}-\mathrm{O}$ Conjunto de indicadores foca nos processos da $13,14,15$ e 16 cadeia de suprimentos?

D - Os indicadores de resultado podem ser 17, 18 19, 20, 21, 22 e 23 desdobrados em indicadores de tendência?

E - O sistema de medição de desempenho é integrado 24,25 e 26 ao sistema informatizado de gestão? 


\section{ANEXO B - Questionário para Levantamento de Informações}

Este questionário tem por objetivo o levantamento de informações sobre medição de desempenho. Este faz parte de uma dissertação de mestrado desenvolvido por Emerson Bond na Universidade de São Paulo, sob a orientação do Prof. Dr. Luiz Cesar Ribeiro Carpinetti.

A finalidade é avaliar o uso de indicadores de desempenho internos e externos a empresa.

\section{Parte I - A empresa}

Nome do respondente:

Cargo e departamento:

Nome da empresa:

Setor Industrial:

Número de funcionários:

Faturamento anual em 1.000 R\$: 


\section{Parte II Avaliação do sistema de medição de desempenho}

1 - Como funciona o processo de criação de novos indicadores de desempenho?

2 - Existe um processo de verificação e validação dos indicadores de desempenho existentes?

3 - As medidas usadas estão relacionadas as diferentes perspectivas listadas?

Financeira

Clientes

Operações

Fornecedores

Recursos Humanos

4 - Existe alguma outra perspectiva considerada pelo conjunto de indicadores?

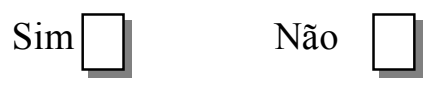

Se sim, indicar quais perspectivas.

5 - Quais são os indicadores usados para avaliar o desempenho:

Financeiro:

Clientes:

Operações:

Fornecedores:

Recursos Humanos

6 - O sistema de medição de desempenho é desenvolvido a partir de conceitos de balanceamento das diferentes perspectivas?

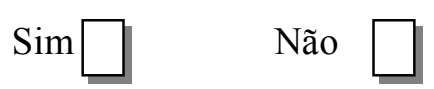

Se sim, discorrer sobre como foram utilizados estes conceitos:

7 - Os indicadores são visualizados ou agrupados por perspectivas?

Se sim, discorrer sobre como é visto este agrupamento:

8 - Qual é a estratégia de negócio e como essa estratégia se desdobra em estratégias para a área de manufatura? 
9 - Para a linha de produtos principal, quais os requisitos de desempenho (fator de valor para os clientes)?

\begin{tabular}{|l|l|l|}
\hline \multicolumn{1}{|c|}{ Fator de Valor (Requisito) } & $\begin{array}{c}\text { Tipo de Cliente (Final ou } \\
\text { intermediário) }\end{array}$ & Grau de Importância \\
\hline $\begin{array}{l}\text { Qualidade de projeto de } \\
\text { produto }\end{array}$ & & \\
\hline Assistência técnica & & \\
\hline Custo/Preço & & \\
\hline Prazo introduzir & & \\
\hline Pontualidade de & & \\
\hline $\begin{array}{l}\text { Capacidade } \\
\text { inovações tecnológicas }\end{array}$ & & \\
\hline Outros: & & \\
\hline
\end{tabular}

10 - Quais são as dimensões das operações que são priorizadas? (Ordenar de 1 menos prioritário a 5 - mais prioritário)

conformidade (produto) com as especificações qualidade de projeto de produto qualidade de serviço pós-venda flexibilidade do mix de produção flexibilidade do volume

\begin{tabular}{|l|l}
\hline & pontualidade na entrega \\
redução do prazo de entrega \\
menor preço/custo \\
inovação do produto \\
time to market
\end{tabular}

11 - O que foi considerado para a priorização das dimensões das operações consideradas acima. (Ordenar de 1 -menos prioritário a 5 - mais prioritário)
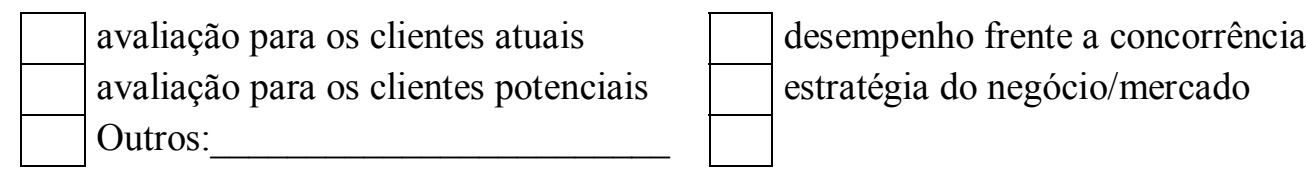
12 - Indicar o grau de prioridade das áreas chave de desempenho listadas abaixo para a satisfação dos clientes e atingimento dos objetivos estratégicos do negócio. (Ordenar de 1 -menos prioritário a 5 - mais prioritário)

\begin{tabular}{|l|l|}
\hline & Integração com os clientes \\
Integração com fornecedores \\
Integração com engenharia \\
Integração com o marketing \\
\hline Gerenciamento da garantia da qualidade \\
Programa de qualidade total \\
\hline Gerenciamento da qualidade de produto \\
\hline & $\begin{array}{l}\text { Gerenciamento da qualidade de processo } \\
\text { Eficiência da mão de obra }\end{array}$ \\
\hline & $\begin{array}{l}\text { Eficiência do uso do equipamento } \\
\text { Introdução de novos produtos } \\
\text { Tecnologia de produto } \\
\text { Tecnologia de produto } \\
\text { Gerenciamento de estoques }\end{array}$
\end{tabular}

\begin{tabular}{|l|l}
\hline & Gerenciamento da produção \\
Gerenciamento de compras \\
Gerenciamento de vendas \\
Gerenciamento ambiental \\
Ger. Desenvolvimento novos produtos \\
Trabalho em equipe, gestão participativa \\
Programa de sugestões \\
Programa de educação/treinamento \\
Programa de motivação \\
Delegação responsabilidade/autoridade \\
Uso da tecnologia da informação/CIM \\
Gerenciamento da manutenção \\
Gerenciamento logística de distribuição \\
Outras:
\end{tabular}

13 - Em quais etapas da cadeia de valor e processos de suporte que medidas de desempenho são mais usados (Ordenar de 1- menos prioritário a 5- mais prioritário)

- Processos primários

Entendimento do mercado e consumidores

Desenvolvimento de visão e estratégia

Projeto de produtos e serviços

Marketing e Vendas

Produção e entrega (empresa de manufatura)

Produção e entrega (empresa de serviços)

Atendimento de pedidos e serviços aos clientes

- $\quad$ Processos de suporte e gestão

Desenvolvimento e gerenciamento de Recursos Humanos

Gerenciamento de informações

Gerenciamento financeiro e de recursos físicos

Execução de programa de gerenciamento do meio ambiente

Gerenciamento dos relacionamentos externos

Gerenciamento de melhorias e mudanças

14 - Indicar (listar) os indicadores de desempenho usados pela empresa para gerenciar o desempenho em cada uma das áreas de desempenho consideradas prioritárias (chave).

15 - Quais são os processo de negócio que a empresa desenvolve?

16 - Como se caracteriza a cadeia de suprimentos da linha de produto principal?

17 - Quais são os processos de negócio da cadeia da linha do produto principal? 
18 - Quais das práticas abaixo são adotadas pela empresa. Utilize os campos para a direita para marcar às praticas executadas e da direita para indicador as práticas que possuem algum indicador de desempenho.

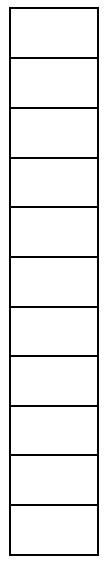

estabelecimento de parcerias

Outsourcing

EDI - Electronic Data Interchange

ESI - Early Supplier Involvement

ECR - Efficient Consumer Response

Postponed Manufacturing

Mass Customization

VMI - Vendor Managed Inventory

In-plant representatives

Outras:

Outras:

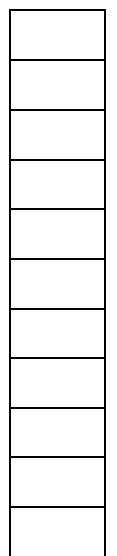

19 - Existe um desdobramento dos indicadores principais em outros indicadores?

20 - Os indicadores de desempenho operacionais permitem que a empresa:

\begin{tabular}{|l|l|}
\hline & Identifique problemas \\
& Previna problemas \\
& Ambos \\
& Nenhum
\end{tabular}

21 - Existe um mapa de relacionamento entre os indicadores?

22 - Os indicadores são analisados considerando os relacionamentos existentes entre eles?

23 - Os indicadores promovem de alguma forma o melhoramento contínuo ou apenas tem a tarefa de monitorar resultados?

24 - Como funciona a coleta e armazenagem das informações?

25 - Os indicadores de desempenho podem ser visualizados no principal sistema de gestão da empresa?

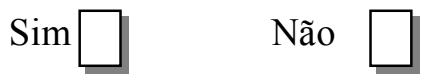

26 - Os relatórios são sumarizados a partir de uma base de dados única ou são compostos de várias bases que se relacionam? 


\section{REFERÊNCIAS BIBLIOGRÁFICAS}

ADELMAN, S.; MOSS, L. (2000). Data Warehouse Goals and Objectives, Part 1. http://www.datawarehouse.com (16 Março de 2000).

ARTLEY, W.; STROH, S. (2000). The performance based management handbook: establishing an integrated performance measurement system. Washington, Performance-Based Management Special Group.

ASSEN, M.F. et al. (2000). An agile planning and control framework for customerorder driven discrete parts manufacturing environments. International Journal of Agile Management Systems. 2/1. p. 16-23.

ATKINSON, A.A. et al. (1997). A stakeholder approach to strategic performance measurement. Sloan Management Review. outono. p. 25-37.

BEAMON, B.M. (1999). Measuring supply chain performance. International Journal of Operations \& Production Management, v. 9, n. 3, p. 275-292.

BEAMON, B.M.; WARE, T.M. (1998). A process quality model for the analysis, improvement and control of supply chain systems. International Journal. of Physical Distribution \& Logistics Management. v. 28, n. 9/10, p. 704-715.

BERGAMASCHI, S.; REINHARD, N. (2000). Implementação de sistemas para gestão empresarial. /Apresentado ao 24. Encontro Nacional da Associação Nacional dos Programas de Pós-graduação em Administração, Florianópolis, $2000 /$.

BITITCI, U.S. (1994). Measuring your way to profit. Management Decision. v. 32, n. 6, p. 16-24.

BITITCI, U.S. (1995a). Modeling of performance measurement systems in manufacturing enterprises. International Journal of Production Economics. n. 42, p. $137-147$. 
BITITCI, U.S. (1995b). Measuring the integrity of your business. Management Decision. v. 33, n. 7, p. 10-18.

BITITCI, U.S. et al. (1997). Integrated performance measurement systems. International Journal of Operations \& Production Management. v. 17, n. 5, p. 522-534.

BITITCI, U.S. (2000). Dynamics of performance measurement systems. International Journal of Operations \& Production Management. v. 20, n. 6, p. 692-704.

BLENKINSOP, S.A.; BURNS, N. (1992). Performance measurement revisited. International Journal of Operations \& Production Management. v. 12, n. 10, p. $16-25$.

BOURNE, M. et al. (2000). Design, implementing and updating performance measurement systems. International Journal of Operations \& Production Management. v. 20, n. 7, p. 754-771.

BOWERSOX, D.J.; CLOSS, D.J. (1996). Logistical Management: the integrated supply chain process. New York, Macmillan Publishing.

BROWN, M.G. (1996). Keeping Score: using the right metrics to drive world-class performance. Portland, Productivity

BROWN, M.G. (2000). Winning score: how to design and implement organizational scorecards. Portland, Productivity.

BRYMAN, A. (1995). Research methods and organization studies. London, Routledge.

CAETANO, A.G.L.S. (2000). Sistemas de supervisão de chão-de-fábrica: uma contribuição para implantação em indústrias de usinagem. Dissertação (mestrado), Escola de Engenharia de São Carlos, Universidade de São Paulo.

CAMPOS, V.F. (1994). Gerenciamento da rotina. Belo Horizonte, FCO, Universidade Federal de Minas Gerais.

CARPINETTI, L.C.R. (2000a). Proposta de um modelo conceitual para o desdobramento de melhorias estratégicas. Gestão \& Produção. v.7, n.1.

CARPINETTI, L.C.R. (2000b). Uma proposta para o processo de identificação e desdobramento de melhorias: um enfoque estratégico. Tese (Livre Docência) Escola de Engenharia de São Carlos. São Carlos. Universidade de São Paulo. 
CAJAVILLE, A. (2000). A organização integrada. HS Management.

CHUNG, S.H.; SNYDER, C.A. (2000). ERP adoption: a technological evolution approach. International Journal of Agile Management Systems. 2/1. p. 24-32.

CONTI, C.O. (2001). Contribuição à medida de desempenho em células de manufatura. Dissertação (Mestrado) - Escola Politécnica. São Paulo. Universidade de São Paulo.

COOPER, M.C. et al. (1997). Supply chain management: more than a new name for logistics. The International Journal of Logistics Management. v. 8, n. 1, p. 1-14.

CORREA, H.L. et al. (1997). Planejamento, programação e controle da produção: MRPII, ERP: conceitos, uso e implantação. São Paulo, Atlas.

DANIELS, R.C.; BURNS, N.D. (1997). A framework for proactive performance measurement system introduction. International Journal of Operations \& Production Management. v. 17 n. 1. p. 100-116.

DEARDEN, J. (1969). The case against ROI control. Harvard Business Review. p. 124-135. May-Jun.

ECCLES, R.G. (2000). Manifesto da mensuração do desempenho. In: Medindo o Desempenho Empresarial. Rio de Janeiro, Campus.

ECCLES, R.G.; PYBURN, P.J. (1992). Creating a comprehensive system to measure performance. Management Accounting. Oct. p. 41-44.

FILHO, J.T. (2001). Transformando Dados Corporativos em Inteligência Competitiva. http://www.informal.com.br/artigos/AE11.html (15 Maio de 200).

FILHO, G.P.; HAMACHER, S. (2000). Modelo para Avaliação dos Ganhos do Gerenciamento da Cadeia de Suprimentos. /Apresentado ao 24. Encontro Nacional da Associação Nacional dos Programas de Pós-graduação em Administração, Florianópolis, 2000/.

FUJINO, A. (1993). Serviços de informação tecnológica para empresa industrial: subsídios para o planejamento a partir de estudo de usuários. São Paulo. Dissertação (Mestrado) - Escola de Comunicação e Artes, Universidade de São Paulo.

GARVIN, D.A. (1992). Gerenciando a qualidade: a visão estratégica e competitiva. Rio de Janeiro, Qualitymark.

GIL, A.C. (1991). Como elaborar um projeto de pesquisa. São Paulo, Atlas. 
CHOW, G. et al. (1994). Logistics performance: definition and measurement. International Journal of Physical Distribution \& Logistics Management. v. 24, n. 1, p. $17-28$.

GUPTA, A. (2000). Enterprise resource planning: the emerging organizational value systems. Industrial Management \& Data Systems. 100/3. p. 114-118.

HARBOUR, J.L. (1997). The basics of performance measurement. Portland, Productivity Press.

HOEK, R.I.V. (1998). Measuring the unmeasurable - measuring and improving performance in the supply chain. Supply Chain Management. v. 3. n. 4. p. 187192.

HRONEC, S.M. (1994). Sinais vitais: usando medidas do desempenho da qualidade, tempo e custo para traçar a rota para o futuro de sua empresa. São Paulo, Makron Books.

INMON, W.H.; HACKATHORN, R.D. (1997). Como usar o Data Warehouse. Rio de Janeiro, InfoBook.

INMON, W.H. (1997). Construindo o Data Warehouse. 2 $2^{\mathrm{a}}$ ed. Rio de Janeiro, Campus.

IP, W.H. et al. (1999). Enhancing manufacturing information management through TQM. Logistics Information Management. v. 12, n. 4, p. 315-324.

JURAN, J. M.; GRYNA, F. M. (1998). Quality Control Handbook. 4a edição, McGraw-Hill.

KAPPELHOFF, R. (1998). Integration of ERP to the final control elements. ISA Transactions. v. 36, n. 4, p. 229-238.

KAPLAN, R.S.; NORTON, D.P. (1992). The balanced scorecard - measures that drive performance. Harvard Business Review. v. 70, n.1,. p. 71-79. Jan-Fev.

KAPLAN, R.S.; NORTON, D.P. (1993). Putting the balanced scorecard to work. Harvard Business Review. v. 71, n. 5, p. 134-147. Sep-Oct.

KAPLAN, R.S.; NORTON, D.P. (1996a). Balanced scorecard: A estratégia em ação. Rio de janeiro, Campus.

KAPLAN, R.S.; NORTON, D.P. (1996b). Using the balanced scorecard as a strategic management system. Harvard Business Review. v. 74, n. 1, p. 75-85. 
KAYDOS, W. (1991). Measuring, managing and maximizing performance. Portland, Productivity Press.

KEEBLER, J.S. et al. (1999). Keeping score: measuring the business value of logistics in the supply chain. Oak Brook, Il, Council of Logistics Management.

KEEGAN, D.P. et al. (1989). Are your performance measures obsolete? Management Accounting. Jun. p. 45-50.

KIYAN, F.M. (2001). Proposta para desenvolvimento de indicadores de desempenho como suporte estratégico. Dissertação (mestrado), Escola de Engenharia de São Carlos, Universidade de São Paulo.

LAMBERT, D. M. et al. (1996). Developing and implementing supply chain partnerships. The International Journal of Logistics Management. v. 7, n. 2, p. 117.

LAMBERT, D.M. et al. (1998). Supply chain management: implementation issues and research opportunities. The International Journal of Logistics Management. v. 9, n. 2, p. 1-19.

LAPIDE, L. (2000). What about measuring supply chain performance? AMR Research. White Paper. http://lapide.ascet.com (12 Fevereiro de 2001).

LOCKAMY, A. (1998). Quality-focused performance measurement systems: a normative model. International Journal of Operations \& Production Management. v. 18, n. 8, p. 740-766.

LYNCH, R.L.; CROSS, K.F. (1991). Measure up - the essential guide to measuring business performance. London, Mandarin.

MANOOCHEHRI, G. (1999). Overcoming obstacles to developing effective performance measures. Work Study. v. 48, n. 6, p. 223-229.

MARTIN, R. (1997). Do we practice quality principles in the performance measurement of critical success factors? Total Quality Management. v. 8, n. 6, p. 429-444.

MARTINS, R.A. (1999). Sistemas de medição de desempenho: Um modelo para estruturação do uso. Tese (Doutorado) - Escola Politécnica. São Paulo. Universidade de São Paulo.

MASKELL, B.H. (1991). Performance measurement for world class manufacturing. Cambridge, Productivity Press. 
McGEE, J.; PRUSAK, L. (1995). Gerenciamento Estratégico da informação. Rio de Janeiro, Campus.

MELLO. R.G. et al. (2000). Avaliação de desempenho para o gerenciamento estratégico do chão de fábrica. /Apresentado ao 24. Encontro Nacional da Associação Nacional dos Programas de Pós-graduação em Administração, Florianópolis, 2000/.

MEYER, C. (1994). How the right measures help teams excel. Harvard Business Review. v. 72. n. 3. p. 95-63. May-Jun.

MORGAN, B.S.; SCHIEMANN, W.A. (1999). Measuring people and performance: closing the gaps. Quality Progress. Jan.

ÑAURI, M.H.C. (1998). As medidas de desempenho como base para a melhoria contínua de processos: o caso da Fundação de Amparo à Pesquisa e Extensão Universitária (FAPEU). Dissertação (Mestrado) - Engenharia de Produção. Florianópolis. Universidade Federal de Santa Catarina.

NEELY, A. et al. (1994). Realizing strategy through measurement. International Journal of Operations \& Production Management. v. 14, n. 3, p. 140-152.

NEELY, A. et al. (1995). Performance measurement system design: A literature review and research agenda. International Journal of Production Economics. $\mathrm{n}$. 4, p. 80-116.

NEELY, A. et al. (2000). Performance measurement system design: developing and testing a process-based approach. International Journal of Production Economics. v. 20, n. 10, p 1119-1145.

NEELY, A. et al. (1996). Performance measurement system design: Should process approaches be adopted? International Journal of Production Economics. n. 4647, p. 423-431.

NEELY, A. (1998). Measuring business performance. London, The Economist In Association With Profile Books.

NOBLE, J.S. (1997). An integrated dynamic performance measurement system for improving manufacturing competitiveness. International Journal of Production Economics. n. 48, p. 207-225.

O'MARA, C.E. et al. (1998). Performance measurement and strategic change. Managing Service Quality. v. 8, n. 3, p. 179-182.

PARKER, C. (2000). Performance measurement. Work Study. v. 49, n. 2, p. 63-66. 
PERERA, S. et al. (1997). Customer-focused manufacturing strategy and the use of operations-based non-financial performance measures: a research note. Accounting, Organization and Society. v. 22, n. 6, p. 557-572.

PIRES, S.R.I. (1998). Gestão da cadeia de suprimentos e o modelo de consórcio modular. Revista de administração - USP, v. 33, n. 3, p. 5-15.

RAO, S.S. (2000). Enterprise resource planning: business needs and technologies. Industrial Management \& Data System. 100/2. p. 81-88.

RENTES, A.F.; CARPINETTI, L.C.R. e VAN AKEN, E. (2002) Measurement System Development Process: A Pilot Application And Recommendations. Anais do PMA Conference, Boston, 17 a 19 de Julho de 2002.

ROLSTADÅS, A. (1998). Enterprise performance measurement. International Journal of Operations \& Production Management. v. 18, n. 9/10, p. 989-999.

ROSE, K.H. (1995). A performance measurement model. Quality progress. p. 63-66. Feb.

SAVOIE, B.J. (1998). The last word on supply chain improvements. IIE Solutions, Out.

SIMONS, R. (2000). Performance measurement \& control sytems for implementing strategy. New Jersey, Prentice Hall.

SLACK, N. et al. (1995). Administração da produção. São Paulo, Atlas.

SPINOLA, M.M.; PESSÔA, M.S.P. (1997). Tecnologia da informação. In: Gestão de Operações. São Paulo, Edgard Blücher.

STAINER, A.; NIXON, B. (1997). Productivity and performance measurement in R\&D. Inst. J. Technology Management. v. 13, n. 5/6, p. 486-496.

STALK, G.J. (1988). Time - the next source of competitive advantage. Harvard Business Review. p. 41-51. Jul-Ago.

SUPPLY CHAIN COUNCIL. (2001). SCOR model overview. http://ww.supplychain.org (12 Maio de 2001).

TONCHIA, S. (2000). Linking performance measurement system to strategic and organizational choices. International Journal of Performance Management. v. 2, n. $1 / 2 / 3$. 
TONI, A. et al. (1995). An instrument for quality performance measurement. International Journal of Production Economics. n. 38, p. 199-207.

TAKASINA, N.T. \& FLORES, M.C.X. (1999). Indicadores da qualidade e do desempenho: como estabelecer metas e medir resultados. Rio de Janeiro, Qualitymark.

U.S. DOE (2000). The performance-based management handbook: establishing an integrated performance measurement system. v. 2.

VOLLMANN, T.E.; \& CORDON, C. (1996). Making supply chain relationships work. M2000 Business Briefing, n.8, Lausanne, IMD.

WAGGONER, D.B. et al. (1999). The forces that shape organizational performance measurement systems: An interdisciplinary review. International Journal of Production Economics. n. 60/61, p. 53-60.

WHITE, G.P. (1996). A survey and taxonomy of strategy-related performance measures for manufacturing. International Journal of Operations \& Production Management. v. 16, n. 3, p. 42-61.

YOSHIZAKI, H. (2000). Supply chain management e logística. http://www.vanzolini.org.br/ (15 Junho de 2001). 